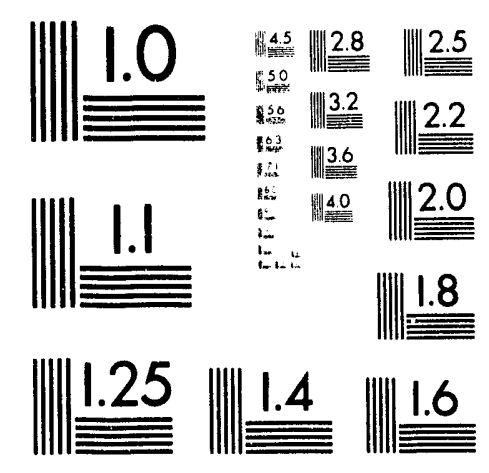



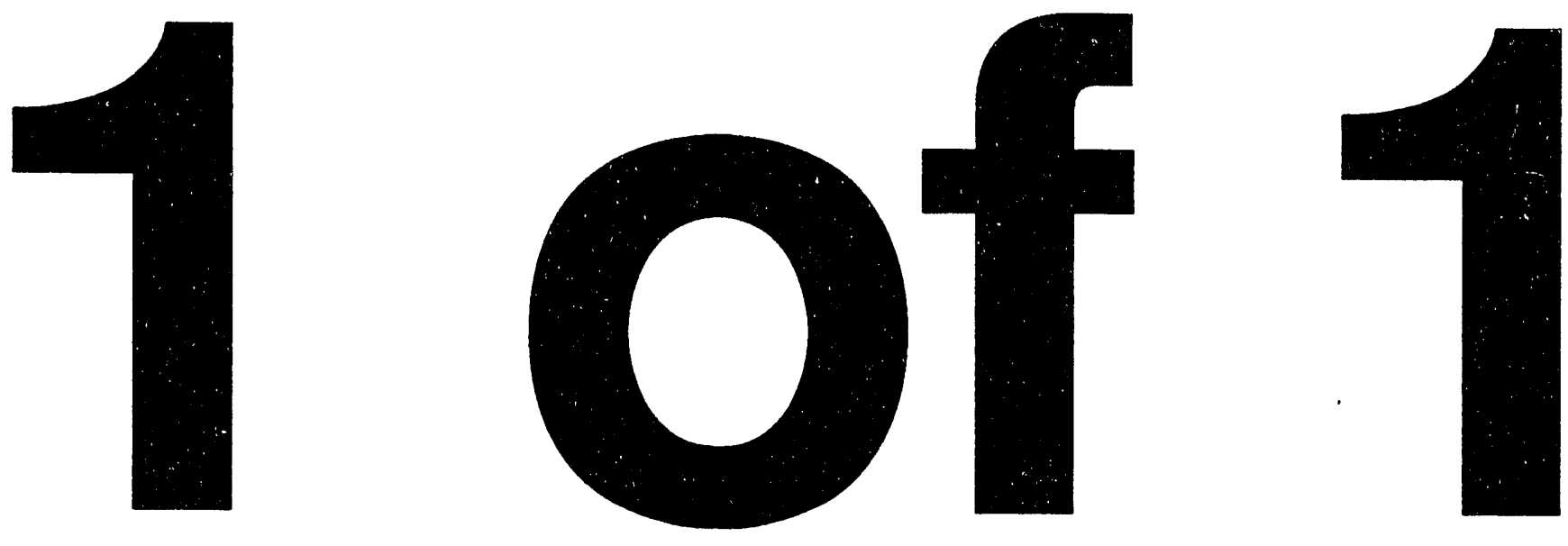


\title{
STRUCTURAL STUDIES IN LIMESTONE SULFIDATION
}

by

\section{Laurent A. Fenouil* and Scott Lynn}

\author{
Energy and Environment Division \\ Lawrence Berkeley Laboratory \\ 1 Cyclotron Road \\ Berkeley, California 94720
}

May, 1993

* M.S. Thesis. This work was supported by the Morgantown Energy Technology Center, Assistant Secretary for Fossil Energy, Office of Coal Utilization, Advanced Research and Technology Development, Division of Surface Coal Gasification through the U.S. Department of Energy under Contract No. DE-AC03-76SF00098.

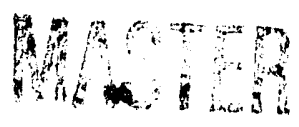




\title{
Structural Studies in Limestone Sulfidation
}

\begin{abstract}
This study investigates the sulfidation of limestone at high temperatures $\left(700-900^{\circ} \mathrm{C}\right)$ :$$
\mathrm{CaCO}_{3}+\mathrm{H}_{2} \mathrm{~S} \rightleftarrows \mathrm{CaS}+\mathrm{H}_{2} \mathrm{O}+\mathrm{CO}_{2}
$$

as the first step in the design of a High-Temperature Coal-Gas Clean-Up system using millimeter-size limestone particles.

Several workers have found that the rate of this reaction significantly decreases after an initial 10 to $15 \%$ conversion of $\mathrm{CaCO}_{3}$ to $\mathrm{CaS}$. The present work attempts to explain this feature. It is first established that millimeter-size limestone particles do not sinter at temperatures up to the $\mathrm{CaCO}_{3}$ calcination point $\left(899^{\circ} \mathrm{C}\right.$ at 1.03 bar $\mathrm{CO}_{2}$ partial pressure). It is then shown that CaS sinters rapidly at 750 to $900^{\circ} \mathrm{C}$ if $\mathrm{CO}_{2}$ is present in the gas phase. Scanning Electron Microscope (SEM) photographs and Electron Dispersive Spectroscopy (EDS) data reveal that the CaS product layer sinters and forms a quasi-impermeable coating around the $\mathrm{CaCO}_{3}$ grains that greatly hinders more $\mathrm{H}_{2} \mathrm{~S}$ from reaching the still unreacted parts of the stone. Moreover, most of the pores initially present within the limestone structure begin to disappear or, at least, are significantly reduced in size. From then on, subsequent conversion is limited by diffusion of $\mathrm{H}_{2} \mathrm{~S}$ through the $\mathrm{CaS}$ layer, possibly by $\mathrm{S}^{2-}$ ionic diffusion. The kinetics is then adequately described by a shrinking-core model, in which a sharp front of completely converted limestone is assumed to progress toward the center of the pellet. Finally, experimental evidence and computer simulations using simple sintering models suggest that the CaS sintering, responsible for the sharp decrease in the sulfidation rate, is surface-diffusion controlled. 


\section{ACKNOWLEDGEMENTS}

This research was supported by Morgantown Energy Technology Center, Assistant Secretary for Fossil Energy, Office of Coal Utilization, Advanced Research and Technology Development Division of Surface Coal Gasification through the U.S. Department of Energy under Contract No. DE-AC03-76SF00098.

I am grateful to my advisor, Professor Scott Lynn, for his help throughout my research. I truly appreciate his advises that kept me on the right track, his constant care in correcting my English and the flexibility he allowed in my work schedule.

I enjoyed working with my labmates Delaina Amos, Nicolas Barthélémy, Rob Broekhuis, Wendy Jaecksch, David Koch, Karen Koigawachi, John Markels, Andy Ting, and Gavin Towler. I am especially grateful to David Koch and Rob Broekhuis for their assistance with computer and software problems. I am also indebted to Gavin Towler with whom I closely worked and from whom I learned a great deal about engineering.

I would also thank Tony Tomsia and Erlene Fong-Mah from the Material Science Division of the Lawrence Berkeley Laboratory for helping me with the Scanning Electron Microscope and the Energy Dispersive Spectroscopy equipment, and Jeff Bullard from the Department of Materials Science and Mineral Engineering of U.C. Berkeley for lending me his B.E.T. apparatus and for sharing his knowledge on sintering.

Finally, I would like to thank the French Ministère des Affaires Etrangères and Elf Aquitaine for their support through the "Bourse Lavoisier" Fellowship. 


\section{TABLE OF CONTENTS}

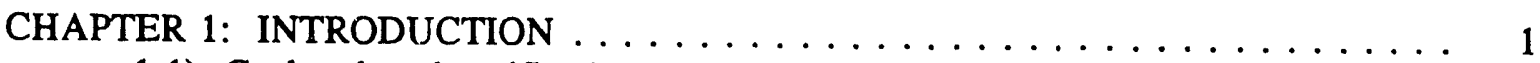

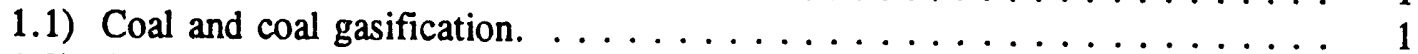

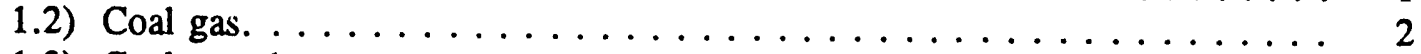

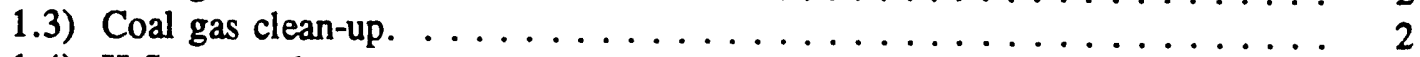

1.4) $\mathrm{H}_{2} \mathrm{~S}$ removal. ......................... 3

CHAPTER 2: PREVIOUS WORK $\ldots \ldots \ldots \ldots \ldots \ldots \ldots$

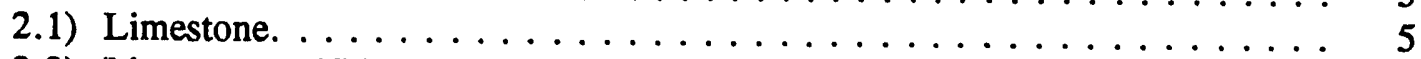

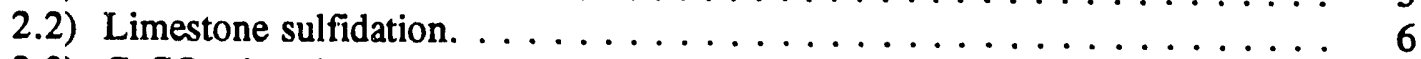

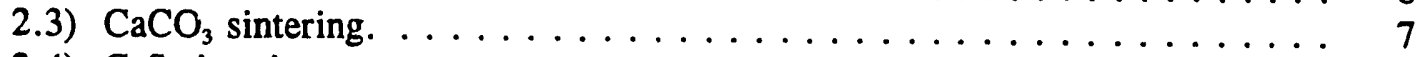

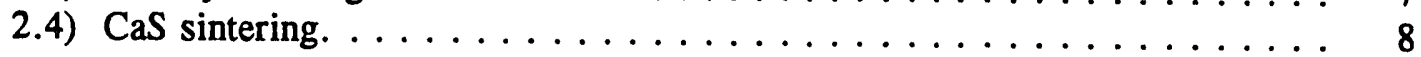

CHAPTER 3: SINTERING THEORY $\ldots \ldots \ldots \ldots \ldots \ldots \ldots \ldots \ldots \ldots \ldots$

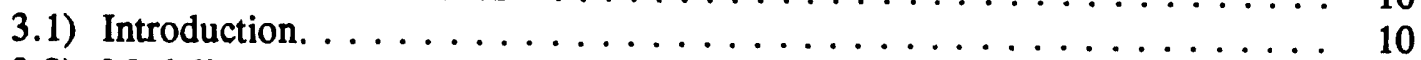

3.2) Modeling. . . . . . . . . . . . . . . . . . . 10

3.2.1) Early stages of sintering: curvature gradient considerations. . . . . 11

3.2.2) Later stages of sintering: surface energy considerations. . . . . . 12

3.3) Other parameters influencing the sintering kinetics. . . . . . . . . . 13

3.3.1) Influence of impurities. . . . . . . . . . . . . . 13

3.3.2) Influence of the gas phase composition. . . . . . . . . . 13

CHAPTER 4: EXPERIMENTAL EQUIPMENT AND PROCEDURES . . . . . . . . . 14

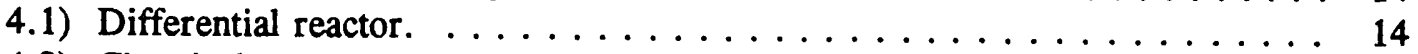

4.2) Chemicals. . . . . . . . . . . . . . . . . . . 14

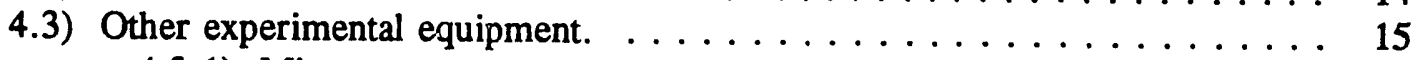

4.3.1) Microscopes. . . . . . . . . . . . . . . . 15

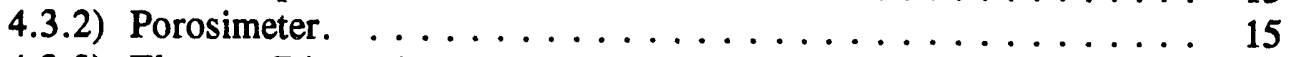

4.3.3) Electron Dispersive Spectroscopy (EDS). . . . . . . . . . 16

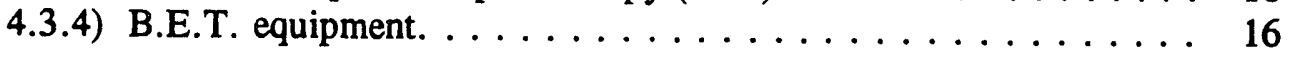

CHAPTER 5: BET MEASUREMENTS $\ldots \ldots \ldots \ldots \ldots \ldots \ldots \ldots \ldots$

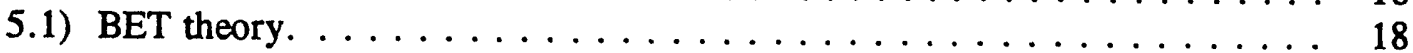

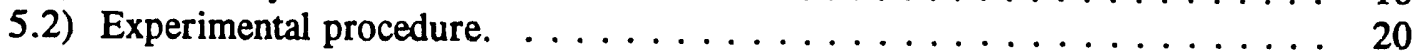

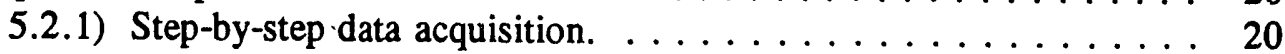

5.2.2) Influence of each step on the accuracy of the surface area

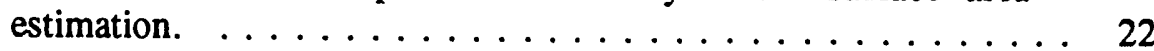

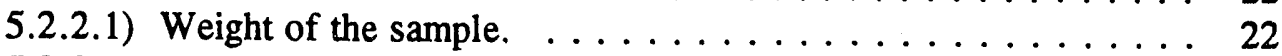

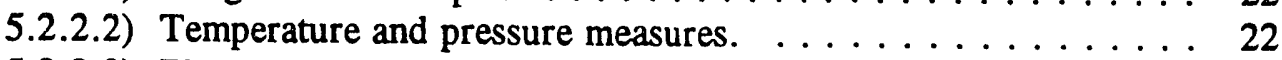

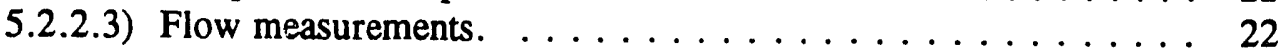

5.2.2.4) Sample cell choice. . . . . . . . . . . . . . 22

5.2.2.5) Drift of the detector base line. . . . . . . . . . . 24

$5.2 .2 .6)$ Calibration volume imprecision. . . . . . . . . . . 24

$5.2 .2 .7)$ Non-linearity of the detector response. . . . . . . . . . 25

5.3) Estimation of surface area. . . . . . . . . . . . . . . . . 29

5.4) Measurement accuracy. . . . . . . . . . . . . . . . 30

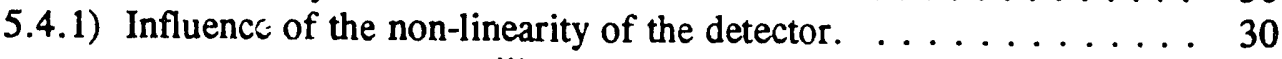


5.4.2) Influence of the fluctuations in calibration volume. . . . . . . 31

5.4.3) Cell influence. . . . . . . . . . . . . . . . 31

5.4.4) Final assessment of accuracy. . . . . . . . . . . 32

CHAPTER 6: LIMESTONE SINTERING EXPERIMENTS $\ldots \ldots \ldots \ldots \ldots \ldots \ldots \ldots$

6.1) Limestone characteristics. . . . . . . . . . . . . . . . 33

6.1.1) Chemical analysis. . . . . . . . . . . . . 33

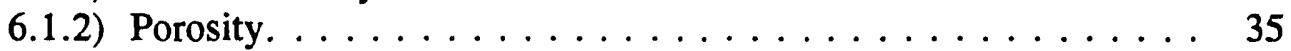

6.1.3) Surface area. . . . . . . . . . . . . . . . . . 35

6.1.4) Scanning Electron Microscope (SEM) and optical microscope

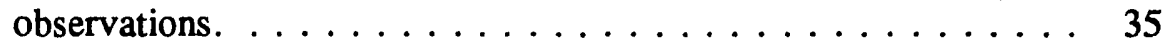

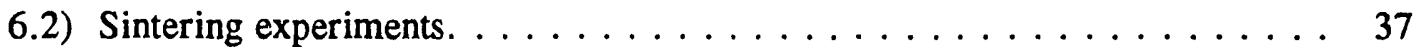

6.3) Conclusions. . . . . . . . . . . . . . . . . . . . . . 44

CHAPTER 7: CALCIUM SULFIDE SINTERING STUDY $\ldots \ldots \ldots \ldots \ldots \ldots \ldots$

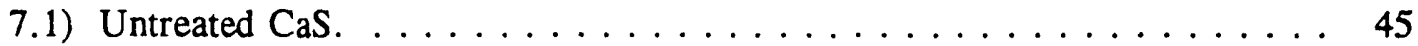

7.2) Sintered CaS. . . . . . . . . . . . . . . . . . . 45

7.2.1) Influence of atmosphere composition on the sintering rate. . . . 45

7.2.2) Calcium sulfide sintering kinetics. . . . . . . . . . 47

7.2.3) Modeling of the CaS sintering kinetics. . . . . . . . 55

CHAPTER 8: LIMESTONE SULFIDATION EXPERIMENTS . . . . . . . . . . . . . 59

8.1) Influence of the temperature and of the $\mathrm{H}_{2} \mathrm{~S}$ partial pressure. . . . . . . . . 59

8.2) Morphological study. . . . . . . . . . . . . . . . 61

8.2.2) Sulfur distribution. . . . . . . . . . . . . . . . 67

8.2.2.1) Particles with low conversion to CaS. . . . . . . . . . . 69

8.2.2.2) Particles with higher conversion to $\mathrm{CaS}$. . . . . . . . . . 69

CHAPTER 9: MORPHOLOGICAL BEHAVIOR OF THE CaS PRODUCT-LAYER $\ldots 72$

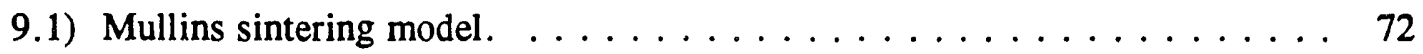

9.2) Computer simulations. . . . . . . . . . . . . . . 74

9.3) Discussion of the values of the physical parameters. . . . . . . . . . 75

9.4) Analysis of the computer simulations. . . . . . . . . . . 76

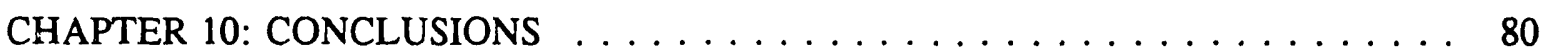

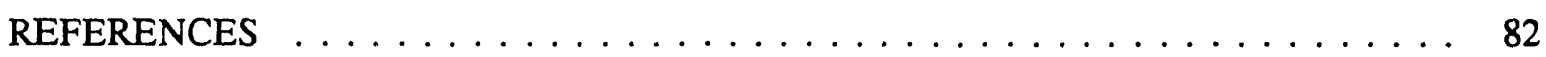

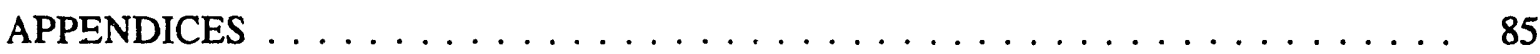




\section{CHAFTER 1: INTRODUCTION}

The goal of this thesis is to investigate the chemical reaction between hydrogen sulfide, $\mathrm{H}_{2} \mathrm{~S}$, and limestone, $\mathrm{CaCO}_{3}$. Due to the complexity of this non-catalytic gas-solid reaction, most of the emphasis has been put into obtaining a deep understanding of the physical and chemical features occurring during the sulfidation reaction.

The objective of this introduction is to provide the reader with the motivations for undertaking such a study.

\section{1) Coal and coal gasification.}

Most energy-resources specialists agree that coal reserves as a source of fuel will outlast oil and gas by a few centuries (Fulkerson, 1990). Even if coal is currently rarely used as a transportation or domestic-heating fuel in the U.S.A. and in Western Europe, it still provides a large share of the fuel for power generation. A traditional power generation technique consists in the production of steam that is sent to a turbine to generate electrical power. Another possible way of extracting energy from coal is by partial combustion with steam (or water) and oxygen (or air) to obtain a mixture referred as "coal gas", chiefly composed of $\mathrm{CO}, \mathrm{CO}_{2}, \mathrm{H}_{2}, \mathrm{H}_{2} \mathrm{O}$ and $\mathrm{CH}_{4}$. This gas mixture, unlike steam, is a fuel. This characteristic accounts for the major advantage of coal gasification versus steam production. Gas turbines, which permit a higher inlet temperature than steam turbines, can be used. Thus, according to Carnot's second law, a better yield of power generation is obtained. This also means less $\mathrm{CO}_{2}$ rejected to the atmosphere for the same power output, which diminishes the "greenhouse effect". 


\section{2) Coal gas.}

A typical coal gas composition is given in Table 1.1 (Barthelemy, 1991): These numbers correspond to a "Texaco gasifier" using 95\% pure oxygen (obtained from cryogenic distillation) as oxidant with the coal fed as a slurry containing $50 \mathrm{wt} \%$ of water. However, these numbers may vary depending on the type of gasifier or on the gas temperature because of the water gas shift reaction:

$$
\mathrm{CO}+\mathrm{H}_{2} \mathrm{O}=\mathrm{H}_{2}+\mathrm{CO}_{2}
$$

Table 1.1: Typical composition of a coal gas.

\begin{tabular}{|c|c|c|c|c|c|c|c|c|}
\hline constituent & $\mathrm{CO}$ & $\mathrm{H}_{2}$ & $\mathrm{CO}_{2}$ & $\mathrm{H}_{2} \mathrm{O}$ & $\mathrm{CH}_{4}$ & $\mathrm{H}_{2} \mathrm{~S}$ & $\mathrm{NH}_{3}$ & $\mathrm{~N}_{2}+\mathrm{Ar}$ \\
\hline mole fraction & 0.396 & 0.303 & 0.108 & 0.165 & 0.001 & 0.010 & 0.002 & 0.016 \\
\hline
\end{tabular}

\section{3) Coal gas clean-up.}

Coal gas clean-up consists of two main tasks: the removal of small solid particles and the removal of gaseous pollutants.

A series of cyclone separators and/or a large solid particle bed can eliminate dust particles having a diameter as small as about one micron with a good efficiency (Towler, 1992). This will filter most of the entrained ashes, tar, alkali salts and heavy metals traces originally present in the coal from the gas (Harte, 1988). It will also reduce erosion of the turbine blades and all subsequent equipment.

Typical coal gases, as indicated in Table 1.1, also contain a small fraction of corrosive and/or pollutant gases such as aminonia, $\mathrm{NH}_{3}$, and hydrogen sulfide, $\mathrm{H}_{2} \mathrm{~S}$, and, to a lesser extent, 
carbonyl sulfide, $\mathrm{COS}$, and hydrogen chloride, $\mathrm{HCl}$. Depending on the quality of the coal, these gases account for as much as a few mole percent of the coal gas mixture. We have to eliminate these gases as soon as possible in the process, preferably before they reach the turbine blades to avoid any extreme corrosion. Moreover, they may not be emitted to the atmosphere because of various environmental laws.

Ammonia is probably the easiest gas to dispose of. Iron oxide particles should convert most of the ammonia into hydrogen and nitrogen at the high temperatures encountered at the gasifier outlet.

Hydrogen sulfide removal is somewhat more involved. Sulfur is present in two main forms in coal: pyriti: and organic. Pyritic sulfur is not a part of the chemical structure of the coal itself. It is contained as mineral inclusions inside the organic matrix of coal. Thus, fine grinding of the raw coal followed by separation of the organic from the mineral phase by flotation appears to be a good means of extracting a large fraction of the pyritic sulfur prior to burning or gasifiing (Lynch, 1981; Brown, 1962). However, one-half or more of the sulfur, along with some nitrogen and oxygen, is organically bound to the coal (Nowacki, 1981). Consequently, it cannot be extracted before the coal is burned. In a gasification process the residual sulfur ir both forms ends up as $\mathrm{H}_{2} \mathrm{~S}$ because of the reducing conditions present in the gasifier.

\section{4) $\mathrm{H}_{2} \mathrm{~S}$ removal.}

Hydrogen sulfide is often removed from a gaseous mixture with the help of wet scrubbers with good efficiency. However, the sour gas cannot be treated at temperatures higher than the atmospheric boiling point of the absorbing solution (generally an aqueous solution of potassium carbonate, or an alkanolamine). In the coal gasification case it would be necessary to cool the 
gas mixture significantly. So, the clean coal gas would enter the combustion chamber of the turbine at a much lower temperature than the roughly $2000^{\circ} \mathrm{F}$ at which the sour gas exits the gasifier. The process efficiency would then seriously drop.

A high-temperature, non-catalytic, gas-solid reaction involving $\mathrm{H}_{2} \mathrm{~S}$ is a much better option than a wet scrubber for maintaining the gas temperature as high as possible. The ideal solid must have a thermodynamically favorable reaction with $\mathrm{H}_{2} \mathrm{~S}$ at temperatures around $2000^{\circ} \mathrm{F}$, but must be inert toward the other coal-gas components. It must also be cheap and naturally abundant. Finally, the sulfur-containing solid product should be environmentally as harmless as possible since it will probably be disposed in landfills. Two minerals, limestone $\left(\mathrm{CaCO}_{3}\right)$ and dolomite $\left(\mathrm{CaCO}_{3}-\mathrm{MgCO}_{3}\right)$ have been proposed as potential candidates. For an $\mathrm{H}_{2} \mathrm{~S}$-removal unit located after the gasifier the reaction is:

$$
\mathrm{CaCO}_{3(s)}+\mathrm{H}_{2} \mathrm{~S}_{(g)}=\mathrm{CaS}_{(s)}+\mathrm{H}_{2} \mathrm{O}_{(g)}+\mathrm{CO}_{2(8)}
$$

A thermodynamic analysis indicates that the sulfidatic $n$ of the calcium carbonate is total whereas the magnesium carbonate does not react with the hydrogen sulfide under the expected conditions in the High-Temperature Gas-Clean-Up unit (Towler, 1992).

In the following work dolomite has not been studied; limestone is potentially more attractive since the magnesium does not react with $\mathrm{H}_{2} \mathrm{~S}$. If we assume the reactions to be thermodynamically controlled, almost twice the weight of dolomite would be required to obtain the same $\mathrm{H}_{2} \mathrm{~S}$ removal as with limestone.

The other advantage of using a moving bed of solid sorbent particles is the filtration of the "gasifier fines" (volatilized alkali salts and heavy metals, non-combusted char, ash...) as mentioned earlier in Section 1.3. 


\section{CHAPTER 2: PREVIOUS WORK}

Many studies of the reaction between calcined limestone $(\mathrm{CaO})$ and half or fully calcined dolomites (respectively $\mathrm{CaCO}_{3}-\mathrm{MgO}$ and $\mathrm{CaO}-\mathrm{MgO}$ ) with $\mathrm{H}_{2} \mathrm{~S}$ have been published (Abbasian et al, 1990; Freund, 1981; Squires et al, 1971; Ruth et al, 1972; Yen, 1979). These works were often concerned with the addition of limestone or dolomite to the coal in the gasifier where the conditions are such that the calcination of the calcium carbonate or the magnesium carbonate might occur rapidly (Freund, 1981), or were coriducted at a $\mathrm{CO}_{2}$ fugacity low enough to obtain partial or total calcination of the calcium carbonate.

We are here interested in the direct sulfidation of the non-calcined limestone:

$$
\mathrm{CaCO}_{3(s)}+\mathrm{H}_{2} \mathrm{~S}_{(g)}=\mathrm{CaS}_{(s)}+\mathrm{H}_{2} \mathrm{O}_{(g)}+\mathrm{CO}_{2(8)}
$$

berause the calcination will be prevented under the expected conditions of the High-Temperature Coal-gas Clean-up unit (Barthelemy, 1991; Towler, 1992; Attar, 1978). Thermodynamic arguments lead us to expect $100 \%$ CaS conversion (Towler, 1992).

\section{1) Limestone.}

Limestone is a sedimentary rock of quite variable composition, mainly consisting of calcium carbonate with some calcium sulfate and magnesium carbonate along with other impurities. Chemical compositions of various limestones can be found in Chan et al (1970), Chang et al (1984), Borgwardt and Roache (1984), Borgwardt et al (1987), and Fuller et al (1987). The specific surface area of most of these stones is low (generally less than $1 \mathrm{~m}^{2} / \mathrm{g}$ ) and the natural porosity ranges from 0 to $8 \%$ (Borgwardt and Roache, 1984; Hartman et al, 1978; Borgwardt et al, 1987). Whereas limestones are considered amorphous, Scanning Electron 
Microscopy pictures of few rock samples taken during this study reveal that they may contain small transparent crystal inclusions, typically a few microns in diameter. More details are given in Section 7.1.

\section{2) Limestone sulfidation.}

Borgwardt and Roache (1984) studied the sulfidation of non-calcined limestone with particles ranging from 1.6 to 100 microns at temperatures between 570 and $850^{\circ} \mathrm{C}$ under an atmosphere of $\mathrm{CO}_{2}(70 \%) \mathrm{N}_{2}(29.5 \%)$ and $\mathrm{H}_{2} \mathrm{~S}(0.5 \%)$. They found that the sulfidation rate sharply decreased after about $11 \%$ conversion for large particles $\left(D_{p}>15 \mu \mathrm{m}\right)$. They presumed that the loss of porosity of the surface limestone at these high temperatures prevents the gaseous reactant from diftising further toward the center of the solid particles (see Section 2.3). They found that the sulfidation kinetics of the non-calcined limestone with particle sizes ranging from 1.6 to $10 \mu \mathrm{m}$ is well described by:

$$
\frac{d\left[\mathrm{CaCO}_{3}\right]}{d t}=\frac{k}{D_{p}}\left[\mathrm{CaCO}_{3}\right]\left[\mathrm{H}_{2} \mathrm{~S}\right]
$$

where $\mathrm{D}_{\mathrm{p}}$ is the diameter of the particle (in $\mathrm{cm}$ ), $\left[\mathrm{CaCO}_{3}\right]$ the unreacted fraction of $\mathrm{CaCO}_{3},\left[\mathrm{H}_{2} \mathrm{~S}\right]$ the gas phase concentration of $\mathrm{H}_{2} \mathrm{~S}$ and $\mathrm{k}$ a constant (that varies with the temperature) being equal to $0.66 \mathrm{~cm} / \mathrm{g} \cdot \mathrm{mol}$ of $\mathrm{H}_{2} \mathrm{~S} \min$ at $750^{\circ} \mathrm{C}$. The $\mathrm{D}_{\mathrm{p}}$ dependency indicates that the reaction is chemically controlled. Ruth et al (quoted in Borgwardt and Roache, 1984) found a similar expression, without the $D_{p}$ dependency, for the sulfidation kinetics of $60-\mu \mathrm{m}$ diameter, halfcalcined dolomites. Squires et al (1971) also found that the reaction was first-order with respect to the $\mathrm{H}_{2} \mathrm{~S}$ partiai pressure. 
Borgwardt also mentioned that $\mathrm{CO}_{2}$ and $\mathrm{H}_{2} \mathrm{O}$ enhanced the sulfidation reaction whereas $\mathbf{H}_{2}$ slowed the reaction rate. However, Ruth et al did not notice any effect on the rate when $\mathrm{H}_{2}$ was introduced in the gas mixture.

Towler (1992) points out some shortcomings in many works published in the sulfurremovai area. Some authors do not carefully report the gas-phase composition during their experimental work and often forget to allow for the water gas shift reaction (rxn 1.1) as a major influence on the actual gas mixture composition. He also shows that about $1 \%$ of $\mathrm{CO}$ in the gas phase is necessary to prevent the CaS oxidation into $\mathrm{CaSO}_{3}$ by $\mathrm{CO}_{2}$. More details on the thermodynamics of the limestone-coal gas mixture can be found in his dissertation (Towler, 1992).

\section{3) $\mathrm{CaCO}_{3}$ sintering.}

Borgwardt (1984) noticed that the external dimensions of the limestone particles remained the same while undergoing calcination or sulfidation. Thus, in the course of reaction 1.1 the porosity of the particle should change because of the molar volume difference between $\mathrm{CaCO}_{3}$ and CaS. Based on the values the densities of $\mathrm{CaCO}_{3}\left(2.71 \mathrm{~g} / \mathrm{cm}^{3}\right)$ and $\mathrm{CaS}\left(2.61 \mathrm{~g} / \mathrm{cm}^{3}\right)$ determined by Borgwardt, we should expect an increase of $25 \%$ of the initial limestone porosity at the end of reaction 1.1. This pore opening should allow the gaseous reactant to reach the core of the particle and the reaction to proceed until completion. It should also be noted that the sulfidation of sintered calcium oxide, $\mathrm{CaO}\left(2.32 \mathrm{~g} / \mathrm{cm}^{3}\right)$, will occur with reduction of the pore volume because of the larger volume of $S^{2-}$ relative to $\mathrm{O}^{2-}$. So, the reaction continues via solidstate diffusion after a crust of non-porous CaS is formed (Borgwardt, Roache and Bruce, 1984). 
Contrary to the conclusions of this analysis, Borgwardt found that sulfidation almost stops after $11 \%$ conversion for large limestone pellets $\left(D_{p}>15 \mu \mathrm{m}\right)$. Borgwardt considered that limestone sintering could be held responsible for the poor conversion. He observed that $1.6-\mu \mathrm{m}$ diameter limestone particles having an initial $4.5-\mathrm{m}^{2} / \mathrm{g}$ surface area sinter to give $3.5-\mu \mathrm{m}$ particles with an average specific surface area of $2.0 \mathrm{~m}^{2} / \mathrm{g}$ after 20 minutes at $850^{\circ} \mathrm{C}$ under one atmosphere of $\mathrm{CO}_{2}$. He checked that no $\mathrm{CaO}$ had formed during these experiments, so that this loss of surface area can only be attributed to a physical change on the stones. Similar experiments were reproduced for this work and we did not notice any significant surface area loss with millimetersize limestone pellet. Explanations of this discrepancy will be presented in Chapter 7 .

\section{4) CaS sintering.}

No extensive study of CaS sintering has so far been conducted. Nevertheless, Attar et al (1979) observed interesting features during calcite (trigonal crystals of calcium carbonate) sulfidation. In the first stages, the chemical reaction on the flat calcite crystal surface is the limiting step until about $80 \mathrm{CaS}$ layers are formed. Then, the newly-formed CaS laver limits gas diffusion. The reaction rate is then limited by the solid-state diffusion through the CaS crust. These results are consistent with Borgwardt and Roache (1984) observations of the steep decline of the sulfidation rate on large pellets after $11 \%$ conversion: 80 molecular layers correspond to about $10 \%$ of the volume of a $1-\mu \mathrm{m}$ diameter $\mathrm{CaCO}_{3}$ grain. This diameter value is consistent with that of the limestone used by Borgwardt in his experiments.

The CaS layer obtained at relatively low temperature is not thermodynamically stable because the sulfur ions have just replaced the carbonate ions in their previous sites without any structural rearrangement. However, the sulfur and carbonate ions do not have the same volume. So, the most stable crystalline structures of $\mathrm{CaCO}_{3}$ and $\mathrm{CaS}$ are not the same. If the 
temperature increases, the rate of diffusion of the $\mathrm{Ca}^{2+}$ and $\mathrm{S}^{2-}$ ions on the surface becomes high enough to allow formation of a more stable CaS crystalline structure. Thus, the formerly flat $\mathrm{CaS}$ crust lets some cracks appear and exposes more fresh $\mathrm{CaCO}_{3}$ to $\mathrm{H}_{2} \mathrm{~S}$. Differential Scanning Calorimetry data from Attar reveal that the rate of ionic diffusion becomes relatively fast at $635^{\circ} \mathrm{C}$ : the time scale of crystalline rearrangement becomes of the order of magnitude of the other experimental time scales, such as the gas diffusion characteristic time or the chemica' reaction rate. Everything that can trigger this "recrystallization" process (temperature, presence of oxygen to form some $\mathrm{SO}_{4}^{2-}$ ions to break the metastable CaS crust, impurities, etc.) will be favorable to a higher $\mathrm{CaCO}_{3}$ conversion into $\mathrm{CaS}$.

Unfortunately, as mentioned in Section 2.2, the reaction rate of the limestone sulfidation drops dramatically after $11 \%$ conversion, even at temperatures as high as $750^{\circ} \mathrm{C}$. Another physical phenomenon has to account for this loss of reactivity. This might be due to sintering of the CaS layer around the limestone grains so that the layer, instead of cracking to allow more $\mathrm{H}_{2} \mathrm{~S}$ to reach the core of the grain, coats the grain with a quasi-non-porous impermeable layer. Since no study of CaS sintering has been published to date, a major topic developed in this thesis is to provide an explanation for the declining sulfidation rate. 


\section{CHAPTER 3: SINTERING THEORY}

\section{1) Introduction.}

Sintering can be defined as the coalescence and growth of the grains forming a porous solid pellet at an elevated temperature. These structural changes can be the result of various mechanisms such as volume, grain-boundary or surface diffusion but also viscous or plastic flow and evaporation-condensation processes (German and Munir, 1976). Every porous solid is susceptible to sintering if the temperature is high enough to overcome the activation energy of the various mechanisms. As a rule of thumb, a solid may sinter if the temperature is higher than 0.6 times its absolute temperature of fusion. A good phenomenological description of the different stages of the sintering pellet is given by Coble (1961). The principal consequence of this physical rearrangement is a loss of specific surface area and porosity.

\section{2) Modeling.}

Most of the kinetic models for isothermal sintering are empirical because of the complexity of the mechanisms. However, numerous approaches based on geometrical and physical considerations have been attempted. One of the most successful, and most widely used, has been developed by German and Munir in 1976.

The original feature of their description is the recognition of the curvature gradient in the interparticle neck regions as the main driving force, at least during the earlier stages of the phenomenon. As the curvature gradient diminishes, the main driving force becomes the excess surface free energy. Most of the models only account for this second driving force and do not consider the impact of the curvature gradient. 


\subsection{1) Early stages of sintering: curvature gradient considerations.}

The derivation of the German-Munir sintering kinetic relies on neck-growth models, a neck being a contact surface between two grains of a pellet. Many neck geometries have been considered. However, they all yield the following kinetic expression:

$$
\left(\frac{S_{0}-S}{S_{0}}\right)^{\omega}=\left[k \exp \left(-\frac{E}{R T}\right)\right] t
$$

where:

- $S_{0}$ is the initial surface area,

- $S$ is the surface area,

- $\mathrm{t}$ is the time,

- $\mathrm{T}$ is the absolute temperature,

- $\mathrm{R}$ is the ideal gas constant, and

- $\omega, \mathrm{k}$ and $\mathrm{E}$ are the three adjustable parameters, $\omega$ being directly related to the sintering mechanism and $\mathrm{E}$ being the activation energy of the mechanism responsible for the sintering.

The value of $\omega$ can be derived from the nature of the neck-growth mechanism and from the particle packing coordination (i.e., the density), and lies between 1.1 and 3.6 for purely physical sintering kinetics, but higher values have been reported when the gas-phase components have a catalytic action on the phenomenon (Borgwardt, 1989 A).

The limit of the validity of this approach is set by the point at which neighboring necks begin to meet each other. It is difficult to determine this limit precisely because it depends on the grain-size distribution and on the neck geometry. However, this limit is generally reached when 50 to $55 \%$ of the initial surface area has been lost. 


\subsection{2) Later stages of sintering: surface energy considerations.}

After the solid has lost about half of its original specific surface area, the curvature gradient becomes much smaller than it initially was. Thus, the dominant driving force shifts to the excess surface energy. The kinetic expression becomes:

$$
\frac{d S}{d t}=-k S^{m}
$$

$\mathrm{k}$ and $\mathrm{m}$ being two constants. Other authors suggest slightly different kinetic expressions for the second stage. Nicholson (1965) used :

$$
\frac{d S}{d r}=-k\left(S-S_{f}\right)
$$

where $S_{\mathrm{f}}$ is the final surface area value that can be reached at a given temperature for a given sample. This expression can be generalized to:

$$
\frac{d S}{d t}=-k\left(S-S_{f}\right)^{w}
$$

where $\mathrm{w}$ is a constant. The following expression:

$$
\frac{d S}{d t}=-k S^{m} t^{-n}
$$

has also been proposed (Greeg et al, quoted in Irabien, 1980). Finally, the evolution of the surface area during the second stage can be considered a linear function of time,

$$
S=a+b t
$$

which is basically equivalent to a very large value of $\omega$ in the German-Munir model (Irabien $e t$ $a l, 1990)$. 


\section{3) Other parameters influencing the sintering kinetics.}

\subsection{1) Influence of impurities.}

The presence of foreign ions in a solid matrix has a large impact on the solid transport properties. Borgwardt (1989) clearly showed that an impure $\mathrm{CaO}$ derived from limestone sinters at a higher rate than $\mathrm{CaO}$ derived from a pure calcium carbonate. The introduction of extrinsic defects (foreign ions in the lattice) enhances the solid diffusion, one of the keys to the sintering mechanism. Thus, any sintering study has to be conducted with a perfectly defined solid composition and any impurity should be carefully reported.

\subsection{2) Influence of the gas phase composition.}

The chemical nature of the gas phase is also crucial. In his study of $\mathrm{CaO}$ sintering Borgwardt (1989 B) noticed that the presence of $\mathrm{H}_{2} \mathrm{O}$ and $\mathrm{CO}_{2}$ enhanced the sintering rate. This catalytic effect comes from the interactions between the gases and the $\mathrm{CaO}$ surface. Anderson and Morgan (1964) investigated the dynamic adsorption/desorption equilibrium of $\mathrm{H}_{2} \mathrm{O}$ with $\mathrm{CaO}$, in which short-lived surface hydroxyl groups may form. They proposed that these groups accelerate the bonding of adjacent $\mathrm{CaO}$ lattices to eliminate surface and promote the mobility of the oxygen ions along the surface. No evidence of such phenomena with $\mathrm{CaCO}_{3}$ and $\mathrm{CaS}$ has been published. 


\section{CHAPTER 4: EXPERIMENTAL EQUIPMENT AND PROCEDURES}

\section{1) Differential reactor.}

All calcined, sintered and sulfided limestone samples were obtained from Gavin Towler of this laboratory, whose research was directed toward the kinetics of the sorption of $\mathrm{H}_{2} \mathrm{~S}$ by limestone. All experiments were carried out with a differential tube reactor. The exact configuration of the reactor as well as the connected apparatus is given in Towler (1992) along with the experimental procedure. The choice of such a reactor was dictated by several considerations, the most critical one being the ability to fix the exact experimental conditions actually seen by the solid pellets. With the chosen reactor configuration the conditions at the solid surface are well controlled:

1) The temperature is roughly constant in the vicinity of the solid pellets. Moreover, a large gas flow rate permits the suppression of external heat- and mass-transfer effects. This considerably simplifies the kinetic study. The conditions at the surface of the solid are those pertaining in the bulk gas phase.

2) The conversion in the gas phase is only differential. So, the gas-phase composition is constant, homogeneous and identical around all the pellets during the whole experiment.

\section{2) Chemicals.}

The gases used in the reactor experiments $\left(\mathrm{CO}_{2}, \mathrm{CO}, \mathrm{H}_{2}, \mathrm{~N}_{2}\right.$ and $\left.\mathrm{H}_{2} \mathrm{~S}\right)$ were industrial grade ( $99.9 \%$ pure) and provided by the Matheson ${ }^{\circledR}$ Gas Products (East Rutherford, NJ).

The calcium sulfide used in the sintering experiments was a purified calcium powder (micrometer-size grains) obtained from Fisher Scientific Co. (Fair Lawn, NJ). 
Finally, the industrial-quality limestone was provided by Great Lakes Calcium Corporation (Green Bay, WI). Section 6.1.1 provides the chemical analysis of this limestone.

\section{3) Other experimental equipment.}

\subsection{1) Microscopes.}

All the optical microscope pictures in this thesis were taken with an Inverted NIKON EPIPHOT-TME Optical Microscope (Nikkon Kogaku K.K., Japan) equipped with a built-in Photomicrographic System. One of the advantages of this equipment is being able to use brightfield as well as darkfield microscopy to enhance the contrast of the picture for various sample constitutions and colors. The magnification ranges from 50 to 400 times.

The Scanning Electron Microscopy (SEM) pictures were obtained on a ISI-DS 130 Dual Stage Scanning Electron Microscope from International Scientific Instruments, Inc. (Santa Clara, CA). All the solid samples were coated with a $200-250 \mathrm{~nm}$ conducting gold layer. This coating was necessary because neither $\mathrm{CaS}$ nor $\mathrm{CaCO}_{3}$ has sufficient electron-conducting properties to permit good quality pictures.

In all cases the pictures were taken on Polaroid 52 Professional Pola Pan 4x5 Instant Sheet Film (Medium Contrast. ISO 400/279).

\subsection{2) Porosimeter.}

A Quantachrome Scanning Porosimeter from the Quantachrome Corporation (Syosset, NY) was used to estimate the porosity of the unreacted limestone. The apparatus consists of two parts: an Autoscan Filling Apparatus operating under pressures between about $50 \mu \mathrm{m}$ of mercury to one atmosphere to fill the pores with a radius larger than $7 \mu \mathrm{m}$ and an Autoscan 60 
Porosimeter designed to measure the volume of the pores with a radius ranging from 7 to 0.0018 $\mu \mathrm{m}$.

\subsection{3) Electron Dispersive Spectroscopy (EDS).}

The EDS equipment came from EDAX ${ }^{\oplus}$ International, a division of North American Philips Corporation (Mahwah, NJ). Most analyses were coupled with SEM pictures from an ISIDS 130C 144-10 Dual Stage Scanning Electron Microscope from International Scientific Instruments, Inc. (Santa Clara, CA).

All the samples had to be coated with a 200 to $250 \mathrm{~nm}$ layer of grap? ite or gold because of the poor electric conductivity of $\mathrm{CaCO}_{3}$ and $\mathrm{CaS}$. EDS spectrometers can qualitatively identify all chemical elements with an atomic number larger than 6 on the surface of a solid. The scanned surface area can be as low as a fraction of a $\mu \mathrm{m}^{2}$ for a depth of about $2.5 \mu \mathrm{m}$ from the skin into the core of the particle. So, this technique is particularly adapted for micron-size grain analysis. Quantitative results are also possible for relatively heavy elements like calcium and sulfur. Unfortunately, this is not achievable with lighter components such as carbon or oxygen where the results are, at best, semi-quantitative.

The coarse, uneven surface of most of the inspected samples created a large electron scattering that could induce a small signal-to-noise ratio. This ratio has been constantly monitored to insure good quality and reliability for each analysis.

\subsection{4) B.E.T. equipment.}

The BET (Brunauer, Emmett, Teller) surface-area measurements were acquired with a Quantasorb $^{\oplus}$ Surface Area Analyzer with its Flow Control Accessories from the Quantachrome Corporation (Greenvale, NY). The gases, nitrogen and helium, used in the surface-area determination were industrial grade and purchased from Airco (BOC ${ }^{\text {ma }}$ Group, Inc., Murray Hill, 
NJ). Every sample was weighed with a Mettler H20T balance. The precision of the balance is

$0.01 \mathrm{mg}$. More details on the equipment, especially on the sample cell and the measurement procedure and precision, are available in Chapter 5. 


\section{CHAPTER 5: BET MEASUREMENTS}

\section{1) BET theory.}

BET surface-area estimations rely on the adsorption of a gas (generally $\mathrm{N}_{2}$ ) on a solid surface at the normal boiling temperature of the adsorbate $\left(-195.6^{\circ} \mathrm{C}\right.$ for $\left.\mathrm{N}_{2}\right)$. The weight of adsorbed gas is a function of the temperature, the pressure and the nature of the interactions between the gas and the solid. At a given temperature, for a given gas, the quantity adsorbed is often a sole function of the gas partial pressure and the solid surface area. By isothermal variations of the gas partial pressure we can record the evolution of the adsorbed weight and construct the adsorption isotherm. The B.E.T. adsorption isotherm is based on the same assumptions used in the development of the Langmuir isotherm, but with the added condition that more than a single molecular gas layer can be adsorbed on the solid surface.

Under a certain set of assumptions Brunauer, Emmett and Teller derived the following relation between the weight of the adsorbed gas, $\mathrm{W}$, and its partial pressure above the solid:

$$
\frac{1}{W}\left(\frac{P_{0}}{P}-1\right)^{-1}=\frac{1}{W_{m} C}+\left(\frac{C-1}{W_{m} C}\right)\left(\frac{P}{P_{0}}\right)
$$

where:

- $\mathrm{W}_{\mathrm{m}}$ is the adsorbed weight that would correspond to a monolayer,

- $\mathrm{P}_{0}$ is the vapor pressure of the adsorbed gas at the isotherm temperature,

- P the partial pressure of the adsorbed gas in the vicinity of the solid surface, and

- $\mathrm{C}$ is referred as the BET constant and is a function of the nature of the gas and the solid. The value of $\mathrm{C}$ ranges from 50 to 300 for $\mathrm{N}_{2}$ ' on most solids. 
The solid surface area is readily deduced from equation 5.2:

$$
S_{t}=\frac{W_{m} N A}{M}
$$

where:

- $S_{\mathrm{t}}$ is the total surface area of the solid sample (in $\mathrm{m}^{2} / \mathrm{g}$ ),

- $\mathrm{N}$ is Avogadro's number $\left(6.023 \cdot 10^{23}\right.$ molecules per mole),

- $\mathrm{M}$ is the molecular weight of the adsorbate $\left(28.023 \mathrm{~g} / \mathrm{mol}\right.$ for $\left.\mathrm{N}_{2}\right)$, and

- $A$ is the cross sectional area of the adsorbate $\left(16.2 \cdot 10^{-20} \mathrm{~m}^{2} / \mathrm{molecule}\right.$ for $\mathrm{N}_{2}$ at its normal boiling point).

$\mathrm{W}_{\mathrm{m}}$ is the inverse of the of the sum of the slope and the intercept of the line obtained by plotting the inverse of $\mathrm{W}\left(\mathrm{P}_{0} / \mathrm{P}-1\right)$ versus $\left((\mathrm{C}-1) / \mathrm{W}_{\mathrm{m}} \mathrm{C}\right) \cdot\left(\mathrm{P} / \mathrm{P}_{0}\right)$ as indicated by equation 5.1 . So we have to determine at least two points of the isotherm to determine $S_{t}$. The straight line passing through these two points provides the values of the slope and intercept necessary to estimate $W_{m}$.

The derivation of the last two equations as well as a presentation and a discussion of the various assumptions made to obtain them can be found in Lowell and Shield (1984). Equation 5.1 usually holds quite well when the ratio $P / P_{0}$ lies between 0.05 and 0.35 . Outside of this partial pressure range, the linearity between the inverse of $W\left(P / P_{0}-1\right)$ and $P / P_{0}$ is generally lost. The partial pressure of $\mathrm{N}_{2}$ is varied by mixing the nitrogen with a non-condensible gas (helium) while keeping the total pressure constant. 


\section{2) Experimental procedure.}

BET surface area analyzers are now very common equipment for surface studies in fields such as ceramics and catalysts, and are generally sold with an "easy to follow" step-by-step procedure manual. When every step is followed, most commercial equipment will yieid a fairly good accuracy (usually less than $10 \%$ error) in the surface area determination.

In our experiments very small quantities of solid material were used because of the size and the differential nature of the reactor (see Chapter 4). Moreover, the intrinsic surface area of most of our samples was less than $1 \mathrm{~m}^{2} / \mathrm{g}$. This is about 1 to 2 orders of magnitude lower than typical fine powders or catalyst pellets customarily studied in surface area analyzers. Thus, the absolute surface area of our samples was so low that we were at the extreme limits of the standard operations of the Quantasorb ${ }^{\oplus}$ Analyzer. We had to operate at a very low attenuation (usually half that recommended in the manual). Hence, a careful analysis of the measurement reliability was necessary since we were at the limit of the range of applicability of the apparatus.

\subsection{1) Step-by-step data acquisition.}

The general measurement procedure may be summarized as follows:

i) The sample weight is measured.

ii) The sample is inserted into the BET cell.

iii) The gas-mixture flow is regulated to the desired value. The flows of $\mathrm{N}_{2}$ and $\mathrm{He}$ are independently controlled and the total flow rate is kept constant at $20 \mathrm{ml} / \mathrm{min}$. The gas mixture leaving the BET cell passes through a detector that determines the $\mathrm{N}_{2} / \mathrm{He}$ ratio by measuring thermal conductivity.

iv) The room temperature and ambient pressure are measured. 
v) The $\mathrm{N}_{2}$ weight counter (in fact an electronic integration of the detector signal) and the $\mathrm{N}_{2}$ detector base line are set to zero when all the flow and temperature conditions are stable. It takes roughly 15 minutes to be sure that all contaminant gases have been expelled from the gas lines and that the gas mixture has a stable temperature and conposition. The desired attenuation of the filter is also set according to the expected value of the signal induced by the $\mathrm{N}_{2}$ adsorption and desorption.

vi) A Dewar full of liquio nitrogen is raised to submerge the BET cell in liquid $\mathrm{N}_{2}$ and drop the temperature at the solid surface and create some significant nitrogen adsorption.

vii) After a minute or two a change in the detector signal is observed, caused by the depletion of $\mathrm{N}_{2}$ in the gas phase (some of it has been adsorbed on the surface of the solid sample).

viii) After the gas flow rate in the detector is stable again, the counter and detector base lines are set to zero again.

ix) The liquid nitrogen Dewar is then lowered. The BET sample cell is then submerged in a stirred conta ner of water to heat (and desorb the nitrogen from) the sample.

x) The quancity of desorbed nitrogen is measured by the counter.

xi) A known volume of gassous nitrogen is injected through the gas line with a syringe. This gas is then uetecteci and the peak is integrated by the counter. This operation is necessary to valibrate the counter.

xii) Another $\mathrm{N}_{2}$-to-He ratio is then chosen to acquire another point for the isotherm. After waiting at least 10 minutes to be sure that the new gas flow rates are stable the whole procedure is restarted from v). 


\subsection{2) Influence of each step on the accuracy of the surface area estimation.}

\subsubsection{1) Weigh of the sample.}

Typical sample weights ranged from 50 to $100 \mathrm{mg}$. Since the balance precision is \pm 0.01 mg no significant error can be attributed to the weight-measurement procedure.

\subsubsection{2) Temperature and pressure measures.}

The room temperature and ambient pressure were respectively determined by an alcohol thermometer and a precise mercury barometer located in the same room as the BET equipment. Sensitivity calculations on temperature and pressure showed that an error of a few degrees centigrade or a few millimeters of mercury had negligible effect on the final value obtained for the surface area.

\subsubsection{3) Flow measurements.}

Originally guaranteed to $\pm 0.01 \mathrm{~cm}^{3} / \mathrm{min}$ (for a total flow rate of $20 \mathrm{~cm}^{3} / \mathrm{min}$ ), the gas flows proved to be stable around their set values with a fluctuation of $\pm 0.01 \mathrm{~cm}^{3} / \mathrm{min}$ for nitrogen and $\pm 0.03 \mathrm{~cm}^{3} / \mathrm{min}$ for helium. This creates a maximum error less than $0.5 \%$ for all the possible flow combinations in our experiments.

\subsubsection{4) Sample cell choice.}

Two different types of sample cell were used for the present work: the "conventional capillary sample cell" for the $\mathrm{CaCO}_{3}$ experiments and the "micro cell" for the $\mathrm{CaS}$ ones.

The two gases $\left(\mathrm{N}_{2}\right.$ and $\left.\mathrm{He}\right)$ tend to separate if the cavity where the sample stands is large enough. This is induced by the large thermal gradient around the cell when it is immersed in the liquid nitrogen bath. The heavy gas tends to settle to the bottom of the cavity. This build-up is very small (less than a fraction of a percent in the variation of the local concentration in the cell) 
and does not affect the adsorbed quantity of nitrogen. However, it may alter the desorption peak detection by creating a spurious signal induced by this inhomogeneity before the real desorption signal. This spurious peak becomes noticeable if a high sensitivity is employed (i.e., a low attenuation). For these reasons, conventional cells with significant internal volume should not be used if the total area of the sample is less than $0.1 \mathrm{~m}^{2}$. Unfortunately, we had to operate with such a cell for the $\mathrm{CaCO}_{3}$ sintering experiments because of the volume of the tested material and because the large diameter of the limestone pellets prevents the use of cells with smaller internal diameter. The total surface area measured in the limestone-sintering experiments averages 0.1 $\mathrm{m}^{2}$. Thus, a "capillary conventional cell" was chosen to reduce the thermal diffusion effect. This cell is very similar to the conventional one except that the internal diameter of the arm from which the gas exits is much smaller. It helps to remix the two gases to recreate a more homogeneous mixture. This is a sure improvement to the "conventional cell". However, a small but noticeable spurious desorption peak was nevertheless occasionally observed in the limestone tests. Fortunately, the area of this peak was significantly smaller than that for the real desorption peak (less than 5\%). Consequently, the introduced error was minimal, although difficult to quantify since the spurious and desorption peaks often slightly overlapped.

We operated with a narrow-bore U-hube for the CaS sintering tests. This narrow tube with no extra volume at its base, often referred as a "micro cell", prevents the gas separation and the existence of the pre-desorption peak. Moreover, the smaller inner diameter of this type of cell creates a higher linear gas velocity which helps to overcome the gas split. Surface areas as low as $0.01 \mathrm{~m}^{2}$ have been accurately evaluated with this U-cell. More details on the performances of the "micro cell" are available in Lowell and Karp (1972). 


\subsubsection{5) Drift of the detector base line.}

A slight drift in the detector base line, i.e., the zero of the detector, was observed on many occasions. I conducted several tests to quantify the influence of this drift on the surface area-evaluations. Figure 5.1 presents a typical result. About every minute, for 20 minutes, 0.03 $\mathrm{ml}$ of nitrogen was sent to the detector and the reading of the counter was noted. The attenuation was on division 4 , the most commonly used throughout the experimental runs. Nothing was changed on the BET apparatus during the 20 minutes of the test but there was a decrease in the value registered by the counter as time increased. A linear regression of the data shows a loss of about 2 counts every minute. To minimize this potential effect during the surface-area measurements, calibrations were performed immediately after recording the desorption peak.

\subsubsection{6) Calibration volume imprecision.}

One other major source of inaccuracy is in reading the syringe used to inject the $\mathrm{N}_{2}$ calibration volume $(250 \mu \mathrm{l}$ of total volume graduated every $5 \mu \mathrm{l}$, equipped with a special anticlogging needle). To test the repeatability of the volume reading, six consecutive measurements of the same gas volume were made and the procedure was repeated for various volumes between 0.01 and $0.06 \mathrm{ml}$. Care was taken to be sure that there were no drift effects during these tests, which could be checked by the randomness of the measurement distribution. The attenuation was on graduation 4. The results are displayed on Figure 5.2 in terms of standard deviation of the six measurements as a function of the volume of gas sent to the detector. The standard deviation ranges from 6.7 to 12.1 counts. This roughly corresponds to 0.5 to $0.6 \mu$ l of nitrogen at this attenuation (see Section 5.2.2.7). The fact that the deviation is not a function of the absolute number of counts confirms that they were mainly due to fluctuations in the volume of gas injected with the syringe. The variations in the standard deviations observed in Figure 5.2 is purely 


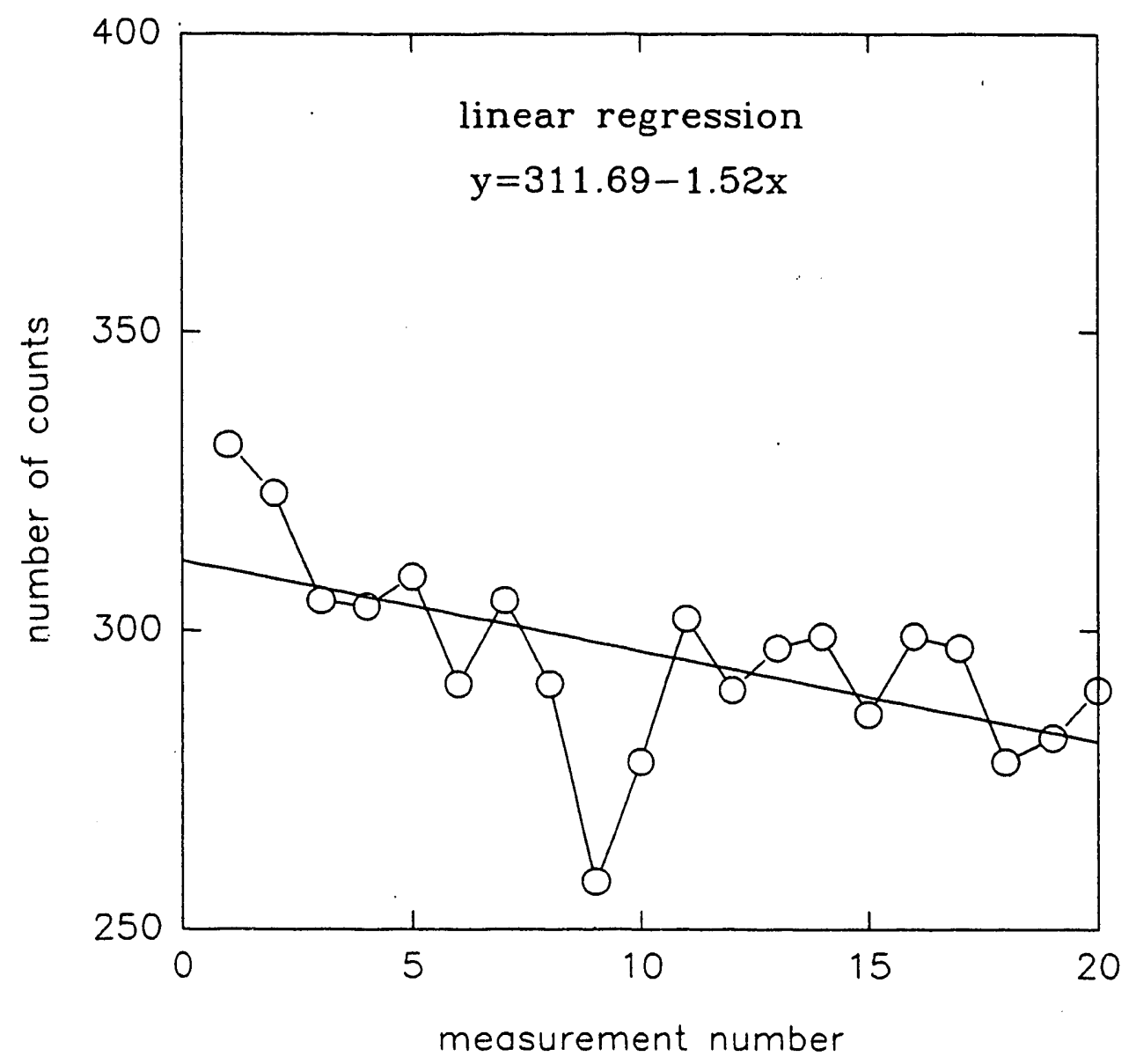

Figure 5.1: Temporal evolution of the counter values for a fixed gas volume $(0.03 \mathrm{ml})$. statistic.

We can conclude that the calibration volume readings are exact within about $\pm 1 \mu \mathrm{l}$. Since the calibration volumes range from 0.01 to $0.06 \mathrm{ml}$ in the $\mathrm{CaCO}_{3}$ and $\mathrm{CaS}$ experiments, the relative error, $\Delta V / V$, ranges from 1.6 to $10 \%$. This inaccuracy is significant $(>5 \%$ ) if the calibration volume is smaller than $0.02 \mathrm{ml}$.

\subsubsection{7) Non-linearity of the detector response.}

Figures 5.3 and 5.4 show a statistical analysis of 16 surface-area measurements of CaS samples (BET 05 series and BET 06-01-01 to 06-01-15. See Appendix 2 for more details). 


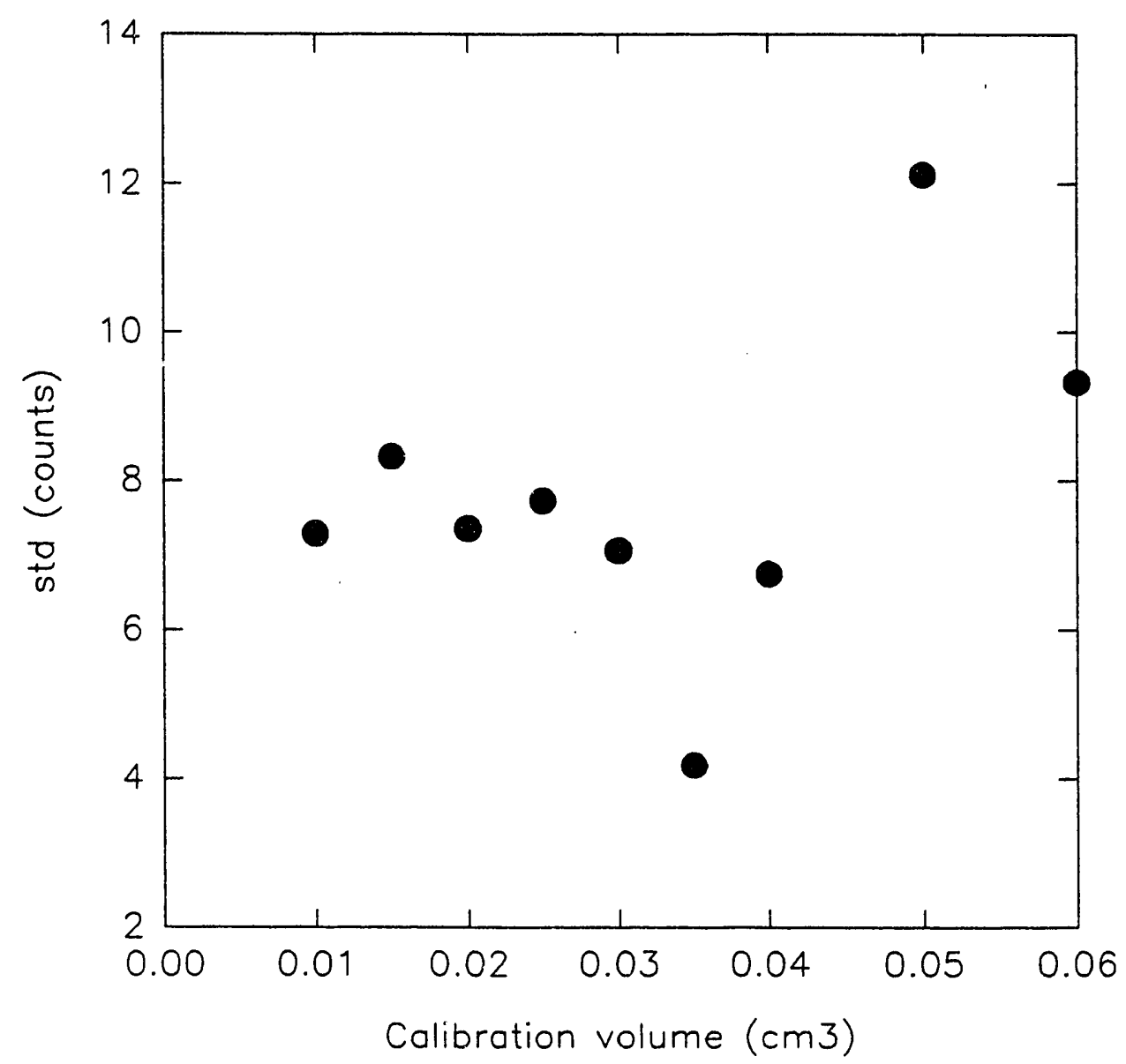

Figure 5.2: Standard deviation on the counts for different calibration volumes.

Figure 5.4 demonstrates that the detector response begins to be highly non-linear if the total number of counts exceeds about 650 . This is due to the saturation of the detection signal, when the counter (merely an integrator) cannot respond quickly enough. This also explains why the standard deviation of the $0.06 \mathrm{ml}$ measurements is significantly higher than the value for the other volumes. To avoid this phenomenon, the attenuation was chosen in such a way that the counts never exceed 650 .

The calibration procedure relies on the assumption that the count number is proportional to the volume of nitrogen passing through the detector. In other terms, it is implied that, if $y$ represents the count number and $\mathrm{x}$ the $\mathrm{N}_{2}$ volume, the relationship $\mathrm{y}=\mathrm{ax}$ (where $\mathrm{a}$ is a constant) 


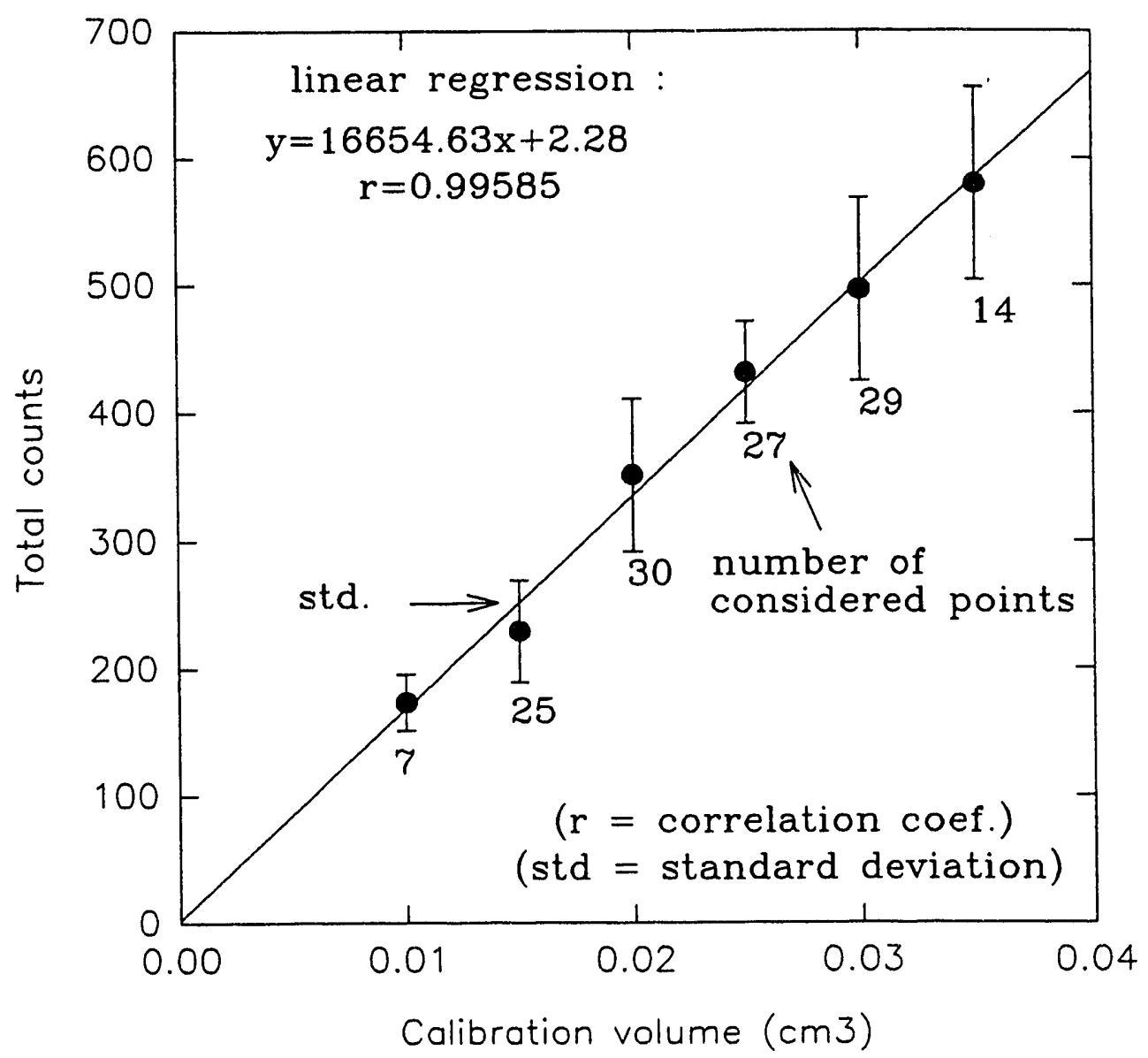

Figure 5.3: Correlation between the calibration volume and the count number for 16 surface-area evaluations.

is valid. The desorbed volume is then considered equal to the product of the calibration volume and the volume-to-calibration-count ratio.

Linear regressions performed in Figures 5.3 and 5.4 show that the data are better fit by the relationship $y=a x+b$ ( $a$ and $b$ being two constants). Figure 5.5 features three different linear regression curves:

i) $y_{1}$ is the result of a linear regression of the data used in Figure 5.2.

ii) $y_{2}$ corresponds to the results experiments similar to the one described in Section 5.2.2.6 except that the detector base line was reset to zero every other measurements. This is similar to a real experimental surface area data acquisition where the base line is carefully reset to zero 


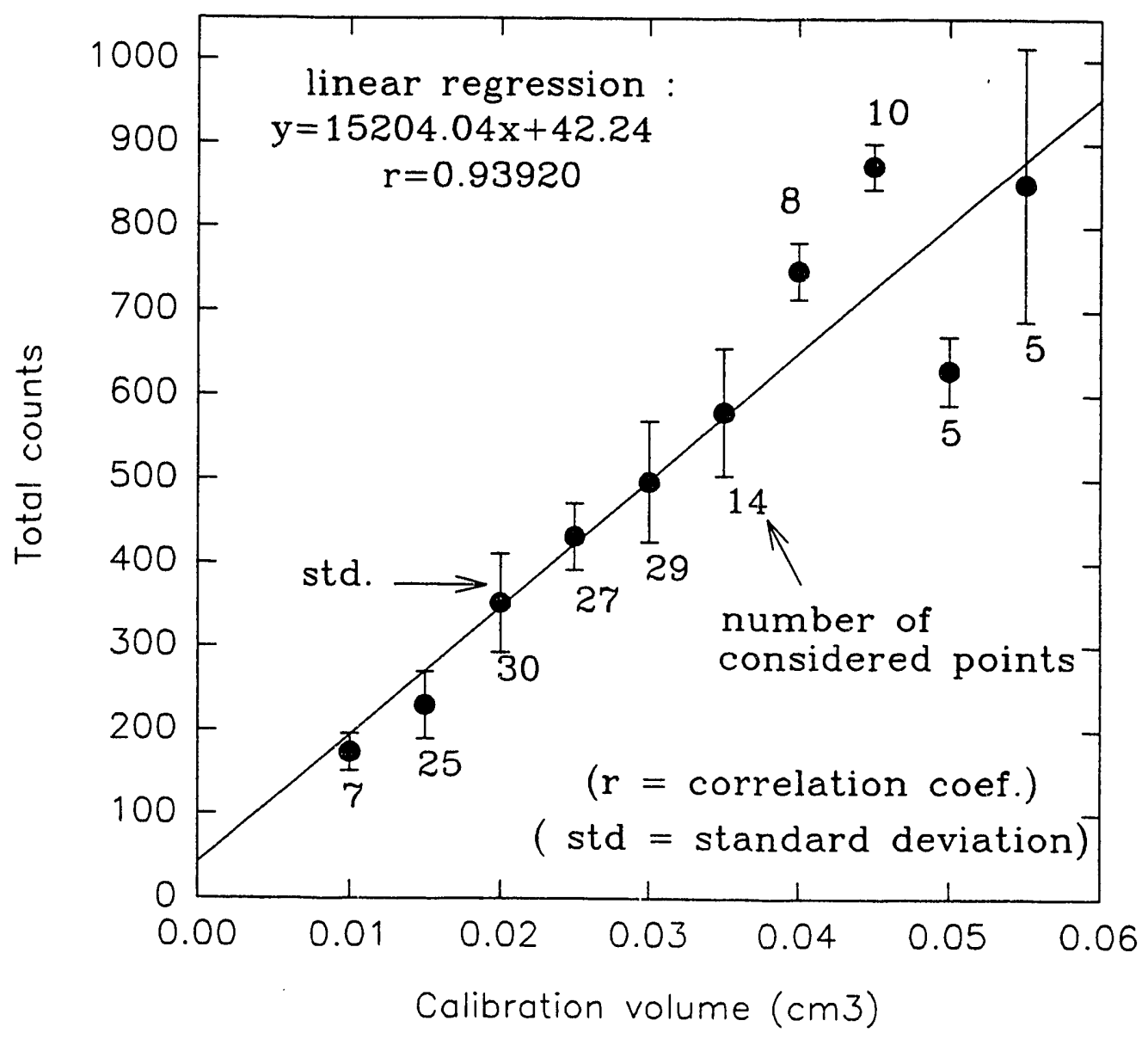

Figure 5.4: Correlation of data of Figure 5.3 except that calibration volumes up to 0.055 $\mathrm{ml}$ have been included.

before each desorption and calibration peak measurements (see Section 5.2.1).

iii) $y_{3}$ is the linear regression presented in Figure 5.3.

None of these regressions yields a value of $b$ equal to zero. It is also clear that the regression $y_{2}$ is closer to what is obtained with actual experimental values than $y_{1}$. The procedure used to generate $y_{2}$ seems valid to better investigate the non-linearity of the detector response. This calibration procedure reveals that $b$ is equal to about -40 instead of zero, as it should be if the detector response were perfectly linear. The influence on the measurement accuracy, along with all other effects described above, are further discussed in Section 5.3. 


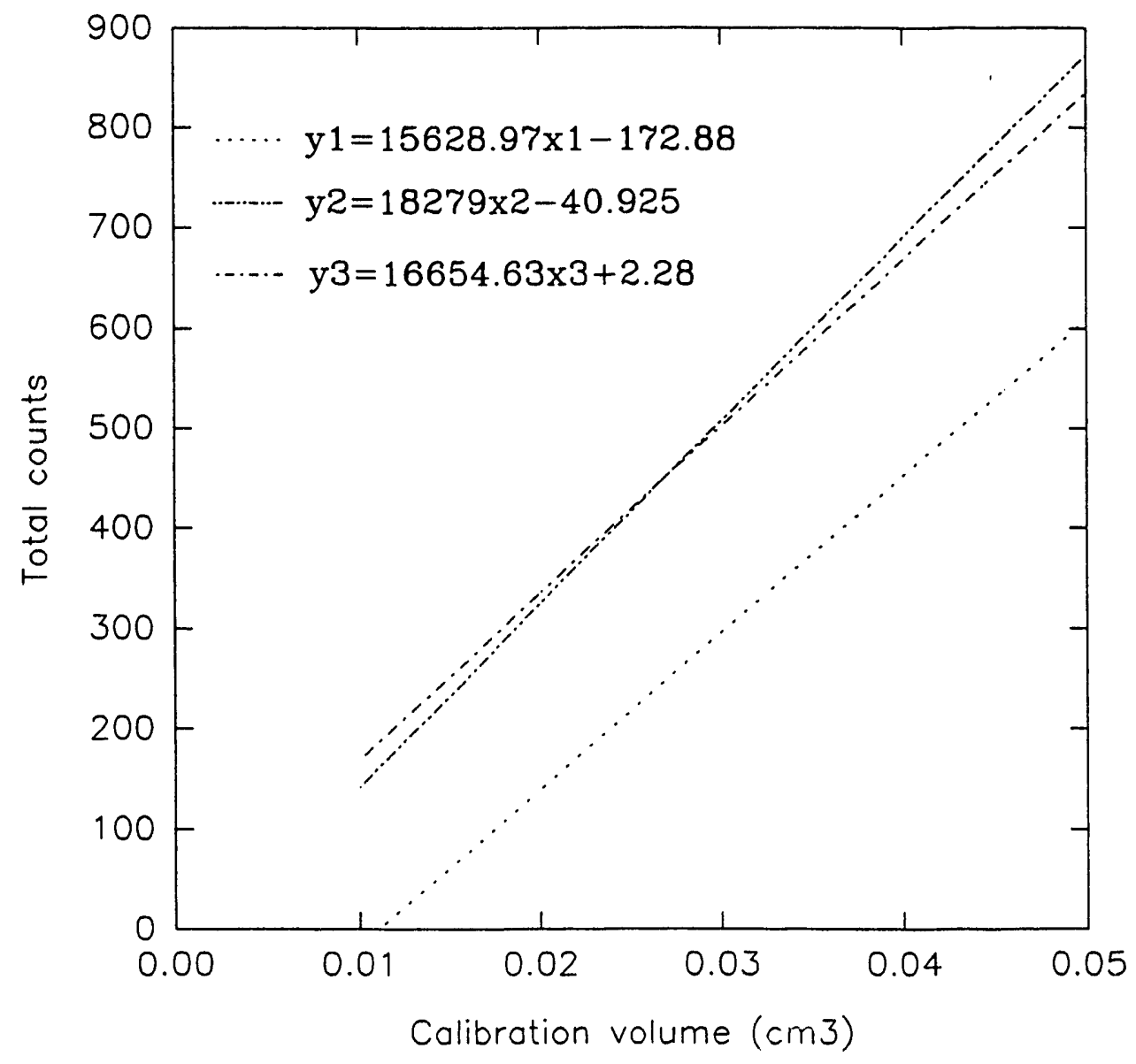

Figure 5.5: Comparison of 3 linear regressions. See text for more details.

\section{3) Estimation of surface area.}

As mentioned in Section 5.1, only two points of the isotherm are necessary to determine the equation of the line predicted by equation 5.1, but in this work four experimental points of the isotherm were determined to improve the measurement accuracy. The four $\mathbf{N}_{2}$ partial pressures were $0.1,0.15,0.20$ and 0.25 of atmospheric pressure. These values were taken using 0.05-0.35 atmosphere $\mathrm{N}_{2}$ partial pressure, the range of applicability of the BET theory as described in Section 5.1. It was also possible to estimate the linear regression coefficient for the four experimental points. For a value larger than 0.99 we could be relatively confident of the validity of the measurements because it would mean that the four points were aligned as expected from equation 5.1. For cases when the regression coefficient was less than 0.99 , one of the four 
points was usually responsible. This measurement was then either repeated to replace the original one or sometimes discarded from the correlation. The entire four points were sometimes repeated when a bad correlation was encountered.

\section{4) Measurement accuracy.}

5.4.1) Influence of the non-linearity of the detector.

The absolute value of the coefficient $b$ defined in Section 5.2.2.7 is around 40. Equations

5.1 and 5.2 imply that:

$$
\left|\frac{\Delta S}{S}\right|=\left|\frac{y-y_{0}}{y}\right|\left|\frac{b}{y}\right|
$$

where:

- $\Delta S / S$ is the relative variation of $S$,

- $\mathrm{y}$ is the calibration count value,

- $\mathrm{y}_{0}$ is the desorption count value, and

- $\mathrm{b}$ is a constant (equal to $\mathbf{4 0}$ in the present case).

The effect of the non-linearity of the detector is lowered if the desorption and calibration volumes are as similar as possible. The relative variation of $S$ was maintained under $5 \%$ in all measurements by a careful choice of the calibration volume. Appendices 1 and 2 provide all of the $y, y_{0}$ and other relevant experimental data necessary for the assessment of the accuracy each experiment. 


\subsection{2) Influence of the fluctuations in calibration volume.}

An estimation of $\Delta S / S$ accounting for an inaccurate reading of the calibration volume yields:

$$
\left|\frac{\Delta S}{S}\right| \propto 2\left|\frac{\Delta V}{V}\right|+\left|\frac{y-y_{0}}{y}\right|\left|\frac{b}{y}\right|
$$

The additivity of the two contributions ( $\alpha$ and $\beta$ ) observed in equation 5.4 stems from the assumption that the values of $y, y_{0}$ and $b$ are statistically non-correlated.

Section 5.2.2.6 established that $\Delta \mathrm{V} / \mathrm{V}$ is readily available since the $\Delta \mathrm{V}$ value has been obtained. I finally chose $\alpha$ equal to $20 \%$ for a calibration volume of $0.01 \mathrm{ml}, \alpha$ equal to $13.3 \%$ for $0.015 \mathrm{ml}$ and $\alpha$ equal to $10 \%$ for $0.02 \mathrm{ml}$ or more. We had expected a decrease of $\alpha$ as we increased V. However, calibration tests (see Section 5.2.2.6) revealed that this was not the case and that $2 \Delta \mathrm{V} / \mathrm{V}$ remained essentially the same for values of $\mathrm{V}$ larger than $0.02 \mathrm{ml}$. Other problems, such as slight variations in the feed ratio or fluctuations in the detector base line, were not included in the error analysis, but were responsible for some variations in the detection process. They were accounted for by making the conservative approximation that the value of $2 \Delta \mathrm{V} / \mathrm{V}$ is $10 \%$ for large volumes, which is consistent with the experimental calibration findings.

\subsection{3) Cell influence.}

A $5 \%$ uncertainty was allotted to the conventional capillary cell to account for the presence of the spurious pre-desorption peak. Since this peak did not arise with the narrow Ucell no correction was made in the $\mathrm{CaS}$ surface area measurements. 


\subsection{4) Final assessment of accuracy.}

All of the preceding accuracy evaluations tend to be quite conservative and in most cases the potential range of error was overestimated. However, measurements of the same sample were occasionally found to differ by a value close to the estimation given in Table 5.1 .

The final estimations of the experimental uncertainty are presented in Table 5.1. The values of $\beta$ were calculated from equation 5.3 and are presented in Appendices 1 and 2 for each measurements. $\beta$ was always less than $5 \%$ if a good experimental procedure was followed.

Table 5.1: Final assessment of uncertainty.

\begin{tabular}{|c|c|c|}
\hline calibration volume (ml) & $\begin{array}{c}\text { Reliability (\%) } \\
(\mathrm{CaS})\end{array}$ & $\begin{array}{c}\text { Reliability (\%) } \\
\left(\mathrm{CaCO}_{3}\right)\end{array}$ \\
\hline 0.01 & $20+\beta$ & $25+\beta$ \\
\hline 0.015 & $13.3+\beta$ & $18.3+\beta$ \\
\hline 0.02 or more & $10+\beta$ & $15+\beta$ \\
\hline
\end{tabular}




\section{CHAPTER 6: LIMESTONE SINTERING EXPERIMENTS}

\section{1) Limestone characteristics.}

\subsection{1) Chemical analysis.}

Table 6.1 presents the average limestone chemical analysis provided by the supplier (Great Lakes Calcium Corporation). Table 6.2 gives the results of elemental analysis of four different samples of the same limestone. These analyses were performed by the U.C. Berkeley Chemistry Department Microanalysis Laboratory and were carried out as follows:

i) C, H, and N contents were measured by a Perkin Elmer $240 \mathrm{CH} \& \mathrm{~N}$ Combustion Analyzer.

ii) Metallic elements were identified by a Perkin Elmer 2380 Atomic Absorption Spectrometer.

iii) Phosphorus was detected via gravimetric wet chemistry.

iv) $\mathrm{S}$ and $\mathrm{Cl}$ were finally measured by sub-contractors of the Chemistry Department, who used fluorescence and combustion analysis techniques.

They were unfortunately unable to detect silicon or to make a direct determination of the oxygen content of the stones with their analytical techniques.

The average of the four analyses in Table 6.2 agrees reasonably well with the composition provided by the Great Lakes Calcium Corporation. However, the individual analyses of the four different batches reveal that the chemical composition can vary significantly from one stone to another. This is particularly noticeable for the calcium and magnesium content. Despite this fact, the limestone used throughout the experiments described in this thesis 
Table 6.1: Chemical analysis of the Great Lakes Calcium limestone (data from the supplier in weight percent).

\begin{tabular}{|c|c|c|c|c|c|c|c|}
\hline $\mathrm{CaCO}_{3}$ & $\mathrm{MgCO}_{3}$ & $\mathrm{SiO}_{2}$ & $\mathrm{Fe}_{2} \mathrm{O}_{3}$ & $\mathrm{Al}_{2} \mathrm{O}_{3}$ & $\mathrm{~S}$ & $\mathrm{Ca}$ & $\mathrm{Mg}$ \\
\hline 97.80 & 1.63 & 0.28 & 0.15 & 0.13 & 0.065 & 39.15 & 0.47 \\
\hline
\end{tabular}

Table 6.2: Chemical analysis of the Great Lakes Calcium limestone (data from the U.C.B. Microanalysis laboratory in weight percent).

\begin{tabular}{|c|c|c|c|c|c|}
\hline & Batch 1 & Batch 2 & Batch 3 & Batch 4 & $\begin{array}{c}\text { average } \\
\text { (std) }\end{array}$ \\
\hline $\mathbf{C a}$ & 37.9 & 33.5 & 36.0 & 32.9 & $\begin{array}{c}35.1 \\
(2.00)\end{array}$ \\
\hline $\mathbf{C}$ & 13.18 & 12.41 & 12.53 & 12.43 & $\begin{array}{l}12.64 \\
(0.32)\end{array}$ \\
\hline $\mathbf{M g}$ & 3.4 & 0.191 & 0.226 & 2.04 & $\begin{array}{c}1.46 \\
(1.34)\end{array}$ \\
\hline $\mathbf{N}$ & 0.06 & 0.19 & 0.08 & 0.10 & $\begin{array}{c}0.11 \\
(0.05)\end{array}$ \\
\hline $\mathbf{H}$ & 0.12 & 0.06 & 0.05 & 0.04 & $\begin{array}{c}0.07 \\
(0.03) \\
\end{array}$ \\
\hline $\mathbf{N a}$ & 0.0233 & NA & NA & NA & - \\
\hline $\mathbf{K}$ & 0.052 & $<0.001$ & $<0.01$ & $<0.01$ & - \\
\hline $\mathrm{Fe}$ & 0.070 & NA & NA & NA & - \\
\hline Al & 0.051 & $<0.005$ & $<0.007$ & 0.01 & - \\
\hline $\mathbf{P}$ & NA & $<0.01$ & $<0.01$ & $<0.01$ & - \\
\hline $\mathbf{S}$ & 0.95 & $<25$ ppm & $<25$ ppm & $<25 \mathrm{ppm}$ & - \\
\hline $\mathbf{C l}$ & $<0.0085$ & $<100$ ppm & $<100 \mathrm{ppm}$ & $<100 \mathrm{ppm}$ & - \\
\hline
\end{tabular}

NA = not analyzed

std $=$ standard deviation 
can be considered relatively "pure" in calcium carbonate and the proportion of magnesium carbonate, the chief impurity, is rather low (1.63 weight percent in average). Numerous limestones exhibit higher magnesium contents.

\subsection{2) Porosity.}

Two evaluations of the porosity with Quantachrome Porosimeter on two different $4.5 \mathrm{~g}$. batches of 3/8-inch to 6-mesh limestone indicated a porosity value somewhere between 8 and $9 \%$.

This $9 \%$ porosity value was independently confirmed by an "Archimedes test" on the same kind of limestones. This test relies on the change of buoyancy of solids immersed in liquids of different densities. It assumes good wettability of the solid pores by the working fluids. This method was commonly used in the ceramic field before the devciopment of porosimeters. The experimental procedure is described in details in Jones et al (1972). Air and a $0.80 \mathrm{~g} / \mathrm{cm}^{3}$ (at $20^{\circ} \mathrm{C}$ ) kerosene were the two experimental fluids. The weights were estimated within $0.01 \mathrm{mg}$.

\subsection{3) Surface area.}

Figure 6.1 displays the distribution of 16 surface area estimations on 3/8-inch/6-mesh limestone samples. The distribution averages $0.27 \mathrm{~m}^{2} / \mathrm{g}$ with a $0.05 \mathrm{~m}^{2} / \mathrm{g}$ standard deviation. This distribution range cannot be attributed only to the imprecision of the BET experimental procedure: each surface-area value is reliable $x_{\text {thin }}$ about $0.05 \mathrm{~m}^{2} / \mathrm{g}$, whereas the experimental measurements scatter from 0.20 to $0.36 \mathrm{~m}^{2} / \mathrm{g}$.

\subsection{4) Scanning Electron Microscope (SEM) and optical microscope observations.}

SEM pictures of uncreated limestone reveal a coarse structure composed of an agglomeration of grains in the micrometer size range. Figures $6.2,6.3$, and 6.4 are SEM pictures of Green Bay Calcium limestone samples at three different magnifications (104, 1050, 


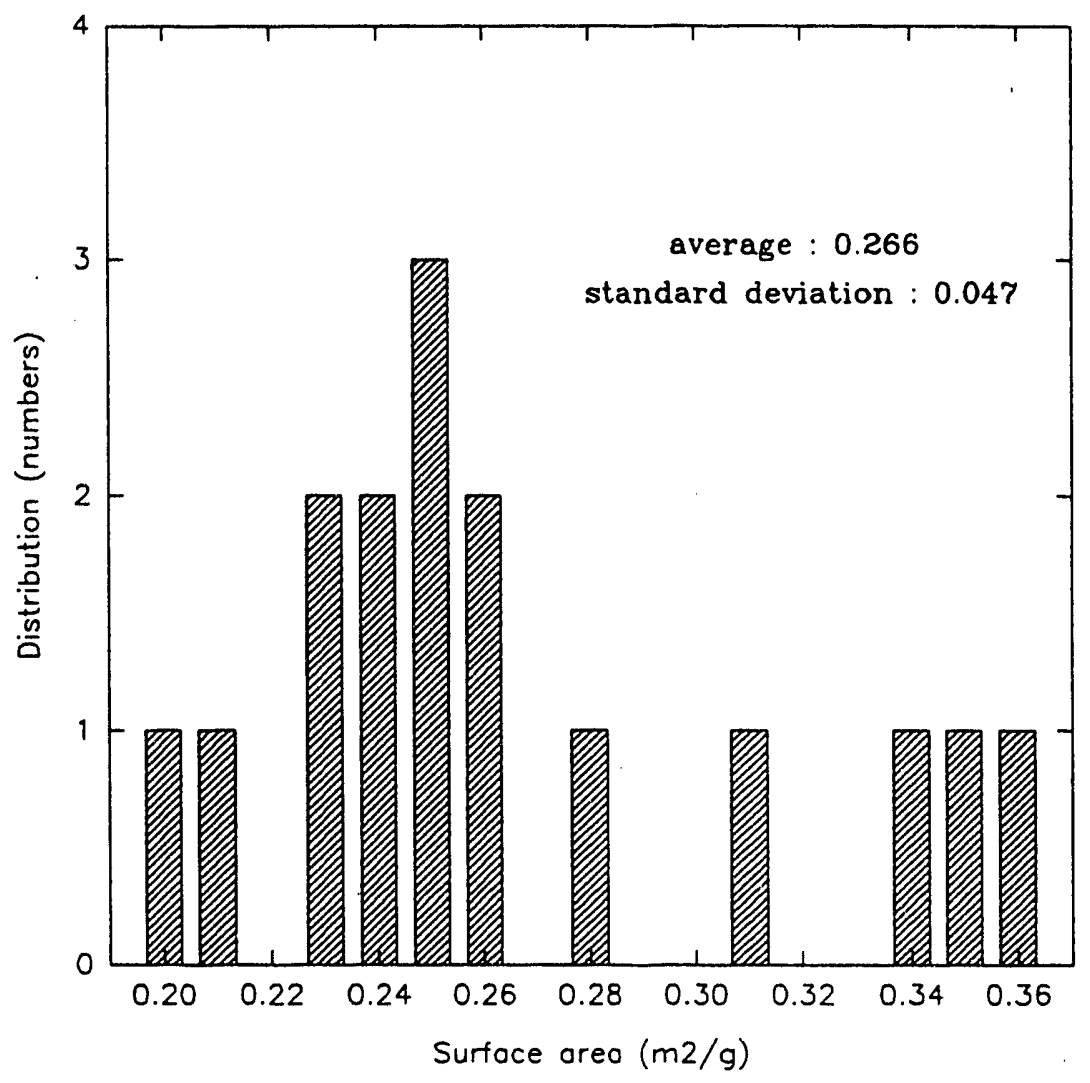

Figure 6.1: Surface-area distribution of limestone samples.

and 2960 times). Figure 6.5 is another SEM picture (magnification $=3100$ times) of the inside of a limestone particle after the strongest heat treatment we performed $\left(120\right.$ minutes at $900^{\circ} \mathrm{C}$, see Section 6.2). Figures 6.4 and 6.5 can directly be compared since they have about the same magnification.

Optical pictures also reveal the presence of crystals in the limestone structure. These crystals were not apparent on the SEM pictures. They are still difficult to identify on the optical photographs. The shinny white spots on Figure 6.6 correspond to calcium carbonate crystals (magnification $=50 \mathrm{X})$.

When limestone is reacted with an acid gas such as $\mathrm{H}_{2} \mathrm{~S}$, the porous medium surrounding the crystals is first attacked. The unreacted crystals then clearly appear when the reacted material is washed away from the limestone pellet. Since the acid diffuses much more easily in the porous 
medium than inside the crystals, the latter resists reaction with the acid longer. That is the reason why it is possible to observe these crystals, which were previously hidden in the porous matrix. The washing of the reacted limestone part away from the rest of the particle is relatively easy, since $\mathrm{CaS}$ is soluble in water whereas limestone hardly is. As a matter of fact, water decomposes the calcium sulfide into calcium bisulfide, $\mathrm{Ca}(\mathrm{HS})_{2}$ and calcium hydroxide, $\mathrm{Ca}(\mathrm{OH})_{2}$. So, as the partially sulfided limestone samples are dropped in water, the product layer is etched, and the calcium carbonate crystals can easily be observed. Figures 6.7 and 6.8 are two photographs of these crystals, taken on an optical microscope (magnification $=50 \mathrm{X}$ ). A particularly perfect crystal, that looks like a calcite crystal (cubic lattice), can be observed in the center of Figure 6.8. Figures $6.9,6.10$, and 6.11 are SEM pictures of the same crystals at respective magnifications of 500,600 , and 2000. EDS analyses confirmed that the crystals are composed of calcium carbonate.

By pouring a dilute aqueous solution of hydrochloric acid onto the limestone pellets, the structural evolution could be followed under an optical microscope. The acidic solution reacted preferentially with the porous matrix of the limestone. Crystals, wherein the liquid could not diffure as fast as in the porous medium, began to arise and were destroyed at a slower rate than the rest of the limestone pellet. No pictures of this experiment are enclosed in this thesis because the presence of the liquid above the solid particles made them very fuzzy.

\section{2) Sintering experiments.}

Twenty batches of 10 to 17 limestone particles of 3/8-inch to 6-merh size were exposed to several temperatures ranging from 750 to $910^{\circ} \mathrm{C}$ for various durations. During all these heat treatments, the atmosphere was composed of $100 \% \mathrm{CO}_{2}$ to prevent limestone calcination at high 


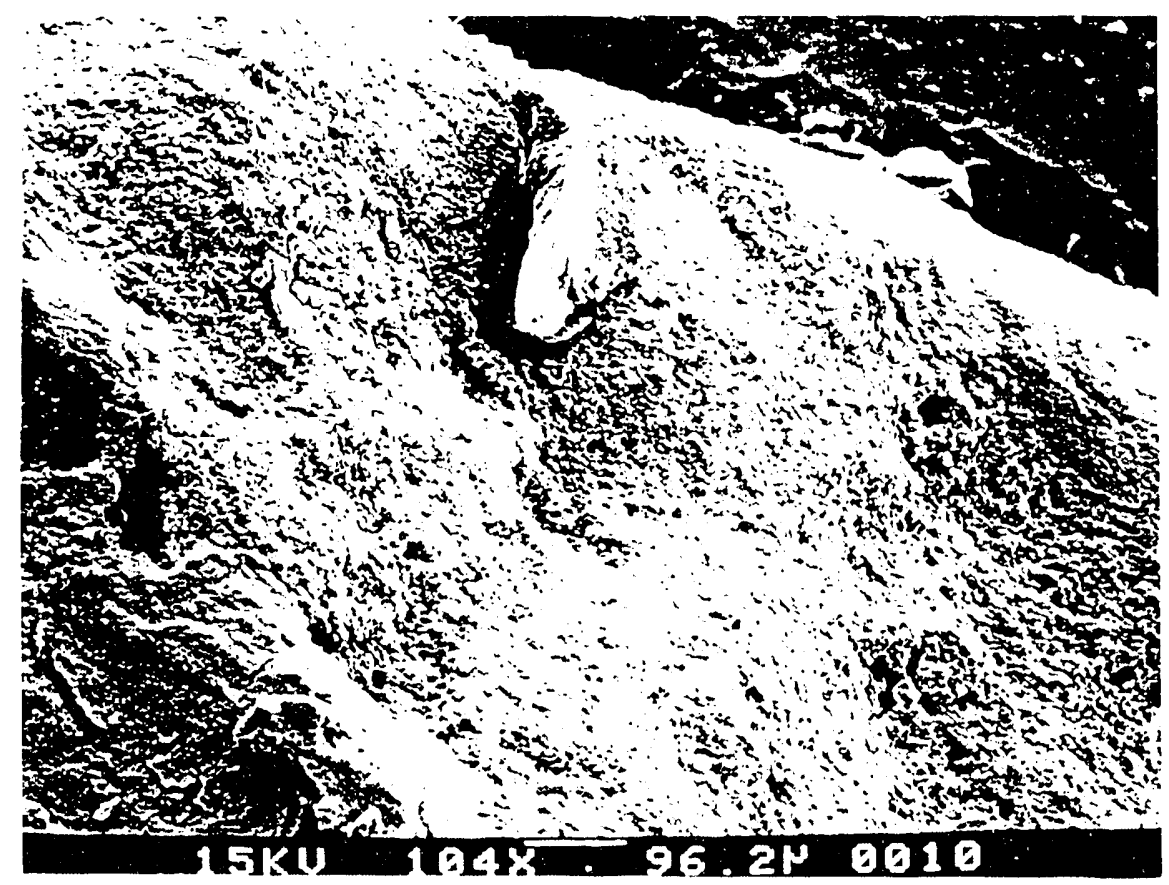

Figure 6.2: SEM picture of a non-treated limestone sample.

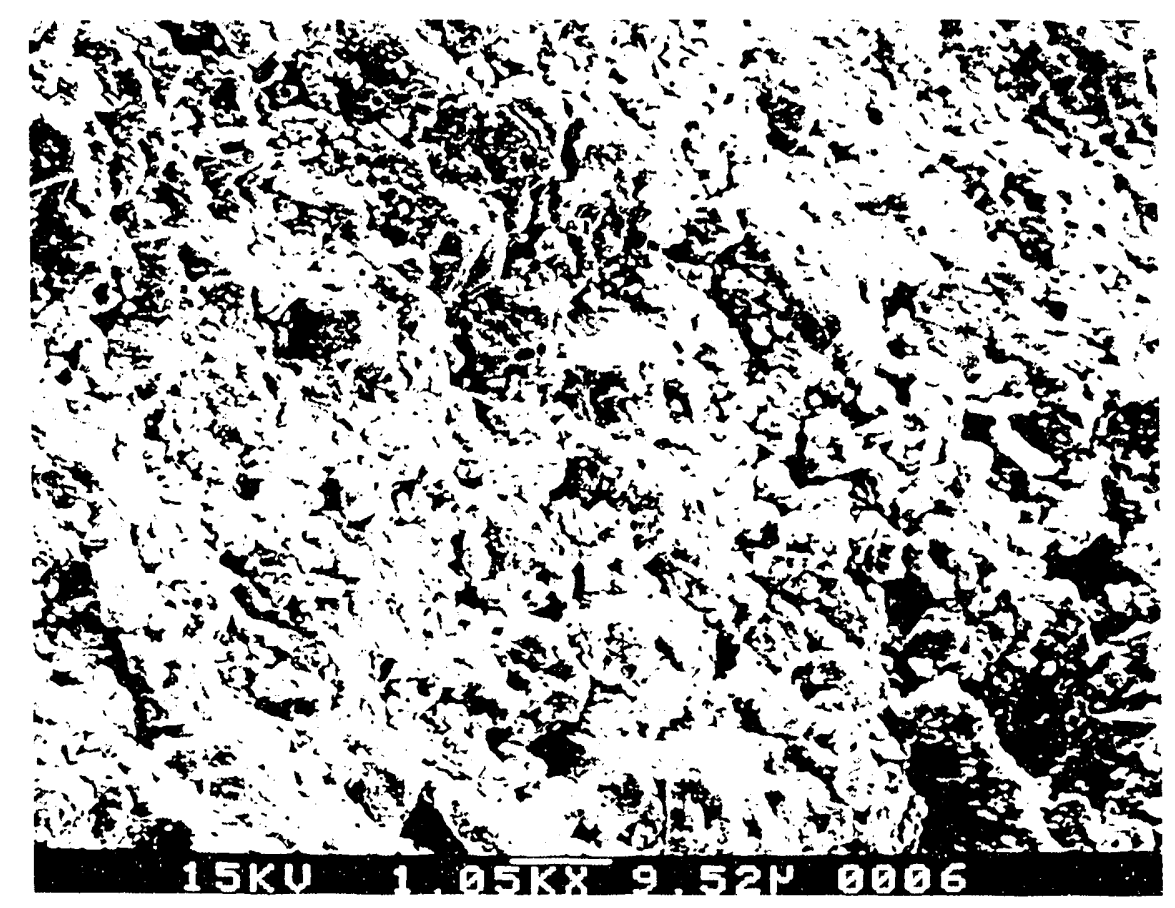

Figure 6.3: SEM picture of a non-treated limestone sample. 


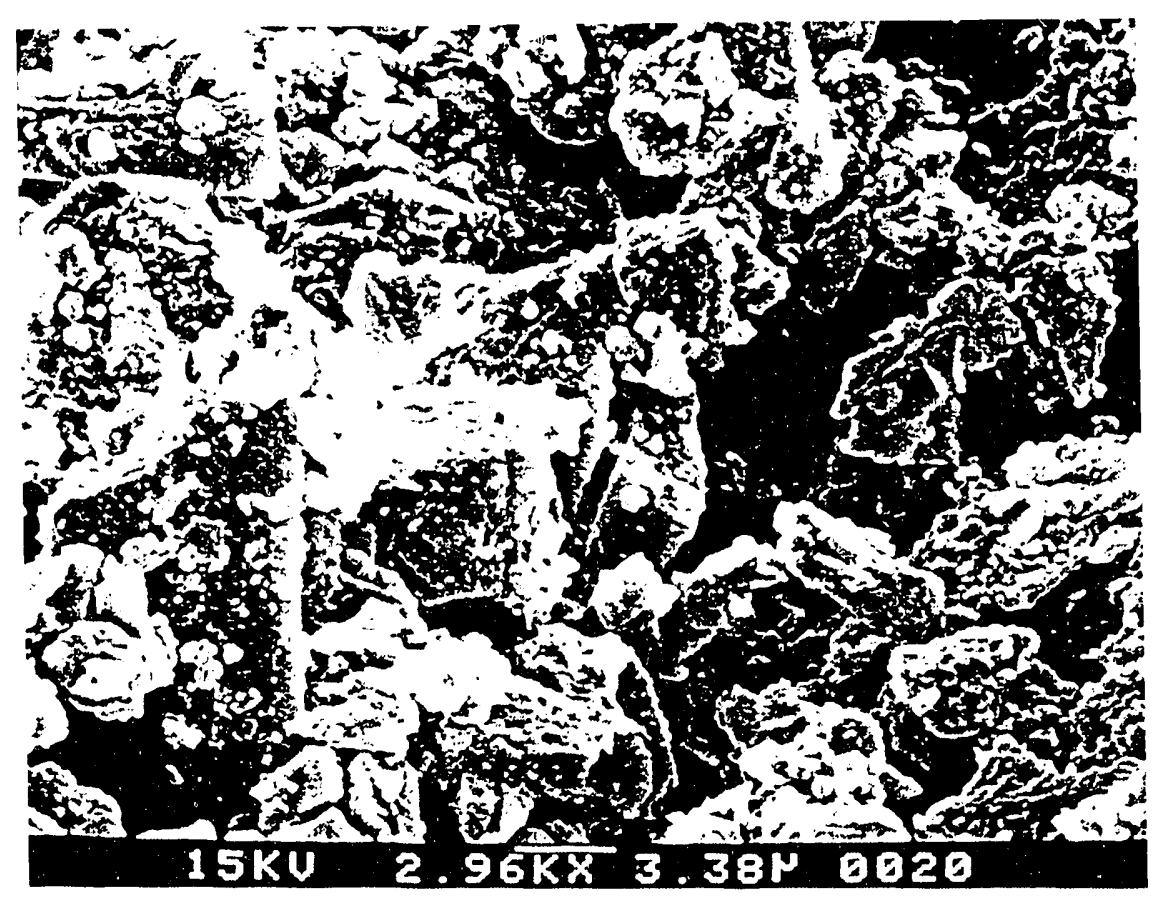

Figure 6.4: SEM picture of a non-treated limestone sample.

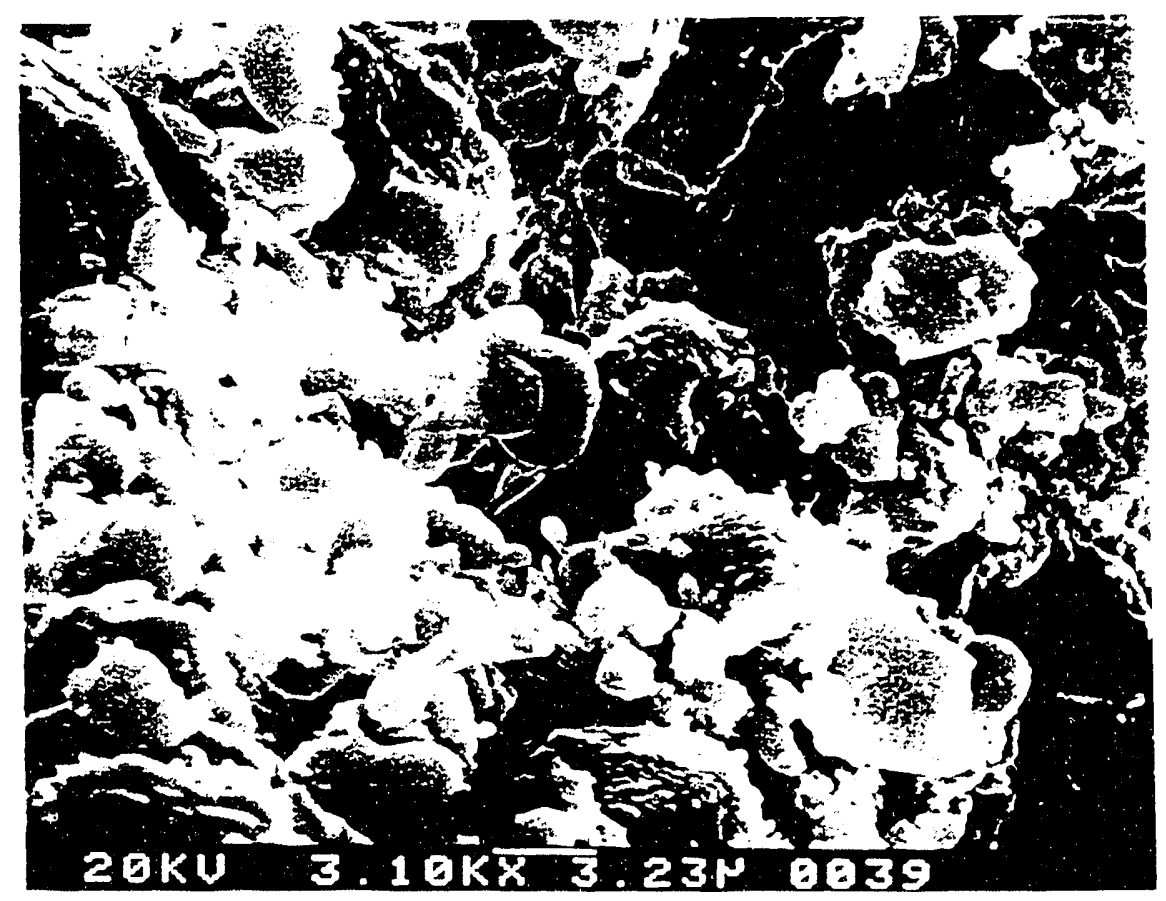

Figure 6.5: SEM picture of a limestone sample after heat treatment. 


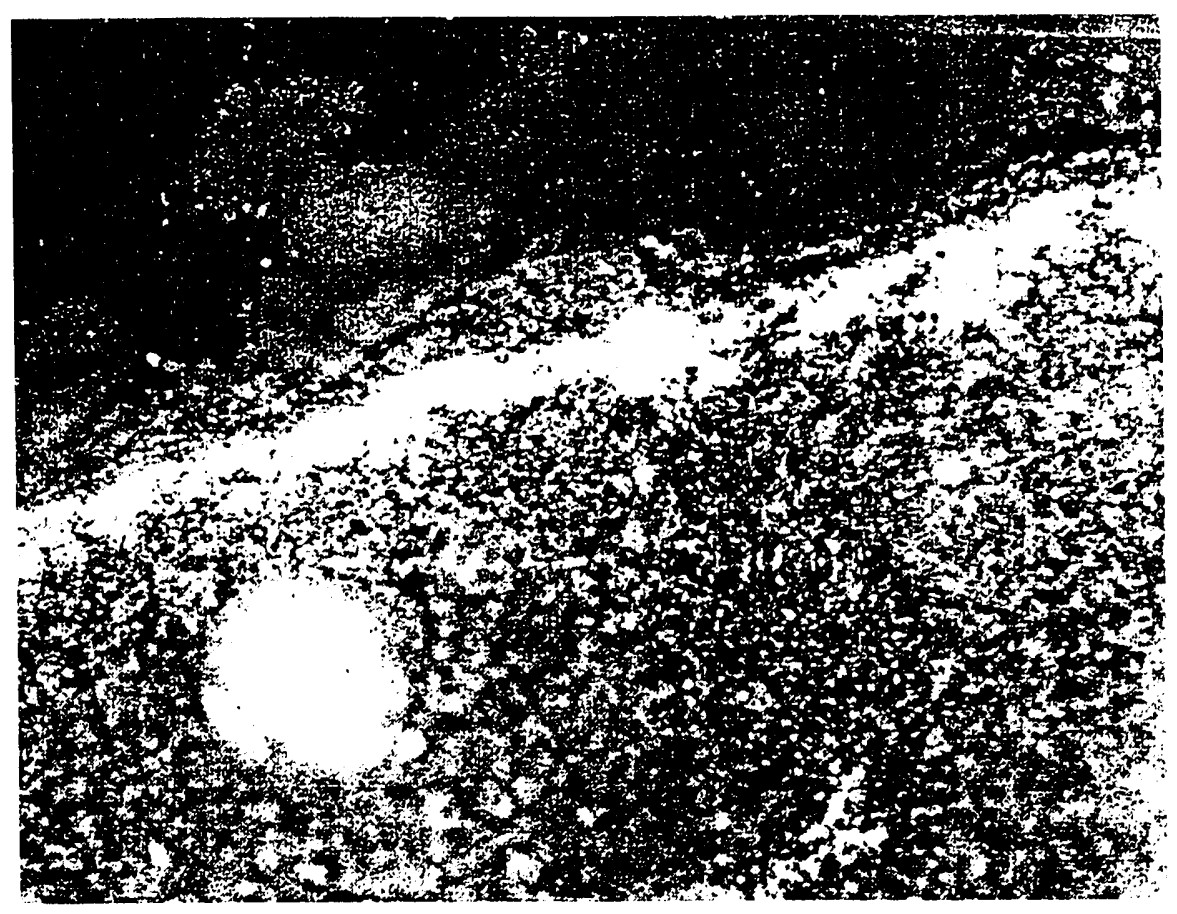

Figure 6.6: Picture of a limestone sample (X 50).

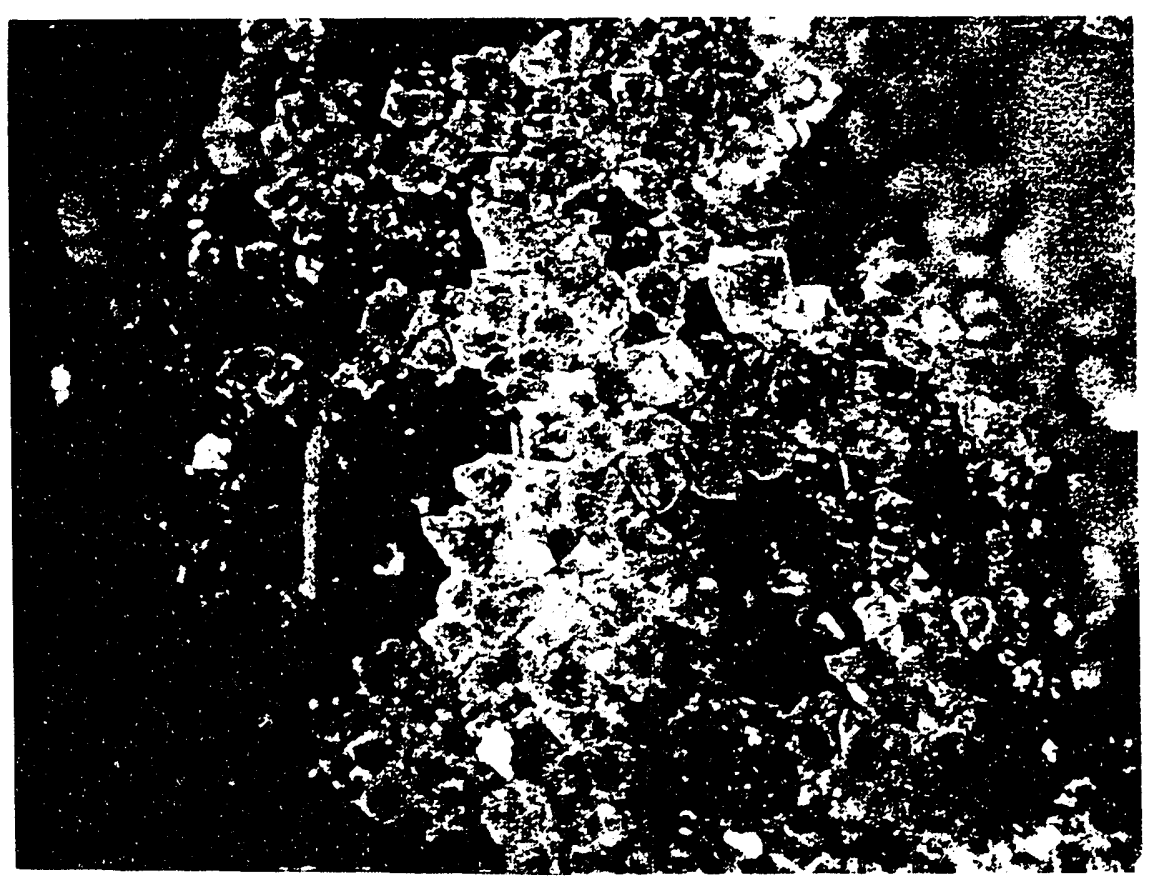

Figure 6.7: Picture of limestone crystals (X 50). 


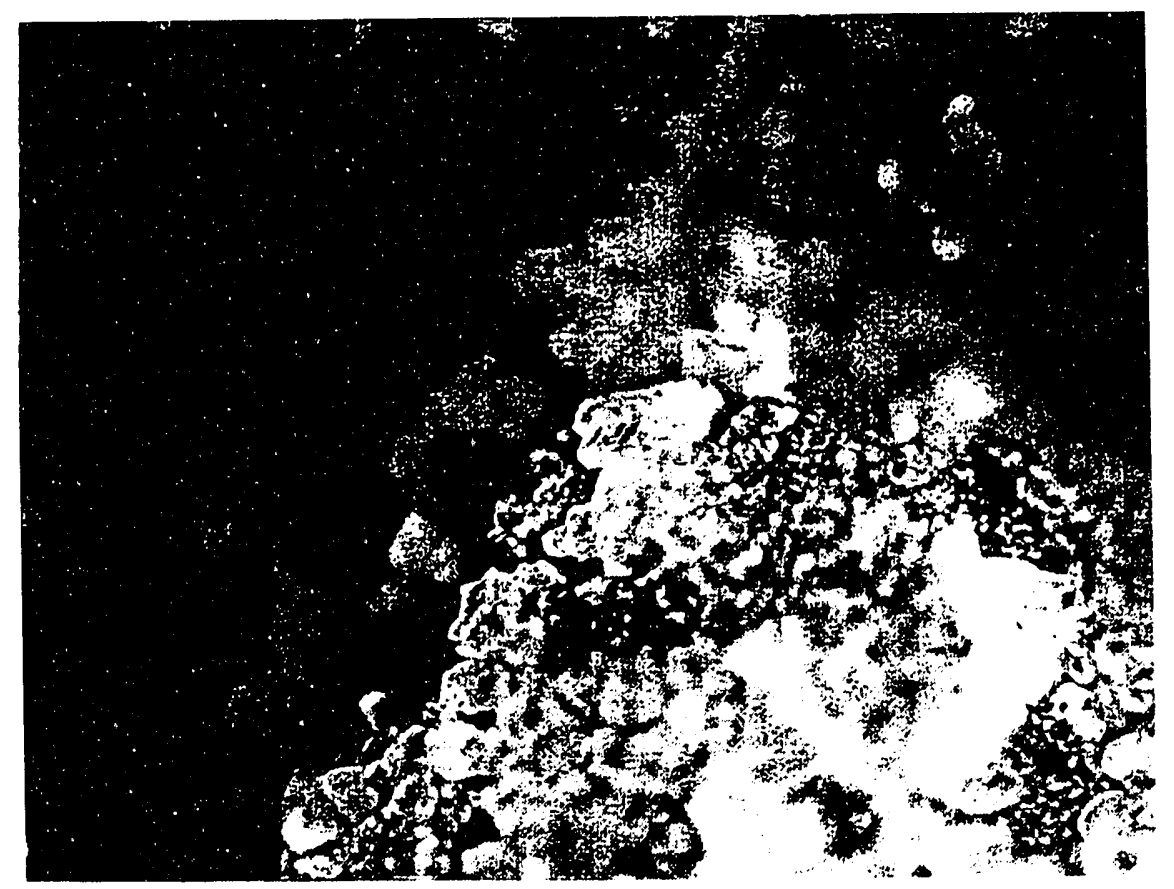

Figure 6.8: Picture of crystals from the limestone (X 50).

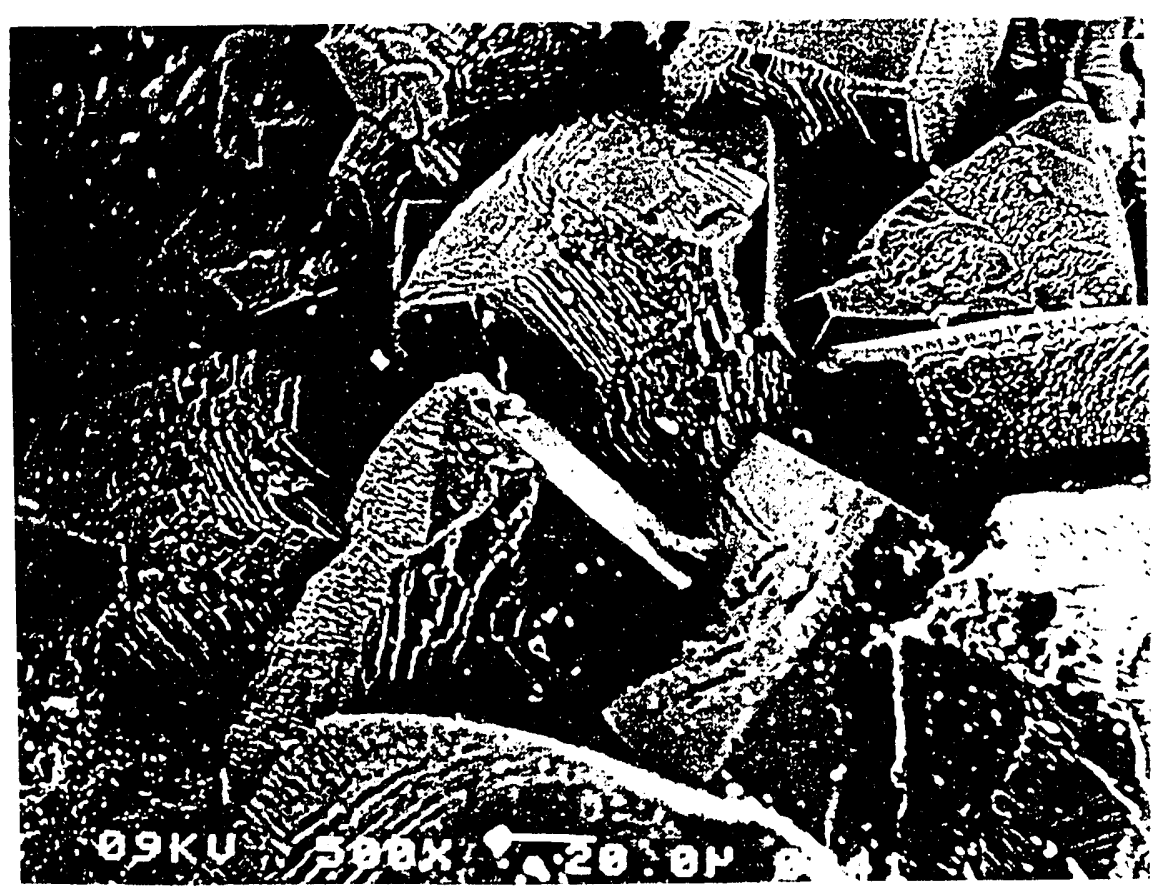

Figure 6.9: SEM picture of crystals from the limestone. 


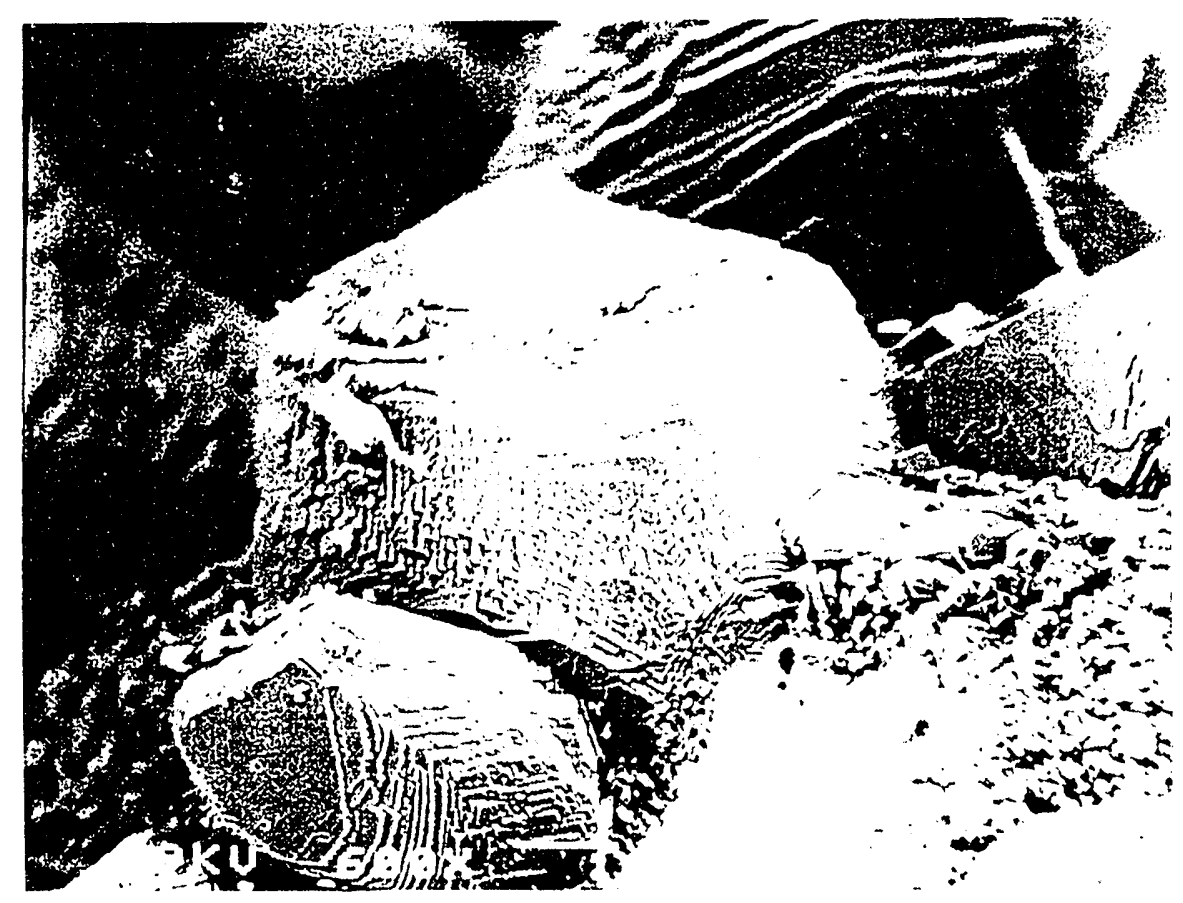

Figure 6.10: SEM picture of crystals from the limestone.

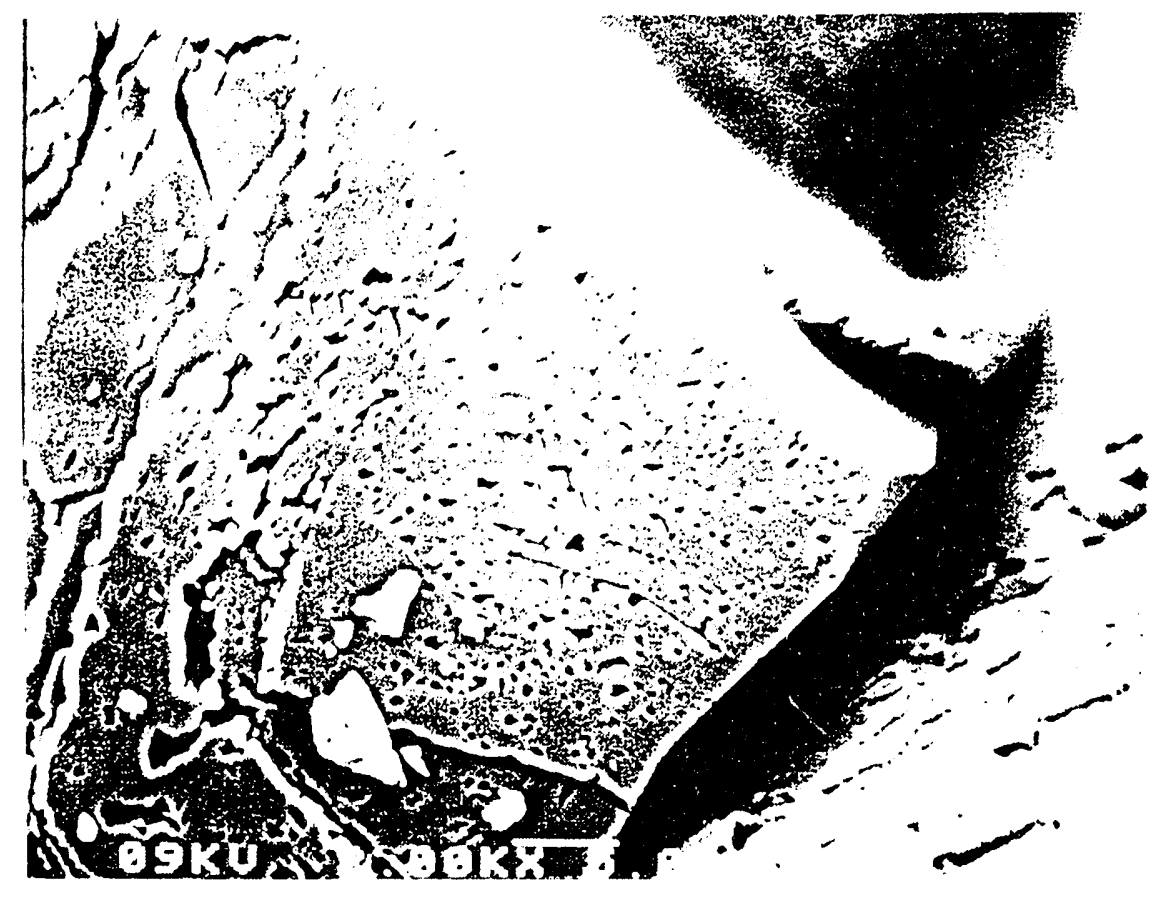

Figure 6.11: SEM picture of crystals from the limestone. 
temperatures. Under these reaction conditions the calcination temperature was $899^{\circ} \mathrm{C}$. The outcomes of these sintering tests are presented in Table 6.3.

Table 6.3: Surface area of limestone samples after various heat exposures.

\begin{tabular}{|c|c|c|c|c|c|}
\hline $\begin{array}{l}\text { Time } \\
(\min )\end{array}$ & 5 & 20 & 40 & 80 & 120 \\
\hline $750^{\circ} \mathrm{C}$ & & & $\begin{array}{l}0.45 \pm 0.08 \\
0.49 \pm 0.08 \\
\text { (same sample) }\end{array}$ & & \\
\hline $800^{\circ} \mathrm{C}$ & & & $0.32 \pm 0.06$ & & $\begin{array}{l}0.23 \pm 0.04 \\
0.29 \pm 0.05 \\
\text { (2 samples) }\end{array}$ \\
\hline $850^{\circ} \mathrm{C}$ & & $0.25 \pm 0.05$ & $0.30 \pm 0.05$ & $0.33 \pm 0.06$ & $0.26 \pm 0.05$ \\
\hline $900^{\circ} \mathrm{C}$ & $\begin{array}{l}0.23 \pm 0.04 \\
0.28 \pm 0.05 \\
(2 \text { samples })\end{array}$ & $\begin{array}{l}0.24 \pm 0.04 \\
0.31 \pm 0.06 \\
(2 \text { samples })\end{array}$ & $\begin{array}{l}0.21 \pm 0.04 \\
0.28 \pm 0.05 \\
(2 \text { samples })\end{array}$ & $\begin{array}{l}0.23 \pm 0.04 \\
0.33 \pm 0.06 \\
\text { (2 samples) }\end{array}$ & $\begin{array}{l}0.20 \pm 0.04 \\
0.25 \pm 0.05 \\
(2 \text { samples) }\end{array}$ \\
\hline $910^{\circ} \mathrm{C}$ & & & $0.22 \pm 0.05$ & & $0.24 \pm 0.04$ \\
\hline
\end{tabular}

No noticeable sintering occurs at temperatures up to the calcination point for as long as two hours, the expected characteristic time of the coal-gas-clean-up process. All surface area determinations vary from 0.20 to $0.33 \mathrm{~m}^{2} / \mathrm{g}$, roughly the same range as the original untreated limestone. Moreover, no apparent correlation in the surface area evolution can be identified, neither with respect to the temperature, nor to the exposure time. The results of Table 6.3 averages $0.28 \mathrm{~m}^{2} / \mathrm{g}$ with a standard deviation of $0.07 \mathrm{~m}^{2} / \mathrm{g}$, which is similar to the distribution observed with the original limestone batches (Figure 6.1). We can conclude that there is no, or very little, sintering for $3 / 8$-inch to 6 -mesh limestone under $\mathrm{a} \mathrm{CO}_{2}$ atmosphere if the calcination temperature is not exceeded.

On one of the experimental runs the temperature was $913.5^{\circ} \mathrm{C}$, slightly higher than the expected calcination temperature. Of the fourteen stones, two changed color from gray to white. 
The twelve other stones stayed unaltered and their specific surface area remained at $0.24 \pm 0.04$ $\mathrm{m}^{2} / \mathrm{g}$, which is characteristic of our limestone. On the other hand, the two white stones actually were calcined and their specific surface arca increased to about $1 \mathrm{~m}^{2} / \mathrm{g}$. This increase of surface area for limestone upon calcination has often been studied and documented in the literature but is of little interest to us, since the $\mathrm{CO}_{2}$ partial pressure and the temperature will always be such that limestone calcination is thermodynamically impossible in the coal-gas-clean-up unit.

\section{3) Conclusions.}

Our conclusions regarding limestone sintering are different from Borgwardt's findings (see Chapter 2). He used a very fine limestone powder in his experimental work. Thus, two neighboring grains could create a very large curvature zone around their contacting region. Under these conditions sintering occurs. With the millimeter-size limestone particles used in our experiments, small grains are not necessarily in direct contact with each other nor free to merge to develop a new bigger grain and to contribute to a decrease of surface area. Moreover, many of the larger grains are also part of the limestone structure. The natural limestone rock may probably be thought as an already-sintered rock. The sedimentary calcium carbonate deposits have built-up slowly, and high underground pressures and temperatures have slowly acted on the mineral to decrease its surface area over geologic time.

Thus, our findings are not contradictory with Borgwardt's results. However, our results rule out $\mathrm{CaCO}_{3}$ sintering as a potential explanation for the poor conversion of the sulfidation reaction observed for large particles (diameter larger than $100 \mu \mathrm{m}$ ). In a coal-gas-clean-up unit micrometer-size limestone particles are not practical. Particle sizes similar to those we used for this sintering study are more likely to be chosen. Thus, limestone sintering will not be an issue in the sulfidation rate. 


\section{CHAPTER 7: CALCIUM SULFIDE SINTERING STUDY}

\section{1) Untreated CaS.}

As mentioned in Section 4.2, the calcium sulfide used throughout the sintering experiments was a fine, pure powder purchased from the Fischer Scientific Company.

The intrinsic surface area of this powder averages $1.32 \mathrm{~m}^{2} / \mathrm{g}$ with a standard deviation of $0.05 \mathrm{~m}^{2} / \mathrm{g}$ based on three measurements. Since the density of the calcium sulfide is 2.61 $\mathrm{g} / \mathrm{cm}^{3}$, such a surface area corresponds to an average equivalent diameter of about $1.7 \mu \mathrm{m}$ for the powder grains. Scanning electron microscopy pictures confirm this order of magnitude for the powder size.

\section{2) Sintered CaS.}

Eighty-six batches of $\mathrm{CaS}$ powder have been exposed to different high temperatures for several durations and atmospheric compositions. As we did with the limestone, physical changes undergone by the samples were followed by BET surface area measurements as well as by optical and scanning electron microscopy. Moreover, EDS analyses probed for the presence of chemical reactions that could have been responsible for the observed surface area reduction upon heat treatment.

\subsection{1) Influence of atmosphere composition on the sintering rate.}

Calcium sulfide samples were exposed to eight different atmospheres for 40 minutes at about $850^{\circ} \mathrm{C}$. Table 7.1 displays the outcomes of these tests. 
Table 7.1 : Surface area of CaS powder after 40 minutes at $850^{\circ} \mathrm{C}$ for various atmosphere compositions.

\begin{tabular}{|l|c|}
\hline \multicolumn{1}{|c|}{ Atmosphere } & Surface area $\left(\mathrm{m}^{2} / \mathrm{g}\right)$ \\
\hline \hline untreated CaS & $1.32 \pm 0.06$ \\
\hline $100 \% \mathrm{~N}_{2}$ & $1.29 \pm 0.17$ \\
\hline $90 \% \mathrm{~N}_{2} / 10 \% \mathrm{H}_{2}$ & $1.41 \pm 0.18$ \\
\hline \hline $100 \% \mathrm{CO}_{2}$ & $0.73 \pm 0.09$ \\
\hline $95 \% \mathrm{CO}_{2} / 5 \% \mathrm{CO}$ & $0.61^{(1)} \pm 0.09$ \\
\hline $90 \% \mathrm{CO}_{2} / 10 \% \mathrm{CO}$ & $0.71 \pm 0.09$ \\
\hline $5 \% \mathrm{CO}_{2} / 95 \% \mathrm{~N}_{2}$ & $1.01 \pm 0.09$ \\
\hline \hline $100 \% \mathrm{CO}_{2}$ & $0.73 \pm 0.09$ \\
\hline $96 \% \mathrm{CO}_{2} / 4 \% \mathrm{H}_{2}$ & $0.70 \pm 0.04$ \\
\hline $90 \% \mathrm{CO}_{2} / 10 \% \mathrm{H}_{2}$ & $0.69 \pm 0.09$ \\
\hline
\end{tabular}

(1): probably underestimated since the sample was contaminated by carbon deposits ("cocking").

CaS does not sinter under a $\mathrm{N}_{2}$ or $\mathrm{H}_{2}$ atmosphere whereas it loses about half of its initial area at $850^{\circ} \mathrm{C}$ in 40 minutes when $\mathrm{CO}_{2}$ is present in the gas phase.

Carbon dioxide seems to act as a catalyst for the sintering process; the surface area loss is still significant even if the fraction of $\mathrm{CO}_{2}$ is down to $5 \%$, with $95 \%$ of $\mathrm{N}_{2}$.

It is impossible to probe independently the influence of $\mathrm{CO}$ and $\mathrm{H}_{2} \mathrm{O}$ on the sintering rate. The presence of $\mathrm{CO}_{2}$ is necessary if $\mathrm{CO}$ is to be in the gas atmosphere. Otherwise, the carbon monoxide will decompose into $\mathrm{CO}_{2}$ and solid carbon that will contaminate the $\mathrm{CaS}$ samples. This phenomenon was observed in one experimental run with a $95 \% \mathrm{CO}_{2} / 5 \% \mathrm{CO}$ mixture.

It was also impossible to obtain a pure $\mathrm{H}_{2} \mathrm{O}$ atmosphere above the CaS samples inside the reactor with our experimental set-up. Water was only present through the water-gas-shift reaction between $\mathrm{CO}_{2}$ and $\mathrm{H}_{2}$ (reaction 1.1). Thus, the presence of $\mathrm{H}_{2} \mathrm{O}$ in the gas phase was always associated with $\mathrm{CO}_{2}$. Nevertheless, the comparison of the last three results of Table 7.1 indicates 
that there is no significant difference in CaS sintering between samples exposed to $100 \% \mathrm{CO}_{2}$ or $90 \% \mathrm{CO}_{2}$ plus $10 \% \mathrm{H}_{2}$ in the gas phase. Moreover, $90 \% \mathrm{CO}_{2}$ with $10 \% \mathrm{CO}$ or $90 \% \mathrm{CO}_{2}$ with $10 \% \mathrm{H}_{2}$ gives the same reduction in surface area. It is not possible to conclude whether $\mathrm{H}_{2} \mathrm{O}$ has a catalytic effect on CaS sintering but this effect, if it exists, should not have a larger impact than $\mathrm{CO}_{2}$

This distinction does not really matter if we keep the purpose of this study in mind. We are concerned with $\mathrm{H}_{2} \mathrm{~S}$ removal from a coal gas mixture which contains a significant fraction of $\mathrm{CO}_{2}$, along with $\mathrm{H}_{2} \mathrm{O}, \mathrm{CO}$ and $\mathrm{H}_{2}$ as the primary components. The preceding observations are sufficient to indicate that calcium sulfice will sinter in the presence of coal gas at a rate probably similar to that observed with a $96 \% \mathrm{CO}_{2} / 4 \% \mathrm{H}_{2}$ mixture.

\subsection{2) Calcium sulfide sintering kinetics.}

We chose a $96 \% \mathrm{CO}_{2} / 4 \% \mathrm{H}_{2}$ gas mixture as the atmosphere under which to conduct an extensive kinetic study of calcium sulfide sintering. The chief advantage of such a feed is its relatively stable composition when the temperature varies between 750 and $900^{\circ} \mathrm{C}$. To maintain a constant partial pressure for as many components as possible over the experimental range of temperature, a very large fraction of $\mathrm{CO}_{2}$ was introduced. The water gas shift reaction, which equilibrates in a fraction of a second at the temperatures considered, generates some $\mathrm{CO}$ and $\mathrm{H}_{2} \mathrm{O}$. Thus, the gas mixture contains the four main components of real coal gas. The mass balance, constrained by this large fraction of $\mathrm{CO}_{2}$, prevents the partial pressures of the other components from fluctuating significantly. Consequently, the temperature and the exposure time were the only variables tested in this set of experiments. Table 7.2 gives the actual gas-phase composition when a $96 \% \mathrm{CO}_{2} / 4 \% \mathrm{H}_{2}$ mixture is introduced into the differential reactor after thermodynamic equilibrium is reached. This composition is quite constant over the experimental 
temperature range. More details on the atmosphere and experimental temperature choices are given in Towler (1992).

Table 7.2: Influence of the temperature on the equilibrium gas-phase composition for a $96 \%$ $\mathrm{CO}_{2} / 4 \% \mathrm{H}_{2}$ feed.

\begin{tabular}{|c|c|c|c|c|}
\hline Temperature & $\mathrm{CO}_{2}$ (mol\%) & $\mathrm{CO}(\mathrm{mol} \%)$ & $\mathrm{H}_{2} \mathrm{O}(\mathrm{mol} \%)$ & $\mathrm{H}_{\mathbf{2}}$ (mol\%) \\
\hline $750^{\circ} \mathrm{C}$ & 92.1 & 3.81 & 3.9 & 0.19 \\
\hline $800^{\circ} \mathrm{C}$ & 92.1 & 3.83 & 3.9 & 0.17 \\
\hline $850^{\circ} \mathrm{C}$ & 92.2 & 3.85 & 3.81 & 0.14 \\
\hline $900^{\circ} \mathrm{C}$ & 92.2 & 3.88 & 3.8 & 0.12 \\
\hline
\end{tabular}

A large number of reactor runs were necessary to collect enough data points to obtain a realistic analytical kinetic expression. Some BET measurements have been repeated up to four times to increase the precision of the surface area estimations. Moreover, some reactor runs have also been repeated up to three times when the results were not consistent with the other data. However, no experimental point was discarded when it came to determining the final surface-area value, unless a flaw in the experimental procedure was identified or when the error range was judged to be too large ( $>20 \%$ ). The graphs presenting all the experimental results for the four temperature groups $\left(750,800,850\right.$ and $900^{\circ} \mathrm{C}$ ) can be found in Appendix 2. Figure 7.1 presents just the final results, averaging the experimental values when more than one measurement had been performed. The error bars have been omitted for clarity.

It was also checked that the reduction in surface area was only imputable to a physical rearrangement and not to a chemical reaction. This was a legitimate concern because many chemical reactions could have occurred during the heat treatment: if the partial pressure of $\mathrm{CO}_{2}$ is too high $\mathrm{CaS}$ may be oxidized to $\mathrm{CaSO}_{4}$. $\mathrm{CaS}$ samples exposed to $850^{\circ} \mathrm{C}$ for 40 minutes under an atmosphere of pure $\mathrm{CO}_{2}$ were analyzed by EDS. The spectrum is identical to that for 


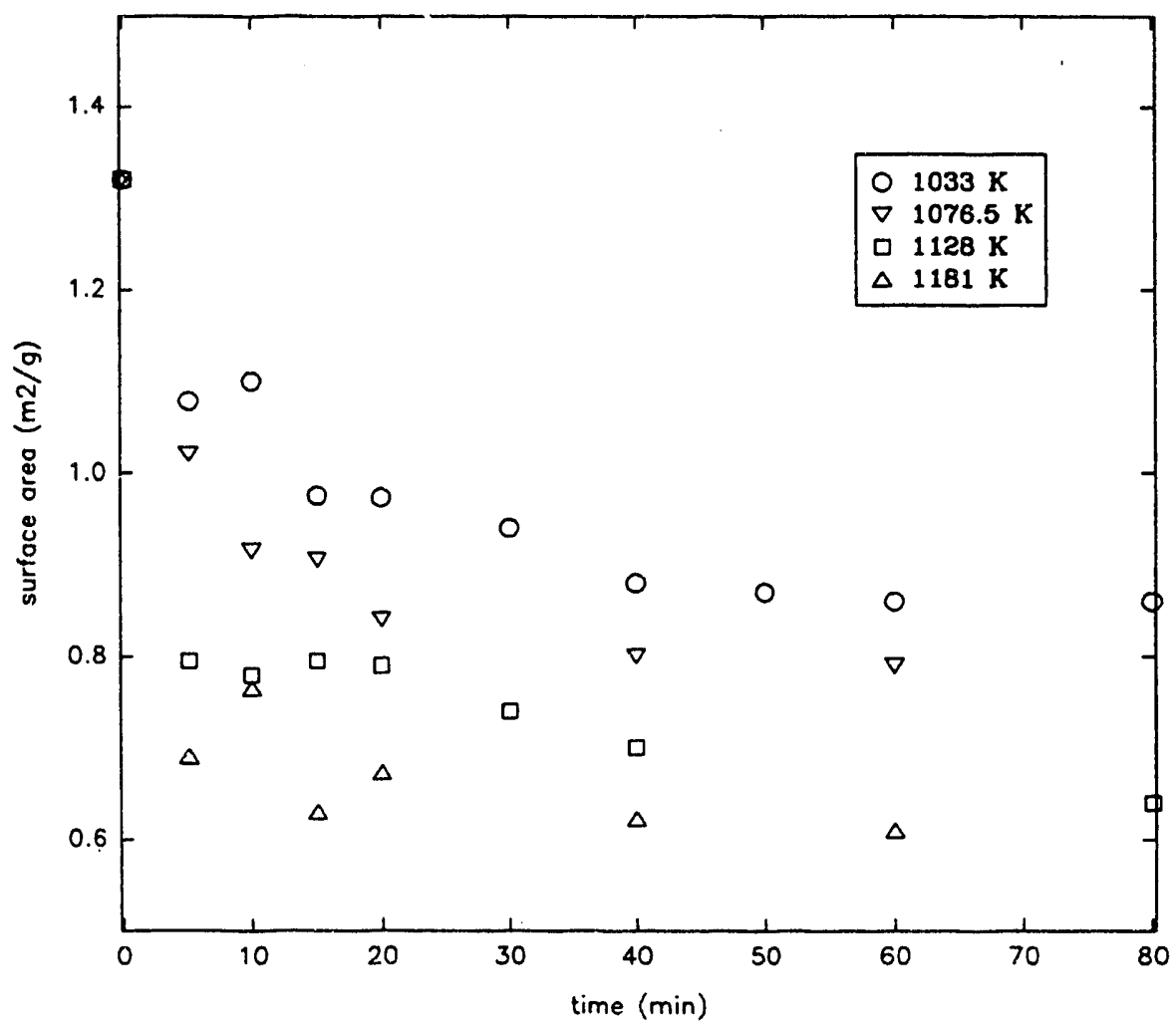

Figure 1.1 : Time evolution of the CaS surface area at different temperatures.

untreated CaS. It shows that no significant chemical reaction takes place during the heat treatment. The loss of surface area is purely due to a physical rearrangement. It proves that we really are observing a sintering phenomenon. It is important to note that this does not rule out possible interactions between the gas phase and the solid surface as an explanation for the sintering mechanism. As the matter of fact, this must be the key to any potential mechanism since we noticed a strong influence of the gas-phase composition on the sintering rate. This will be discussed in more detail in Chapter 9.

Scanning Electron Microscope pictures clearly demonstrate that CaS undergoes a strong morphological change above $750^{\circ} \mathrm{C}$. These modifications are typical of a sintered solid. 
Figures 7.2 and 7.3 contrast the $\mathrm{CaS}$ grains before and after heat treatment in the presence of $\mathrm{CO}_{2}$ at the same 20,200 high magnification (Figure 7.3: 20 minutes at $850^{\circ} \mathrm{C}$; gas feed: $96 \% \mathrm{CO}_{2} / 4 \% \mathrm{H}_{2}$ ). Some other pictures, in particular, show that originally disjoint grains are now merging (Figure 7.4: 20 minutes at $850^{\circ} \mathrm{C}$; gas feed: $96 \% \mathrm{CO}_{2} / 4 \% \mathrm{H}_{2}$. Figure 7.5: 40 minutes at $850^{\circ} \mathrm{C}$; gas feed: $96 \% \mathrm{CO}_{2} / 4 \% \mathrm{H}_{2}$ ). The grains boundarics are clearly identifiablr. Figures 7.6 and 7.7 compare the CaS morphology before and after heat treatment under a $\mathrm{N}_{2}$ atmosphere (40 minutes at $850^{\circ} \mathrm{C}$; gas feed: $100 \% \mathrm{~N}_{2}$, for Figure 7.7). The magnification is 6,010 in both photographs. In contrast to Figures 7.2 and 7.3 , the two pictures look very similar. This is consistent with the absence of a reduction in specific surface area for the reated $\mathrm{CaS}$ powder under a $100 \%$ nitrogen atmosphere, even at temperatures as high as $900^{\circ} \mathrm{C}$. Nevertheless, a noticeable difference can be observed between Figures 7.8 and 7.9. Figive 7.8 is a SEM picture (magnification $=1,010 \mathrm{X}$ ) of the CaS powder after $40 \mathrm{mi}$ utes exposition at $850^{\circ} \mathrm{C}$ under a $100 \% \mathrm{~N}_{2}$ atmosphere. Figure 7.9 is an equivalent photograph at the same magnification, but with a different gas atmosphere (gas feed of $96 \% \mathrm{CO}_{2} / 4 \% \mathrm{H}_{2}$ ). The particles in Figure 7.9 display less sharp angles than those in Figure 7.8. The powder grains have a "smooth" surface, typically encountered in sintered solids. 


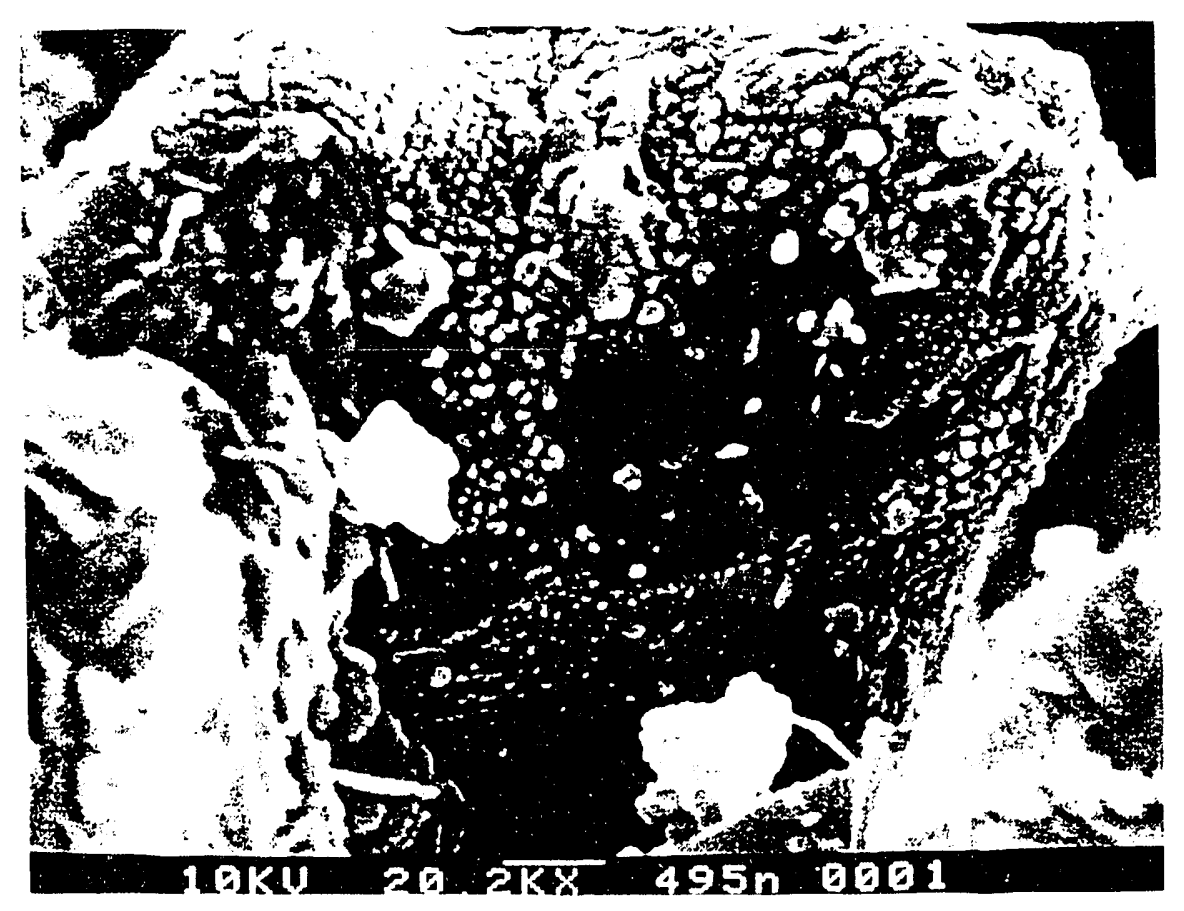

Figure 7.2: SEM picture of untreated CaS grains.

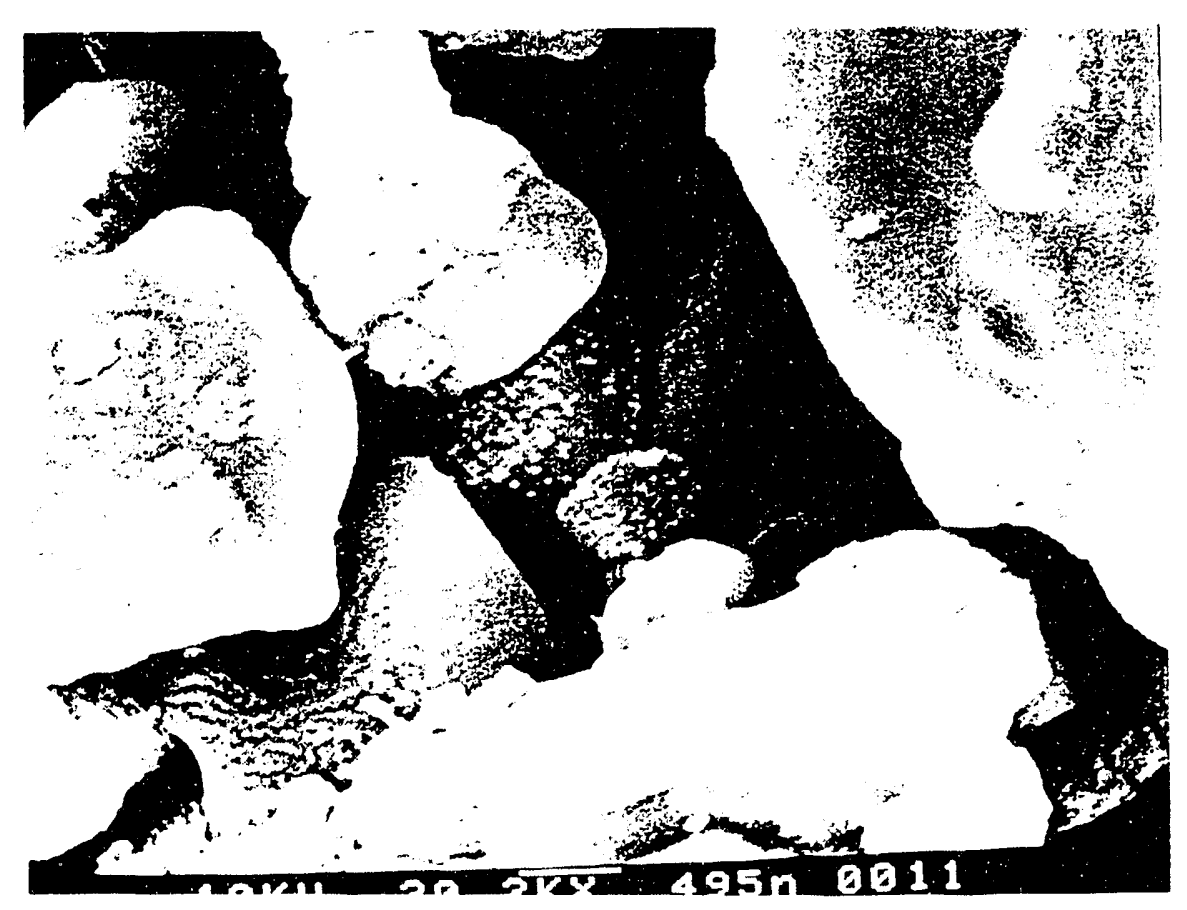

Figure 7.3: SEM picture of sintered CaS grains. 


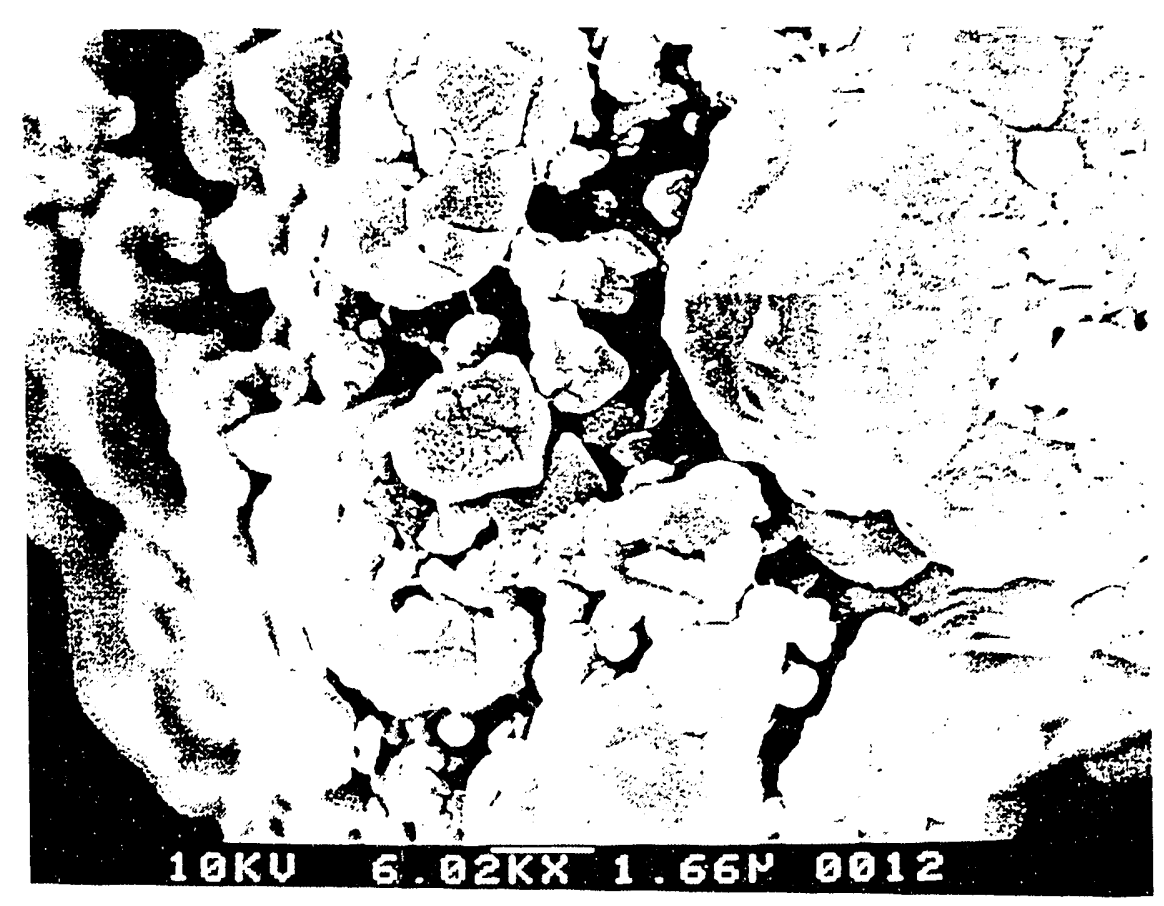

Figure 7.4: SEM picture of sintered CaS grains.

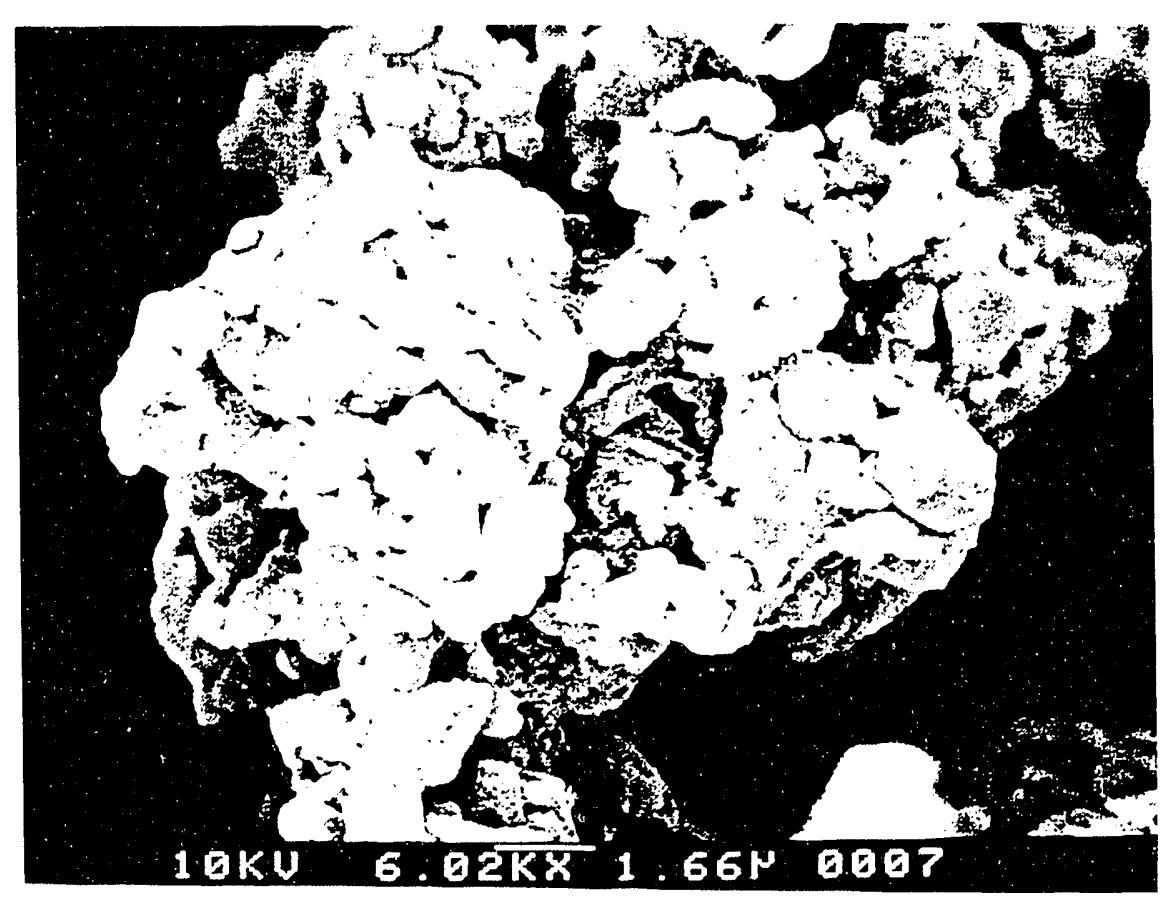

Figure 7.5: SEM picture of sintered CaS grains. 


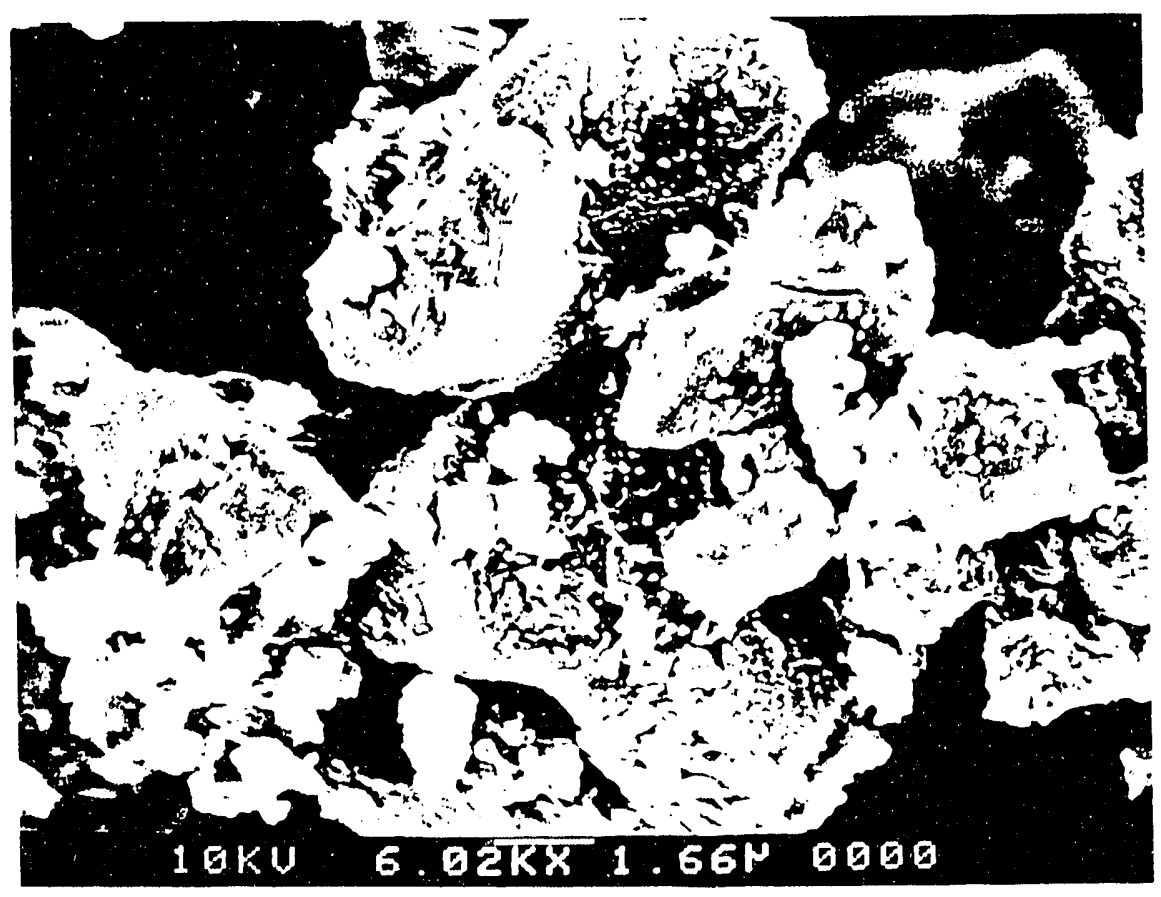

Figure 7.6: SEM picture of untreated CaS grains.

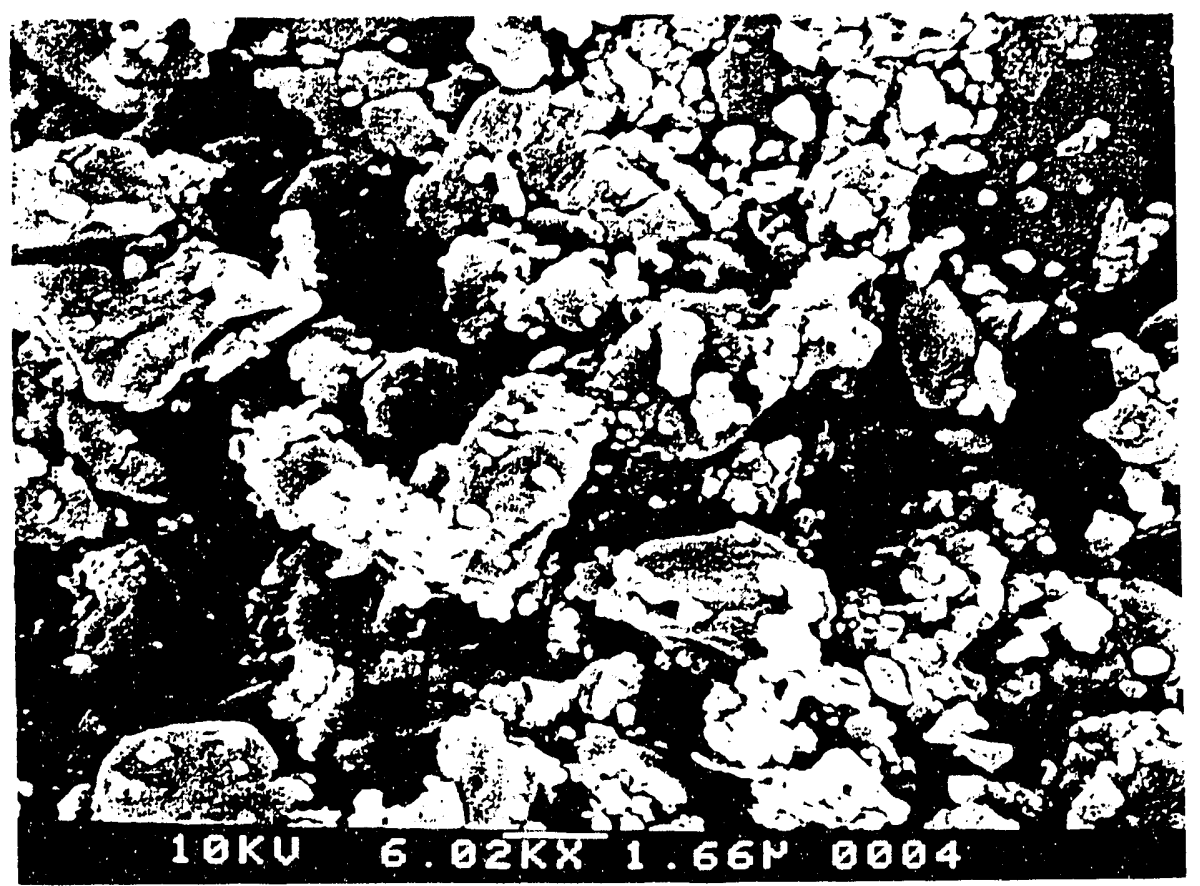

Figure 7.7: SEM picture of CaS grains heated under a $\mathrm{N}_{2}$ atmosphere. 


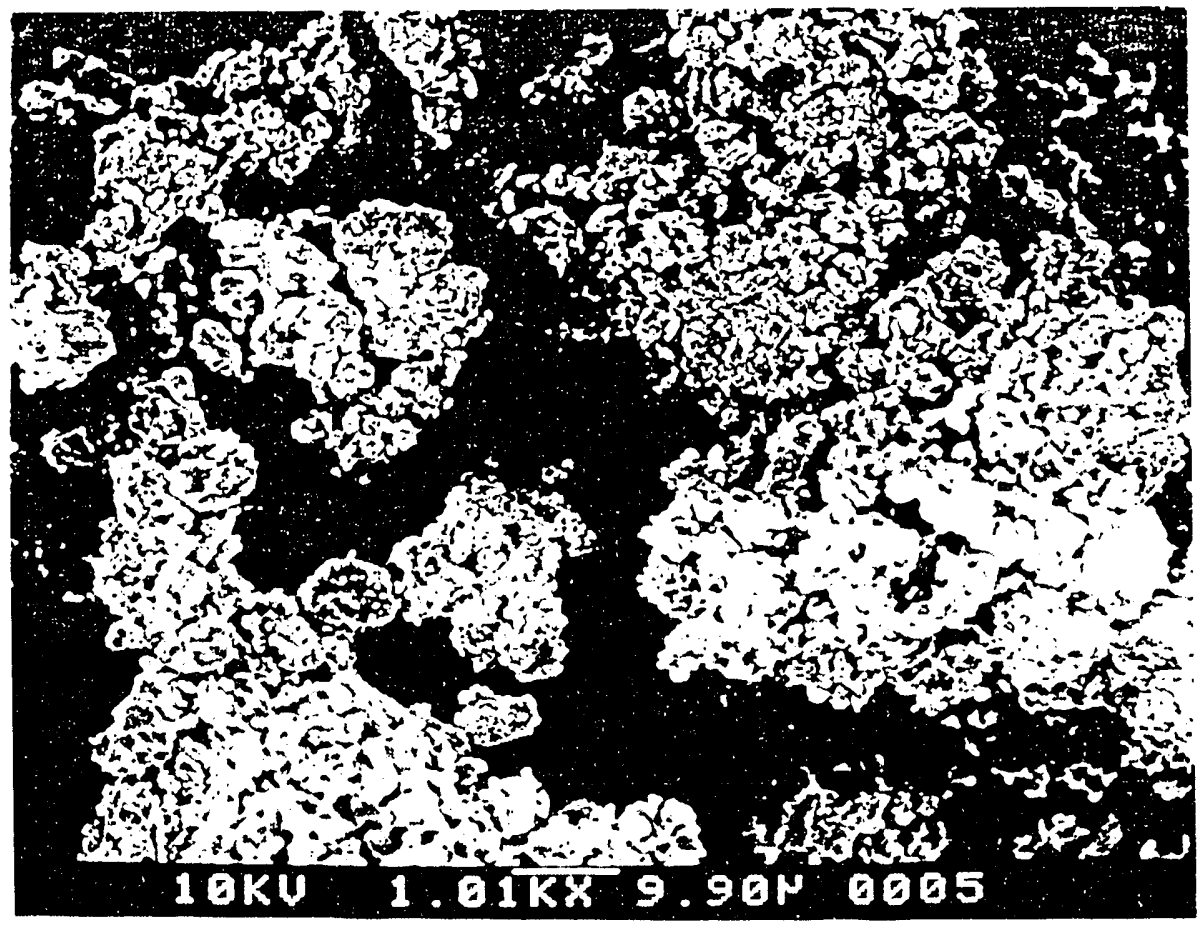

Figure 7.8: SEM picture of CaS grain heated under a $\mathrm{N}_{2}$ atmosphere.

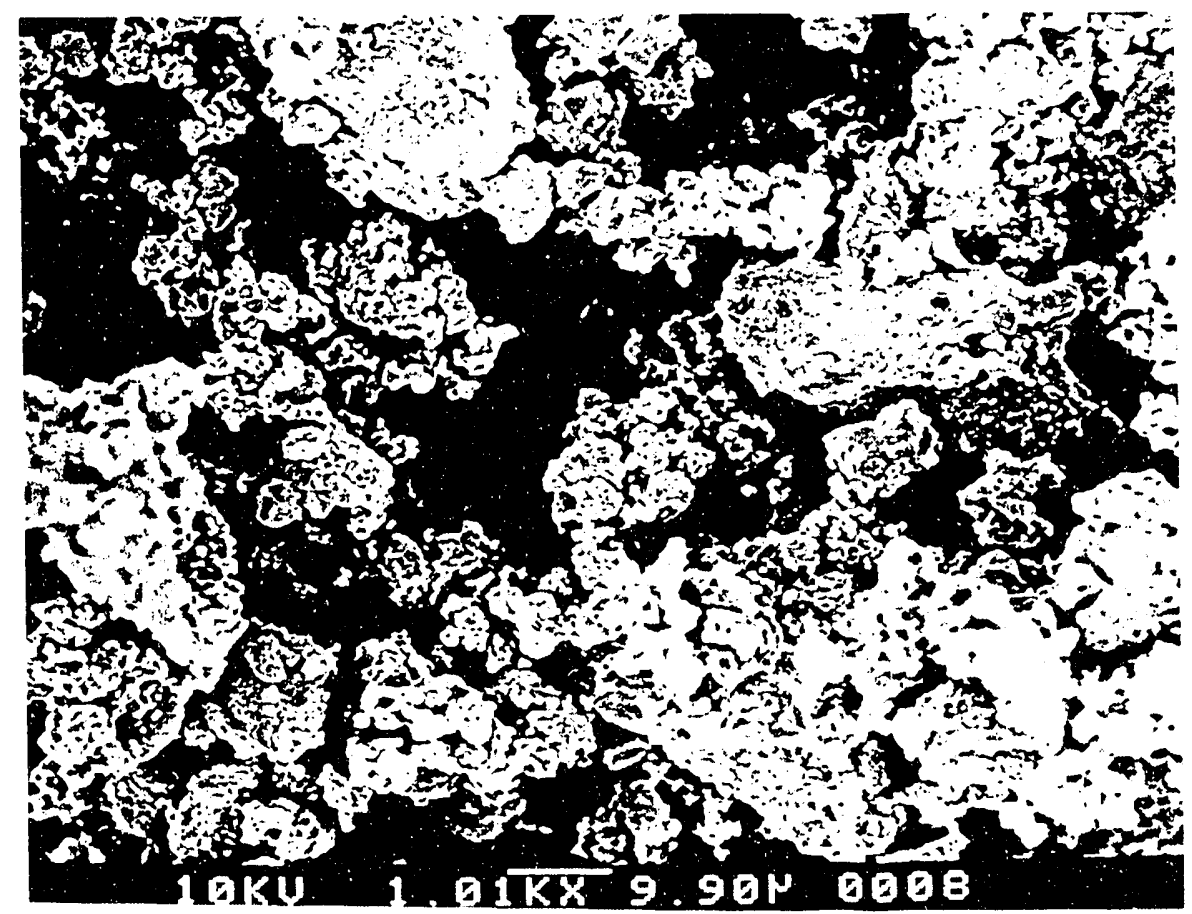

Figure 7.9: SEM picture of sintered CaS grains. 


\subsection{3) Modeling of the CaS sintering kinetics.}

Figure 7.10 provides an iterative, non-linear best-fit of the experimental data of Figure 7.1. The fit has been performed on Sigma-plot" software (Jandel Scientific, Corte Madera, CA) using the German and Munir model with three free parameters $(\omega, \mathrm{k}$ and $\mathrm{E}$ as defined in Section 3.2.1). The software used the Marquardt-Levenberg algorithm. The guess of the initial values of the three parameters is crucial for obtaining a convergence toward a realistic solution, especially with this highly non-linear fitting expression. The fit is only modestly good. It seems particularly inadequate for with an unrealistic value for $\omega$, of the order of 80 . On the other hand, the smoother surface-area diminution at lower temperatures could be quite nicely described with the previous model.

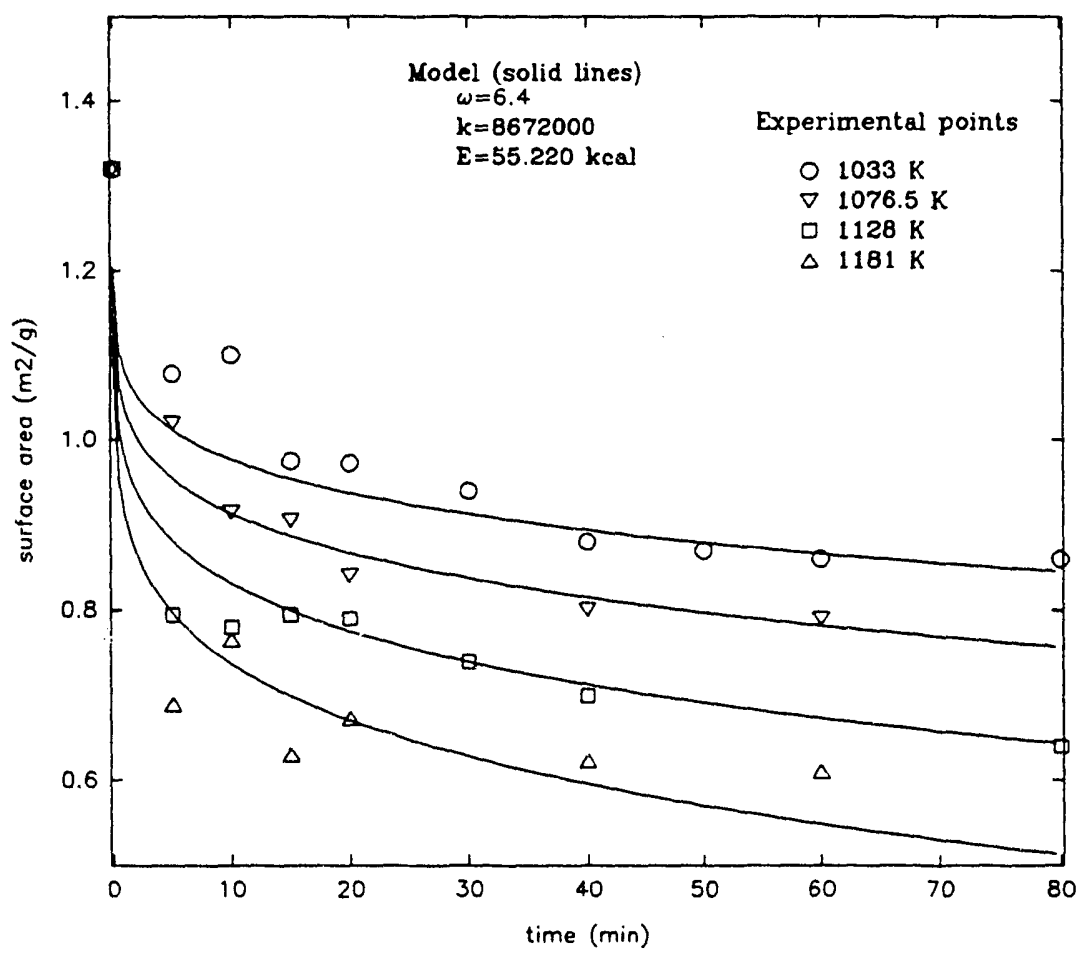

Figure 7.10 : Time evolution of the CaS surface area. Comparison between experiments and the German-Munir model predictions. 
If $\ln \left(1-S / S_{0}\right)$, where $S_{0}$ is the initial surface area, is plotted versus $\ln (t)$, the GermanMunir kinetic expression implies that we should obtain straight lines with identical slopes for the four different temperatures. Figure 7.11 shows that this is roughly true, considering the experimental uncertainty, for the two lower temperatures $\left(750\right.$ and $\left.800^{\circ} \mathrm{C}\right)$ with $\omega$ respectively equal to 3.8 and 4.8. The $\omega$ values (the inverse of the slope of the lines in Figure 7.11) are, however, different from each other at 850 and $900^{\circ} \mathrm{C}$ and also different from the values obtained at lower temperatures. This shows that the German-Munir theory does not hold for CaS at temperatures higher than $800^{\circ} \mathrm{C}$. Figure 7.12 , similar to Figure 7.11 except that one point $\left(750^{\circ} \mathrm{C}\right.$ for 10 minutes) has been discarded, confirms the similarity of the two $\omega$ values at the two lower temperature, thus confirming the validity of the model for them. The German-Munir expression was fitted to the $750-800^{\circ} \mathrm{C}$ experimental data (Figure 7.13). The values of the parameters are displayed on Figure 7.13.

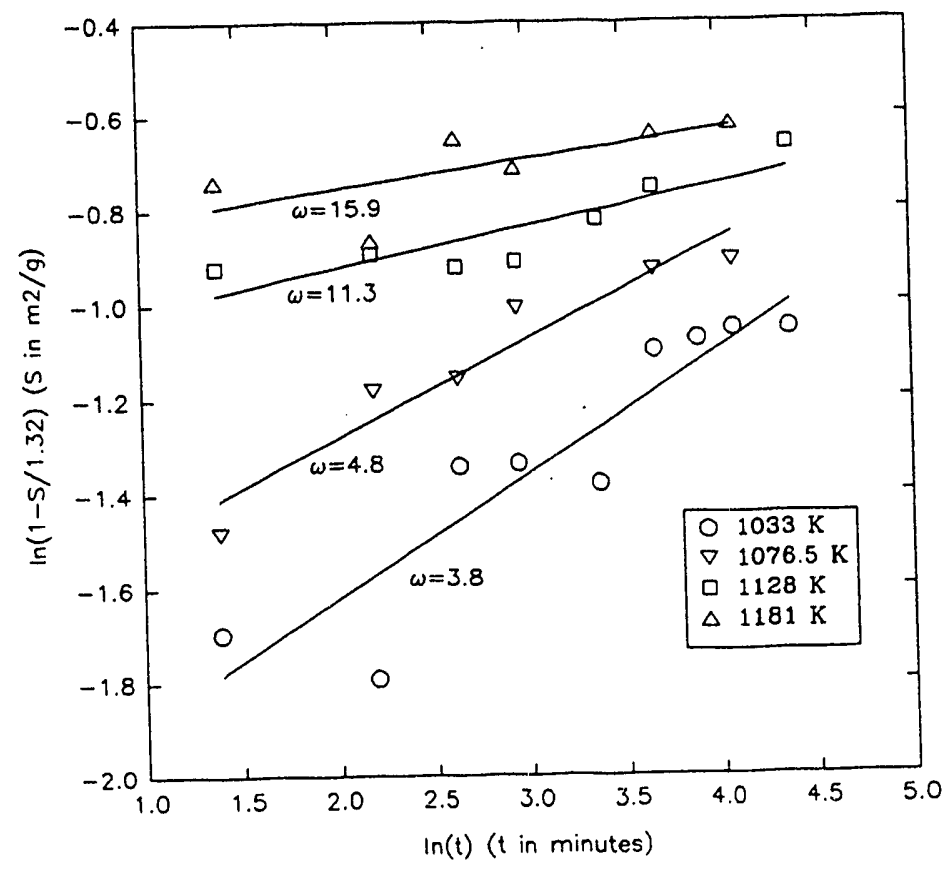

Figure 7.11 : Test of the validity of the German-Munir model. 


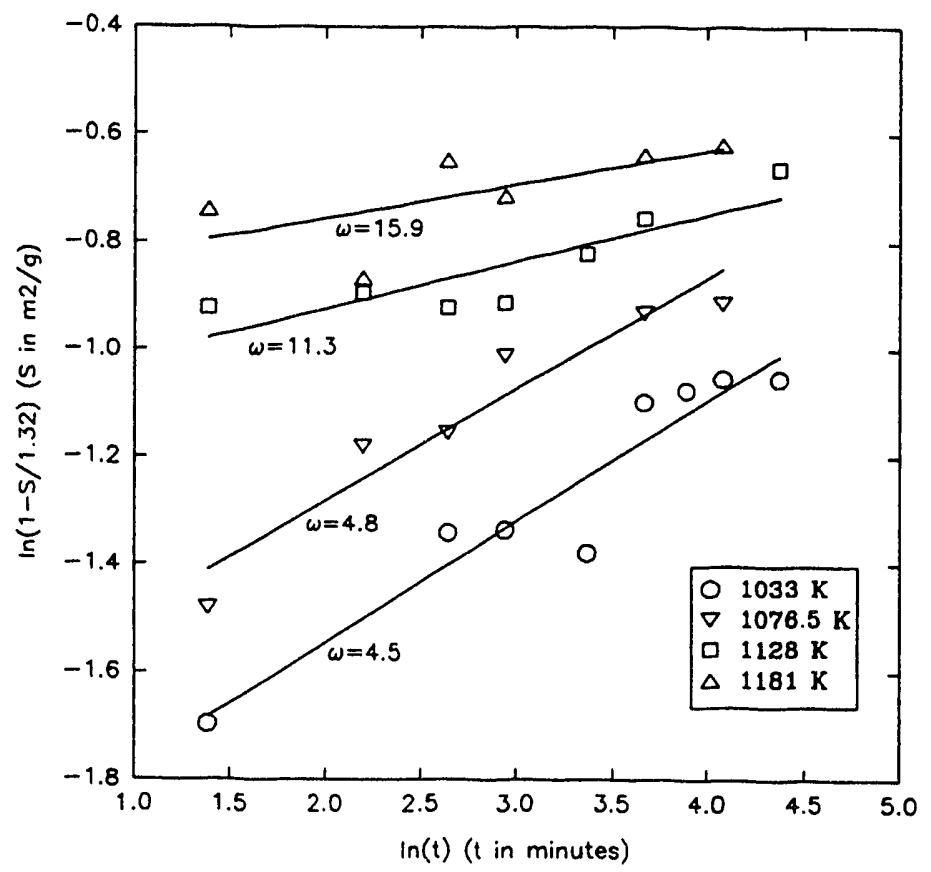

Figure 7.12 : Test of the validity of the German-Munir model.

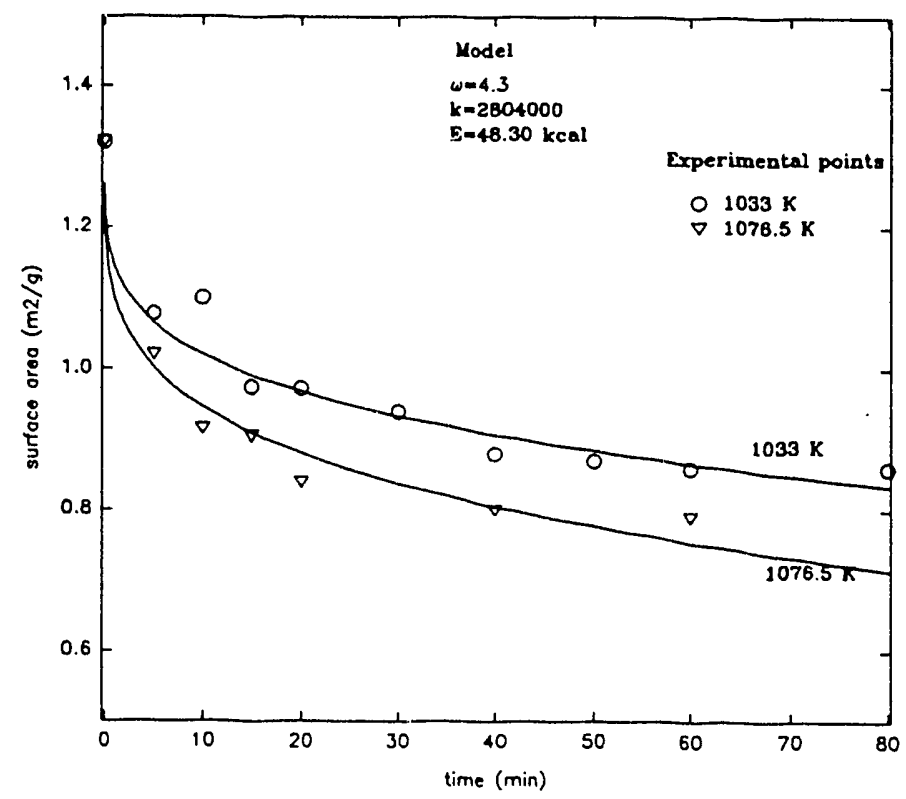

Figure 7.13 : Application of the German-Munir model on the 1033 and $1076.5^{\circ} \mathrm{K}$ experimental data. 
We still have to account for the high-temperature experimental results. The non-validity of the preceding model at these temperatures should not be too surprising because of the rapid large loss of initial suriace area (about $40 \%$ ). It is generally accepted that the German-Munir model does not hold when the surface area loss exceeds 45 to $55 \%$. Thus, at high temperatures we are located at the fringe of applicability of the theory and its failure could have been anticipated. It was, unfortunately, impossible to acquire reliable data below five minutes of exposure time because of the reactor configuration. The temperature experienced by the CaS samples would become very unstable and imprecise since the tubular reactor cell does not equilibrate at its final temperature in less than about a minute after it has been introduced into the furnace (Towler, 1992).

After five minutes at 850 or $900^{\circ} \mathrm{C}$ further surface-area variation is very modest. This behavior has been often observed when the initial loss of surface area exceeds 50\% (Irabien et $a l, 1990)$. In these instances, a linear expression between the surface area and the exposure time gives fairly accurate results (Figure 7.14). This approach is purely empirical but the other, more physical, models described in Chapter 3 give poorer correlations. Moreover, they yield extremely unrealistic values for their physical parameters, especially for the activation energy.

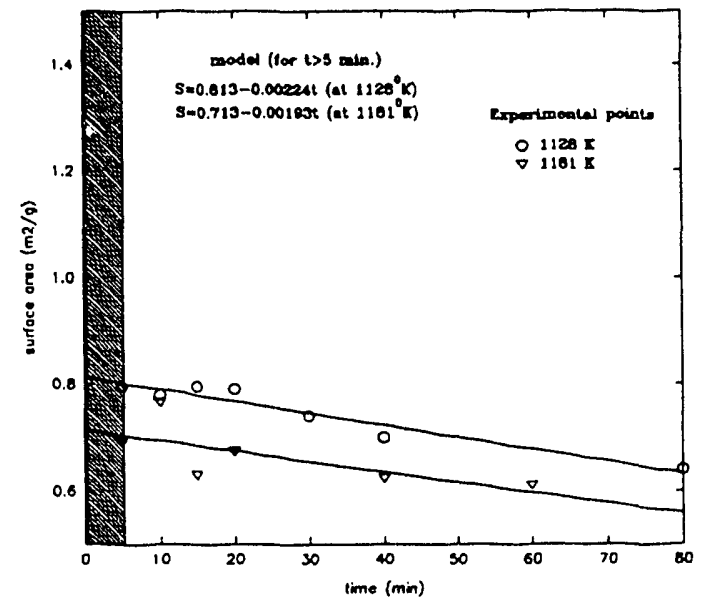

Figure 7.14: Linear regression on high temperatures data. 


\section{CHAPTER 8: LIMESTONE SULFIDATION EXPERIMENTS}

Several batches of 3/8-inch/6-mesh limestone were exposed to diverse gas mixtures at various temperatures for an hour. For the same reasons discussed in Chapter 7, the $\mathrm{CO}_{2}$ fraction in the gas feed was kept very high so that the variations of the reactor temperature would have minimal influence on the gas-phase composition over the limestone samples after thermodynamic equilibrium was reached.

The limestone sulfidation (reaction 1.2) was followed quantitatively as well as qualitatively. The conversion was measured by weight changes, $\mathrm{CaS}$ being lighter than $\mathrm{CaCO}_{3}$. The fact that limestone is not composed of $100 \%$ pure $\mathrm{CaCO}_{3}$ and the uncertainties in the balance readings were taken into account. An accuracy of a few percent, certainly better than $5 \%$, was guaranteed by these simple measurements. The mechanism of the sulfidation reaction has also been studied. So, the morphology of the inside and of the outside of reacted limestone samples has been observed with a scanning electron microscope. Finally, X-ray maps of the sulfur content of the reacted samples were generated, since the sulfur distribution is a good indication of the reaction mechanism.

\section{1) Influence of the temperature and of the $\mathrm{H}_{2} \mathrm{~S}$ partial pressure.}

Changing the temperature from 800 to $900^{\circ} \mathrm{C}$ did not significantly modify the conversion of $\mathrm{CaCO}_{3}$ to $\mathrm{CaS}$ for a $95 \% \mathrm{CO}_{2} / 4 \% \mathrm{H}_{2} / 1 \% \mathrm{H}_{2} \mathrm{~S}$ gas feed to the reactor. The composition of such a mixture at thermodynamic equilibrium is provided in Table 8.1 . The $100^{\circ} \mathrm{C}$ increase only enhanced the conversion by $5 \%$, from 8.2 to $13.2 \%$ (one-hour runs). 
Table 8.1: Equilibrium composition of experimental gas feeds at 800 and $900^{\circ} \mathrm{C}$.

\begin{tabular}{||l|l|l|l|l|l|l|l|l|}
\hline Constituent (\%) & $\mathrm{CO}_{2}$ & $\mathrm{H}_{2} \mathrm{~S}$ & $\mathrm{H}_{2}$ & $\mathrm{H}_{2} \mathrm{O}$ & $\mathrm{CO}$ & $\mathrm{S}_{2}$ & $\mathrm{COS}$ & $\mathrm{SO}_{2}$ \\
\hline Feed 1 at $800^{\circ} \mathrm{C}$ & 90.1 & 0.45 & 0.22 & 4.5 & 4.3 & 0.10 & 0.27 & 0.04 \\
\hline Feed 1 at $900^{\circ} \mathrm{C}$ & 89.4 & 0.241 & 0.194 & 4.65 & 4.93 & 0.178 & 0.17 & 0.23 \\
\hline Feed 2" at $800^{\circ} \mathrm{C}$ & 85.81 & 1.14 & 0.438 & 6.21 & 5.78 & 0.135 & 0.464 & 0.189 \\
\hline Feed 2 at $900^{\circ} \mathrm{C}$ & 84.75 & 0.701 & 0.396 & 6.66 & 0.65 & 0.352 & 0.327 & 0.157 \\
\hline
\end{tabular}

* Feed 1: $94.9 \% \mathrm{CO}_{2} / 4.1 \% \mathrm{H}_{2} / 1 \% \mathrm{H}_{2} \mathrm{~S}$

** Feed 2: $92.2 \% \mathrm{CO}_{2} / 5.9 \% \mathrm{H}_{2} / 1.9 \% \mathrm{H}_{2} \mathrm{~S}$

However, an increase in the fraction of $\mathrm{H}_{2} \mathrm{~S}$ in the gas feed from 1 to $2 \%$ showed a profound impact. At about $900^{\circ} \mathrm{C}$ (i.e., at the vicinity of the $\mathrm{CaCO}_{3}$ calcination temperature) for 60 minutes, a change from a $95 \% \mathrm{CO}_{2} / 4 \% \mathrm{H}_{2} / 1 \% \mathrm{H}_{2} \mathrm{~S}$ to a $92 \% \mathrm{CO}_{2} / 6 \% \mathrm{H}_{2} / 2 \% \mathrm{H}_{2} \mathrm{~S}$ gas feed augmented the conversion from 13.2 to $50 \%$, a fractional increase quite similar to that of the $\mathrm{H}_{2} \mathrm{~S}$ equilibrium composition (see Table 8.1). This allowed us easily to get larger conversions under relatively similar experimental conditions (same temperature, same exposure time, and almost the same gas-phase composition except for the $\mathrm{H}_{2} \mathrm{~S}$ content). It was very important to change as few variables as possible in the different experiments to isolate each parameter that could influence the reaction rate. This is particularly critical because of the potential influence of sintering on the reaction mechanism. Furthermore, it was possible to observe the morphological changes at different stages of reaction 1.2.

We do not have any good explanation for the large increase in the $\mathrm{CaCO}_{3}$ conversion when the fraction of $\mathrm{H}_{2} \mathrm{~S}$ in the gas feed is doubled. It cannot be explained by a shrinking-core model since the increase should only have been twofold if the $\mathrm{H}_{2} \mathrm{~S}$ diffusion through the solid were the rate-limiting step in the kinetics. However, morphological study of the limestone sulfidation (Section 8.2) indicates that, after 10 to $15 \%$ conversion of limestone to calcium sulfide, the reaction proceeds via a shrinking core mechanism. More work needs to be done on the influence of the gas-phase composition on the conversion rate. 


\section{2) Morphological study.}

SEM pictures of the external surface of the particles reveal the same "smoothness" already observed in the pictures of sintered CaS powder. The original limestone-particle surface has lost most of its sharp angles. Moreover, a lot of small pores have disappeared or have significantly shrunk, and small cracks, which were expected to appear on the grain surface because of the difference in molecular volume between $\mathrm{CaS}$ and $\mathrm{CaCO}_{3}$, are not present (see Chapter 2). However, a few large fractures (with a width of the order of a micrometer) exist on the stone surface as we can see in Figure 8.1 (magnification $=67 \mathrm{X}$ ). The samples displayed in Figures 8.1 to 8.5 were obtained after one hour at $800^{\circ} \mathrm{C}$ with a gas feed of $95 \% \mathrm{CO}_{2}, 4 \%$ $\mathrm{H}_{2}$, and $1 \% \mathrm{H}_{2} \mathrm{~S}$. The CaS conversion was about $10 \%$. Figures 8.2 and 8.3 , obtained at higher magnifications (respectively 1010 and $4800 \mathrm{X}$ ), reveal even more of these relatively sharp, medium-sized fractures along with the very wide one that is crossing the whole particle. These fractures are not the result of a purely mechanical effect, such as shocks during the sample handling. Figures 8.4 and 8.5 (both at 8000 times magnification) show how smooth and how deep the internal surface of the fault is. A shock after the completion of the chemical reaction would have created a much sharper and coarser surface. These kinds of fractures have been observed in several different sulfided samples, whereas they were never seen to this extent in fresh limestone samples. 


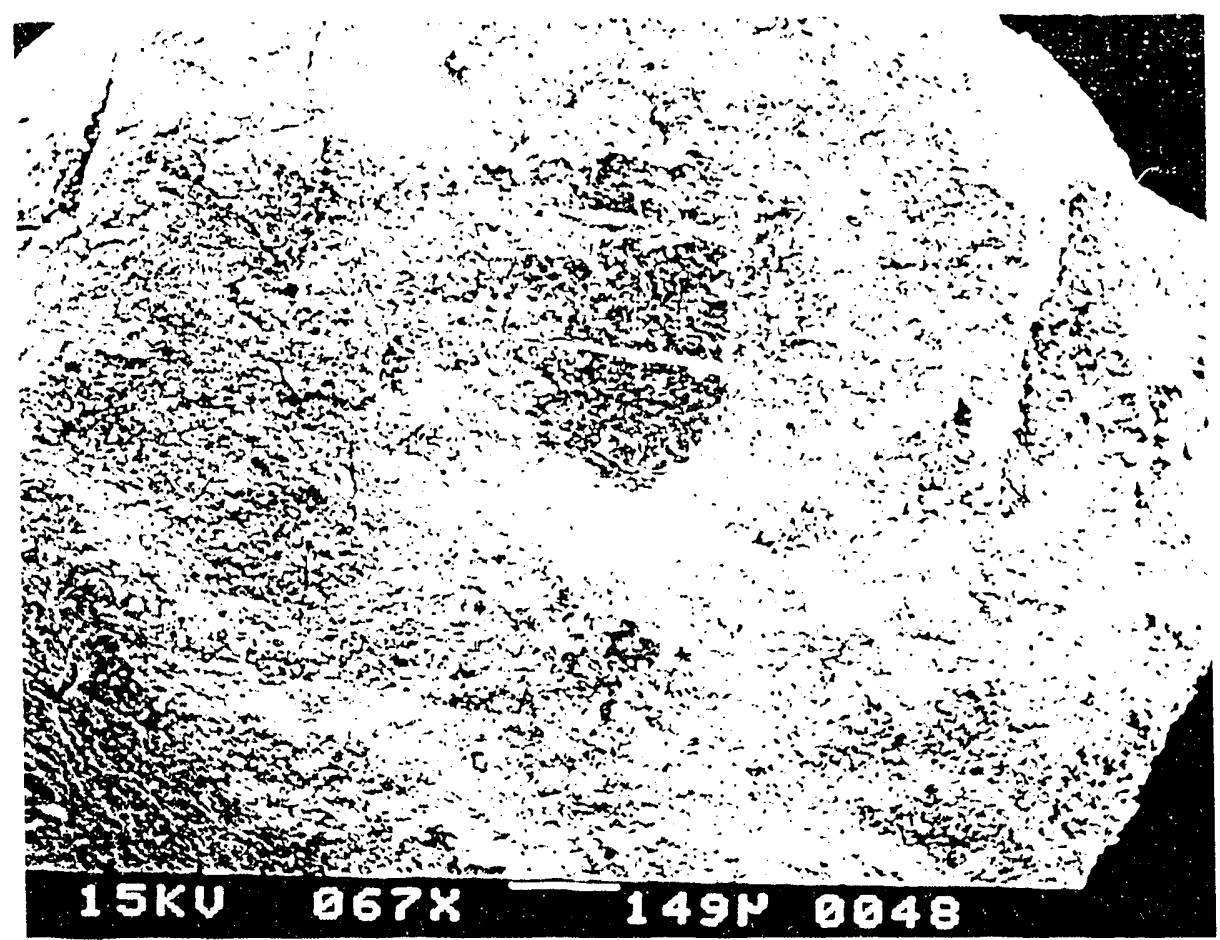

Figure 8.1: External surface of a partially-sulfided limestone sample.

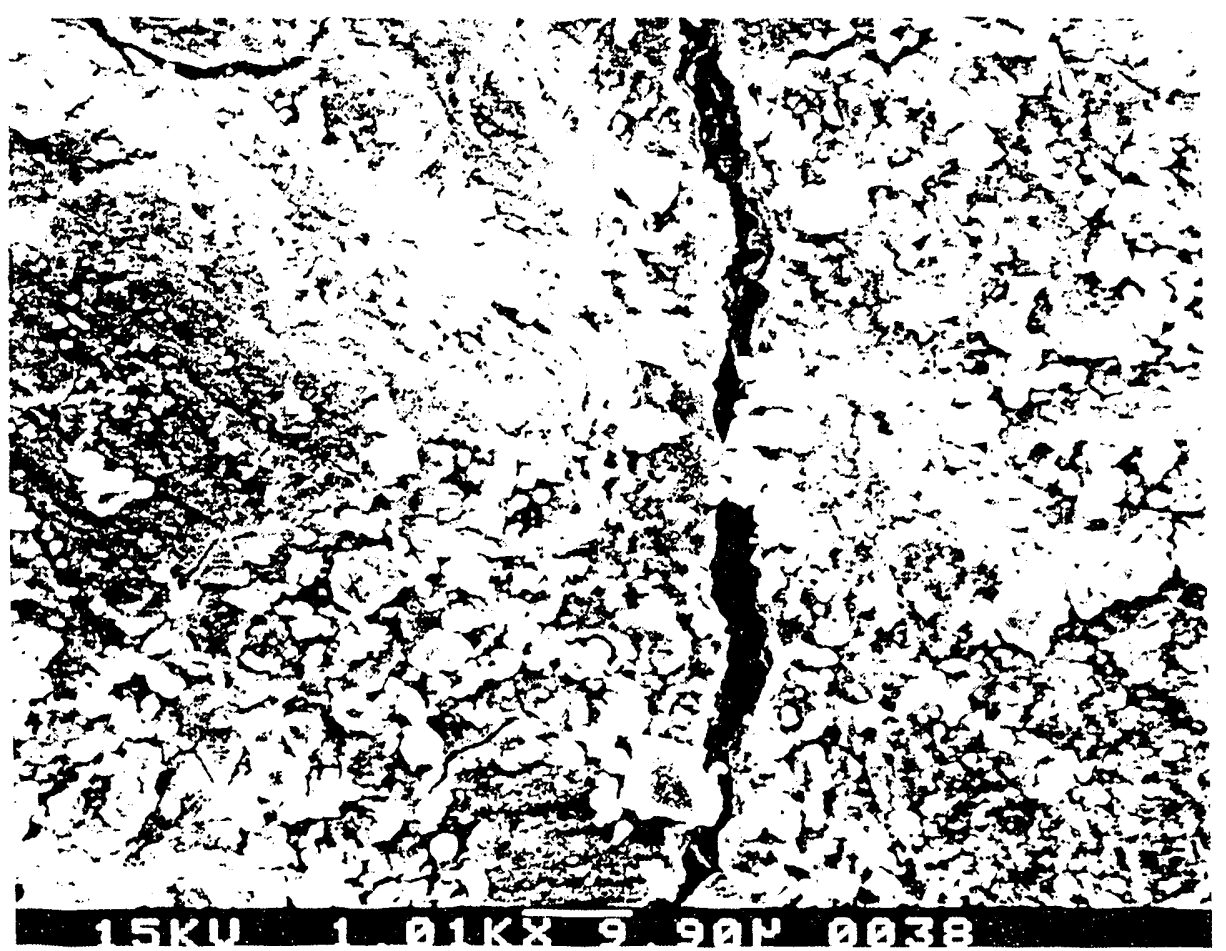

Figure 8.2: External surface of a partially-sulfided limestone sample. 


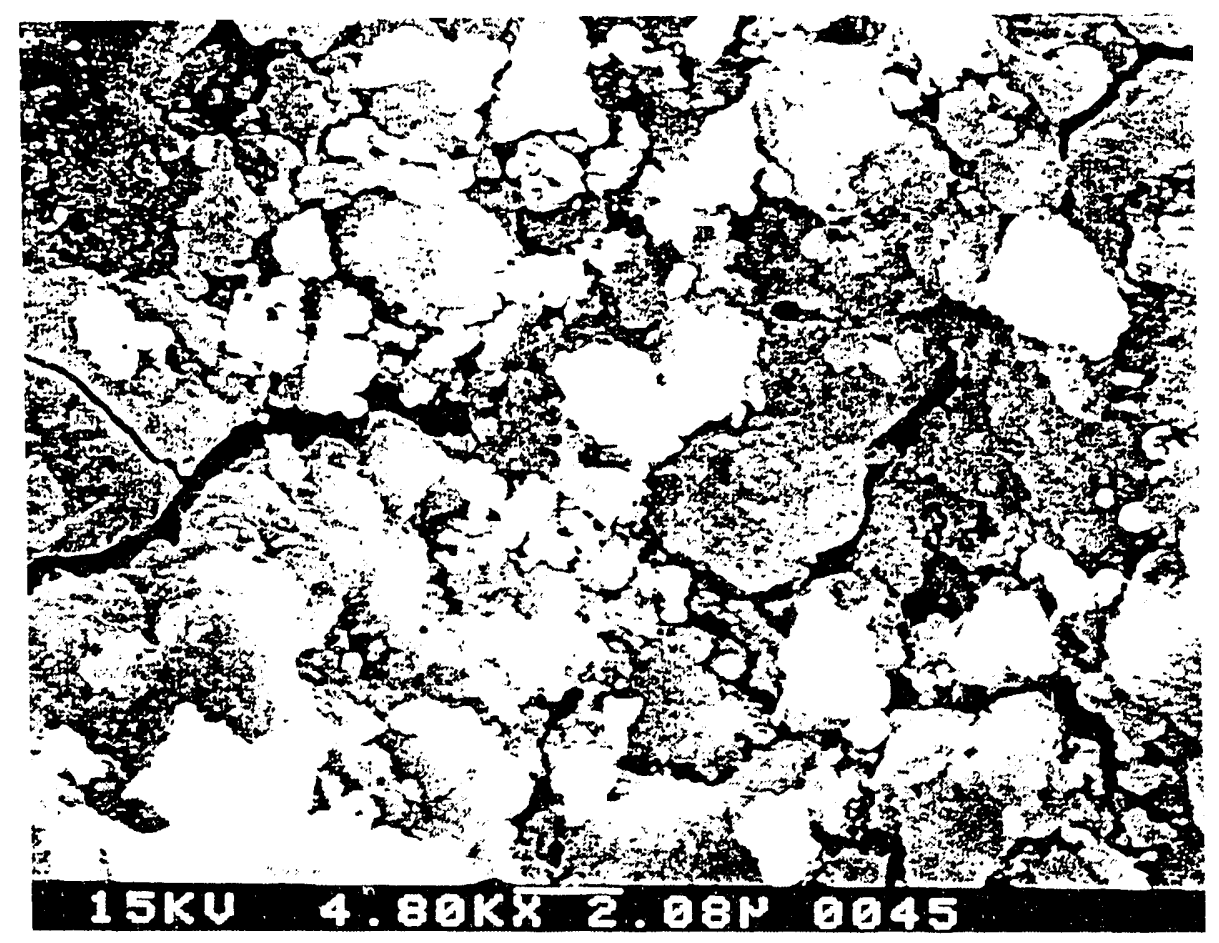

Figure 8.3: External surface of a partially-sulfided limestone sample.

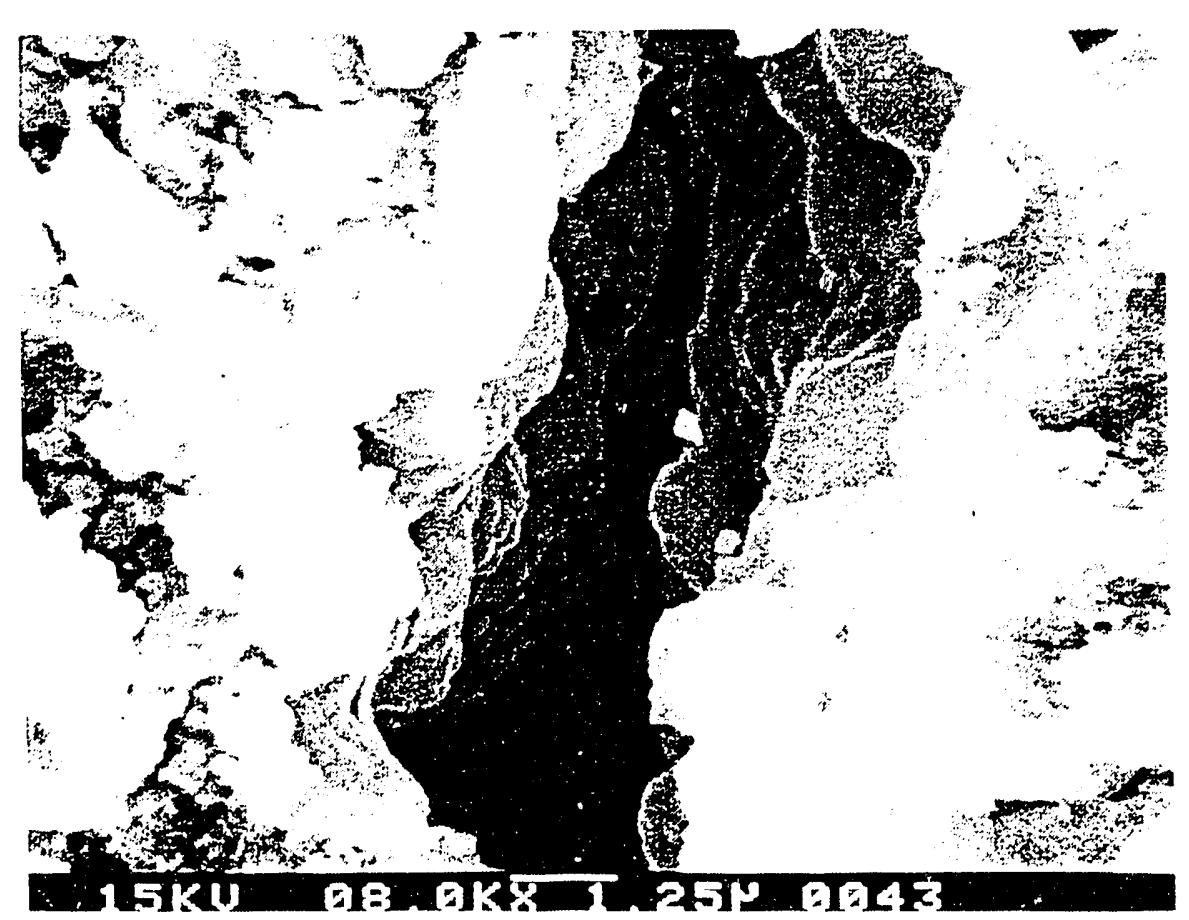

Figure 8.4: Detail of the large fracture observed in Figure 8.1. 


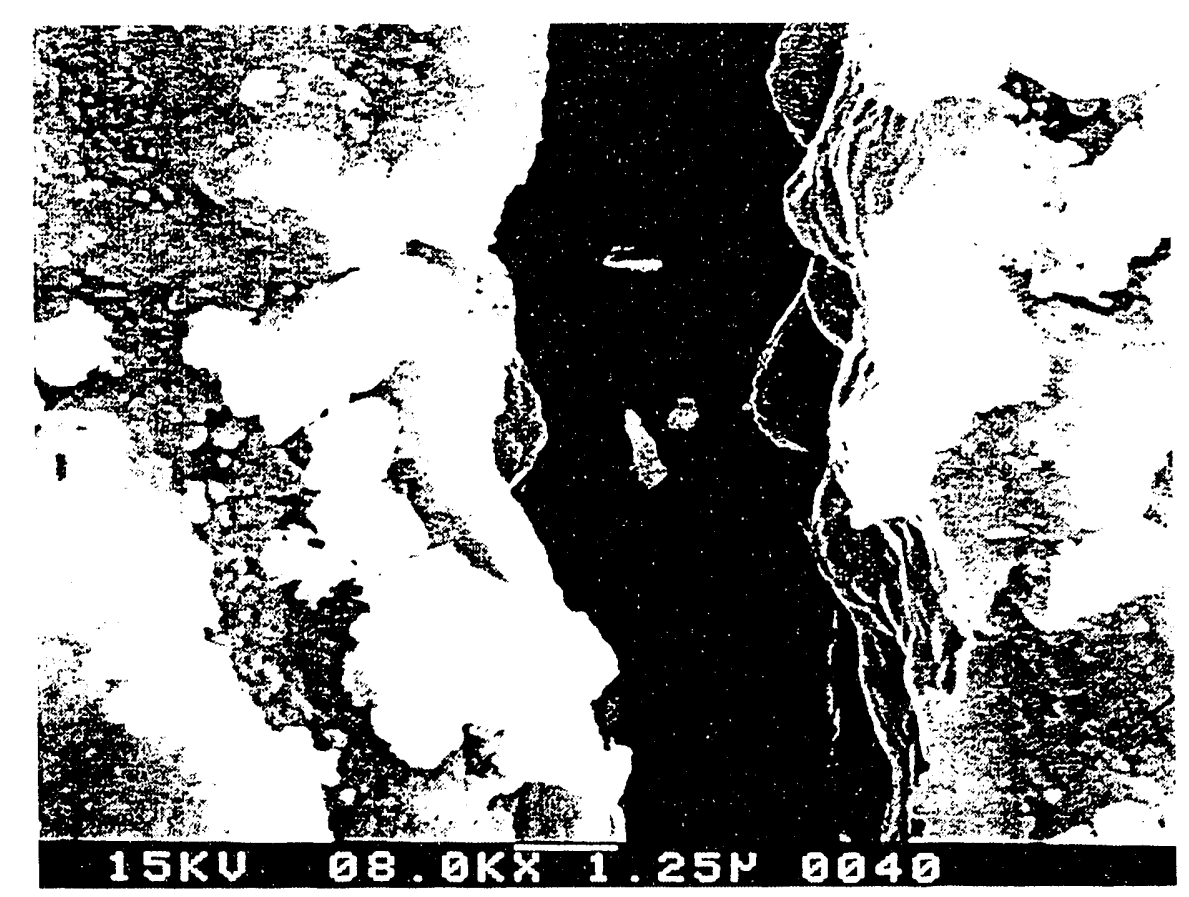

Figure 8.5: Detail of the large fracture observed in Figure 8.1.

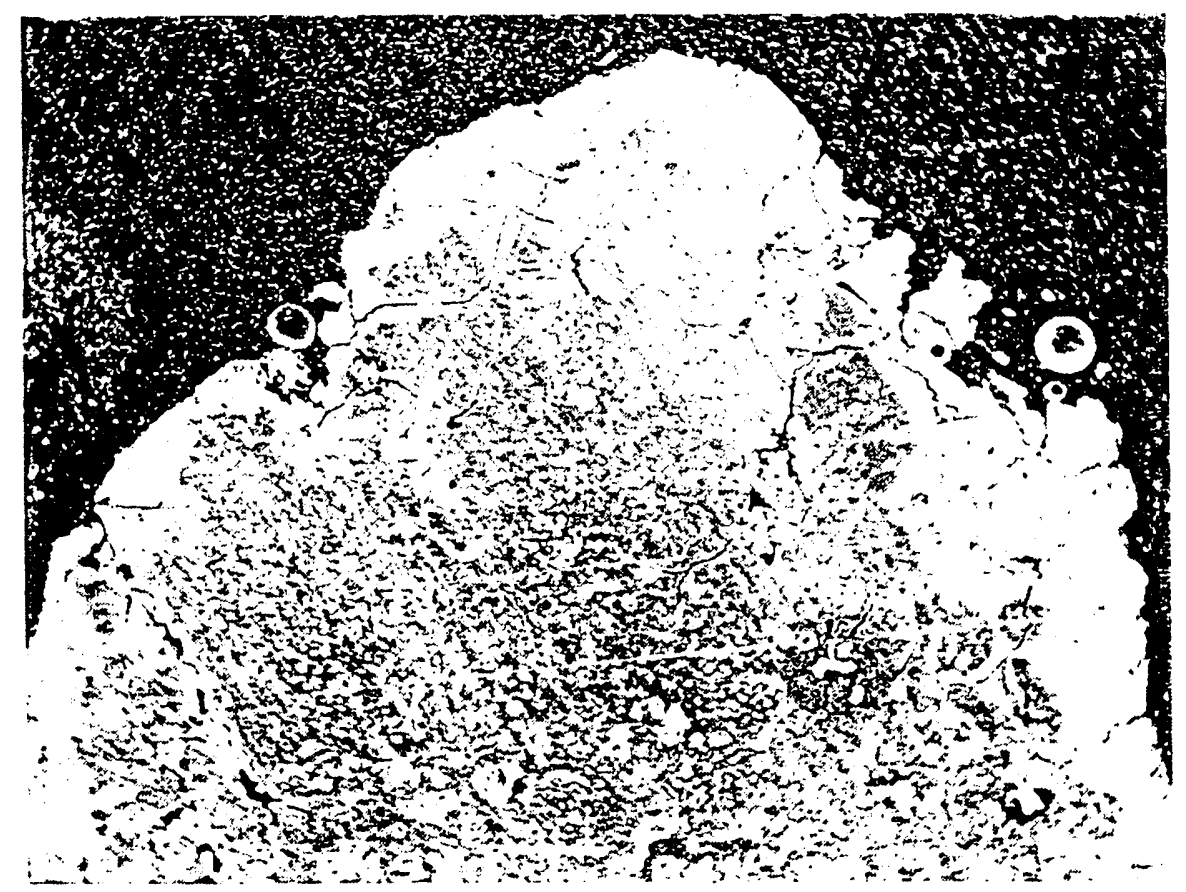

Figure 8.6: Cross-section of a partially-sulfided limestone sample. 
Figure 8.6 (magnification $=49 \mathrm{X}$ ) displays a polished cross-section of a limestone particle that has been converted to about $50 \%$ of CaS (one hour at $900^{\circ} \mathrm{C}$ with a gas feed of $92 \%$ $\mathrm{CO}_{2}, 6 \% \mathrm{H}_{2}$, and $2 \% \mathrm{H}_{2} \mathrm{~S}$ ). It clearly displays the presence of fractures in the inner structure of the limestone. However, the number and size of these cracks are larger in the CaS crust (pale gray) than in the $\mathrm{CaCO}_{3}$ structure (darker gray). This suggests that some fractures were originally present within the limestone structure prior to the reaction. The sulfidation might have either enhanced the size of previously existing cracks, or induced the propagation of initially short fractures deeper into the core of the pellet.

Some reacted limestone particles have been sectioned with a razor blade. The razor blade induced a fracture that carried through the pellet to give two parts of roughly the same size. Thus, the stone separated following the weakest points of its grain-pore network. Figure 8.7 (magnification $=53 \mathrm{X}$ ) and Figure 8.8 (magnification $=800 \mathrm{X}$ ) are two cross-section photographs of reacted limestone samples (limestone exposed one hour at $810^{\circ} \mathrm{C}$ to a gas feed of $95 \% \mathrm{CO}_{2}, 4 \% \mathrm{H}_{2}, 1 \% \mathrm{H}_{2} \mathrm{~S} ; 8.2 \%$ conversion to $\mathrm{CaS}$ ). Figure 8.8 exhibits a very smooth structure, very similar to what we observed in the sintered $\mathrm{CaS}$ pictures. 


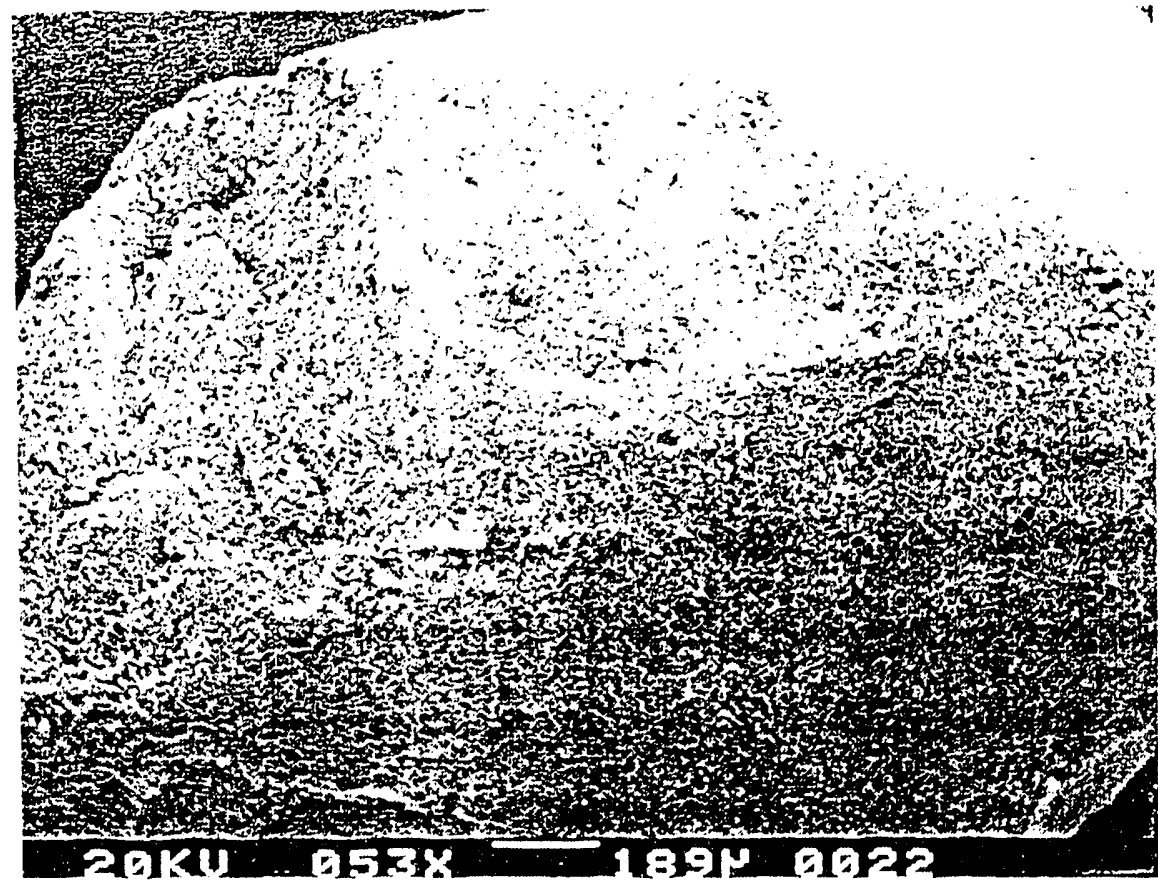

Figure 8.7: Cross-section of a partially-sulfided limestone sample.

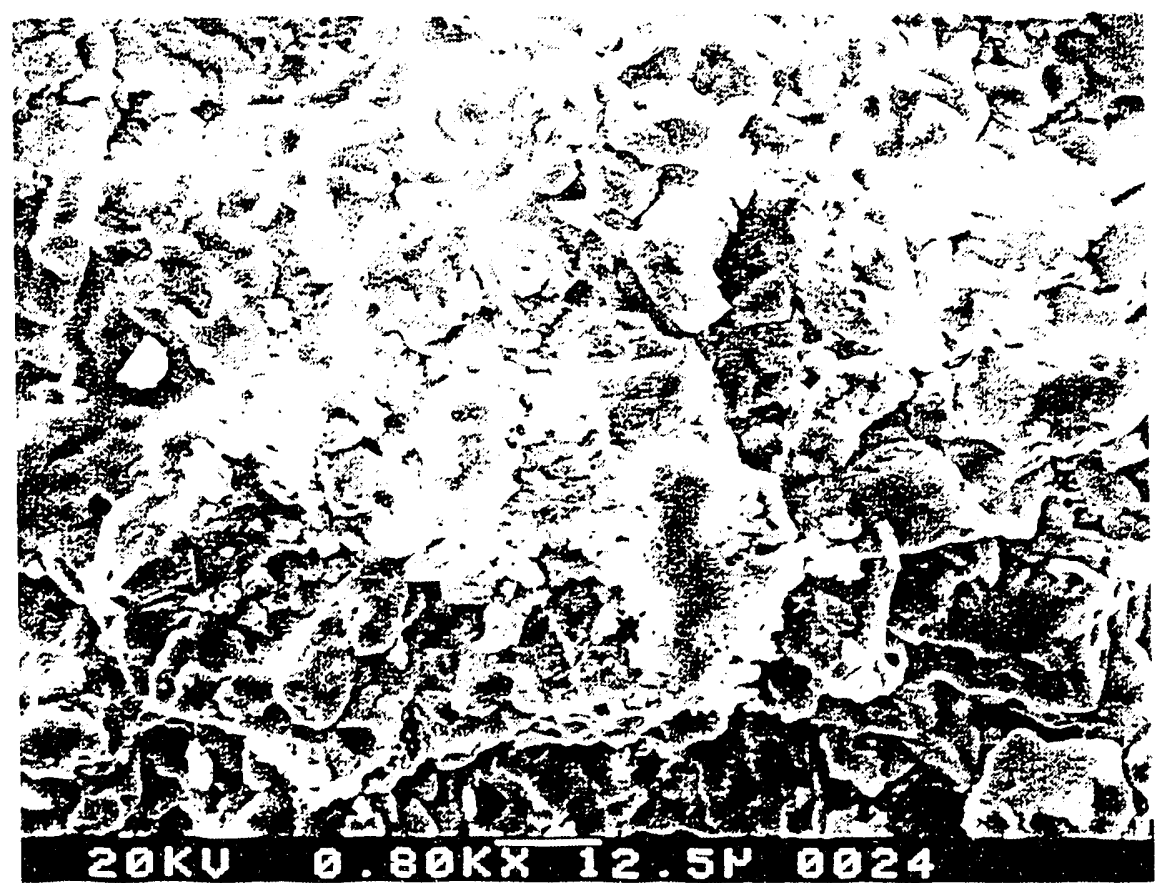

Figure 8.8: Cross-section of a partially-sulfided limestone sample. 


\subsection{2) Sulfur distribution.}

A few samples were polished to allow X-ray mapping of the sulfur in the reacted samples. The sections obtained with a razor blade were too rough to allow good mapping (the electron scattering due to the coarse surface was too large to get a clean signal). It was then crucial to obtain a surface as smooth and flat as possible for a better resolution of the analysis. The final polish was carried with a METADI-1- $\mu \mathrm{m}$-diamond-paste (from Buehler) and provided a very flat cross-section of the center of the particles.

Figures 8.9 and 8.10 (both magnifications $=194 \mathrm{X}$, same experimental conditions as Figure 8.6) demonstrate the close correlation between the color, or rather the tone of gray, and the chemical composition. Figure 8.9 is a sulfur X-ray map. A white spot coincides with an area containing at least $1 \%$ of sulfur atoms. Figure 8.10 is a SEM picture of exactly the same area analyzed in Figure 8.9. Thus, the lighter tone of gray corresponds to a zone very rich in $\mathrm{CaS}$, whereas the darker gray is associated with the original calcium carbonate. These tones are very useful for determining the distribution of $\mathrm{CaS}$ among the $\mathrm{CaCO}_{3}$ crystallites on the SEM pictures. 


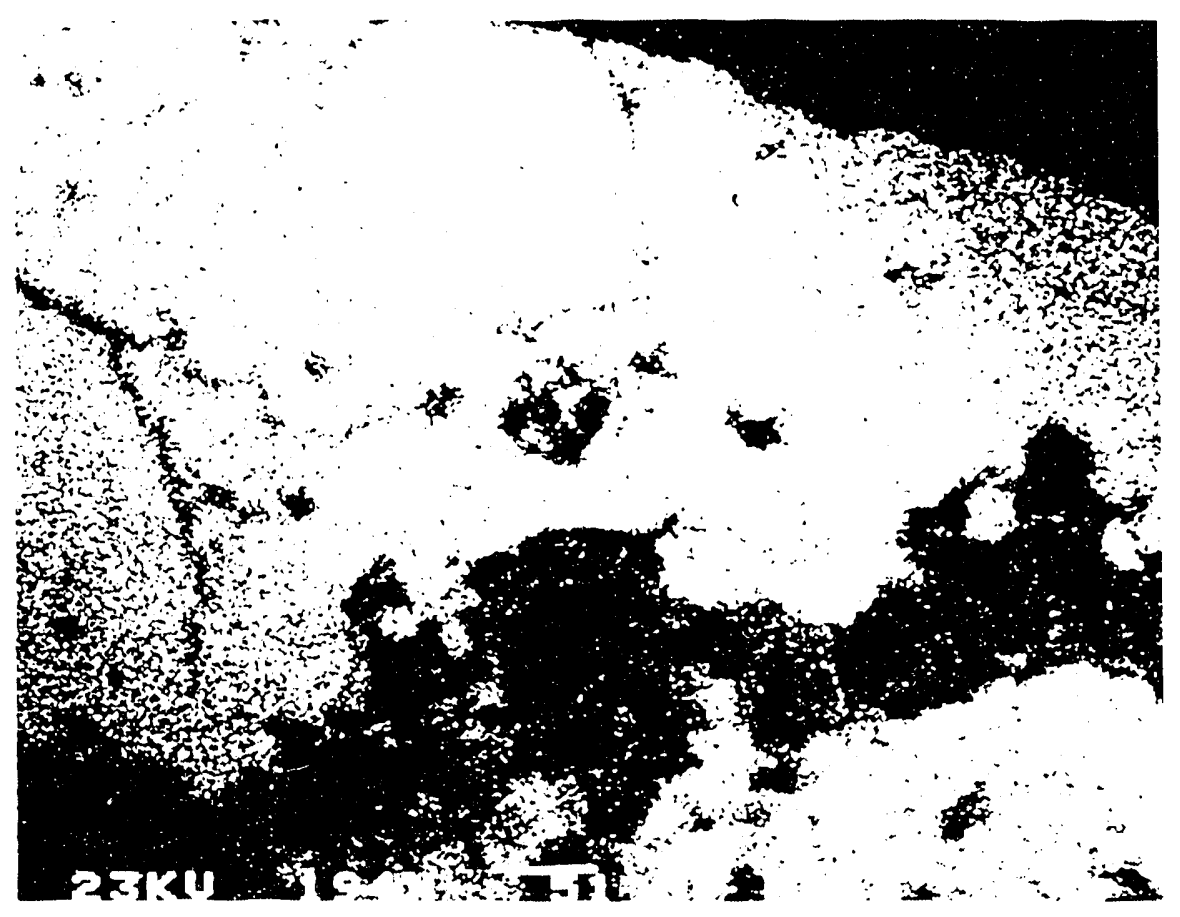

Figure 8.9: X-ray map of the cross-section of a partially-sulfided limestone.

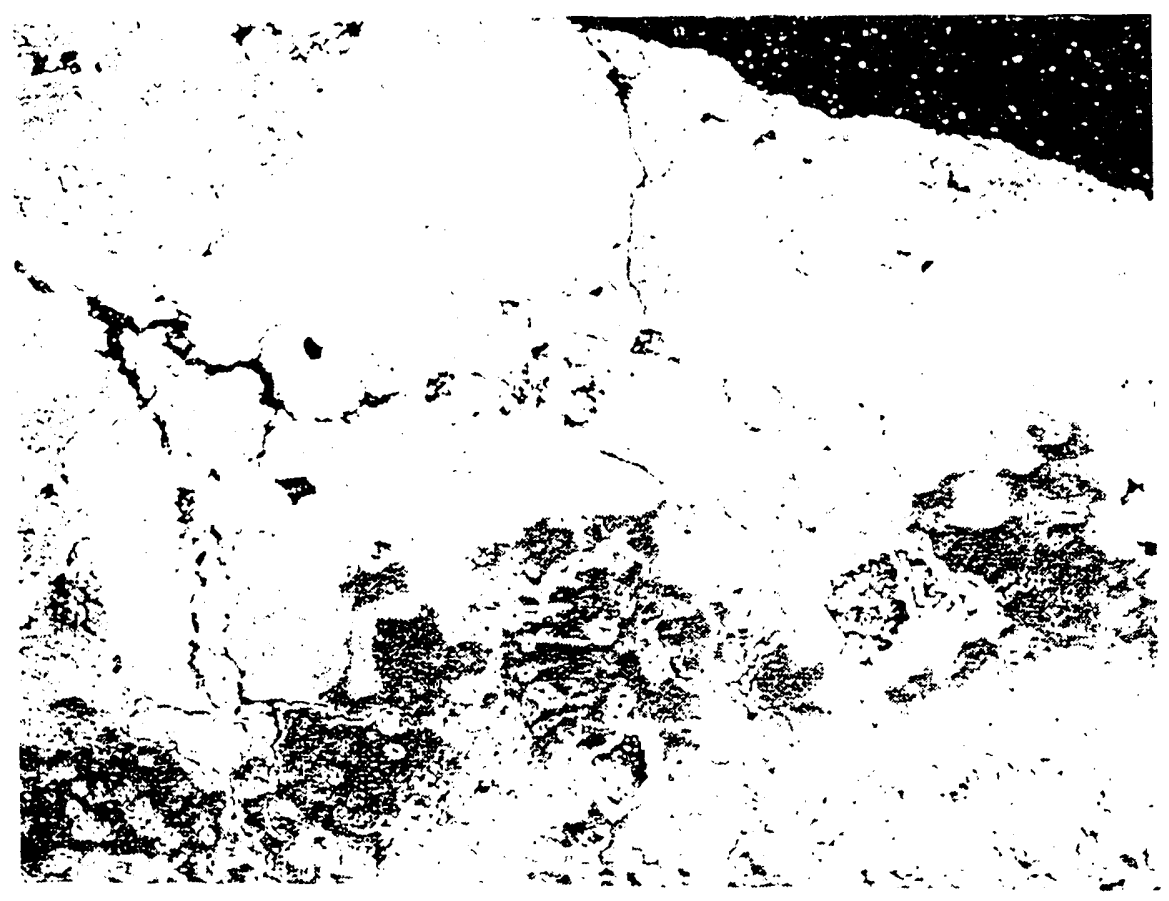

Figure 8.10: SEM picture of the area analyzed in Figure 8.9. 


\subsubsection{1) Particles with low conversion to CaS.}

The sulfided limestone samples can be classified into two main categories, depending on the extent of reaction 1.2 .

For low conversion (about 10\%), the sulfur atoms are relatively homogeneously distributed around all the pores, even in the core of the limestone particle. We can check that the sulfur surrounds the pores but is not present in the core of the $\mathrm{CaCO}_{3}$ grains forming the particle (Figure 8.11, magnification $=250 \mathrm{X}$, same experimental conditions as Figure 8.8). This confirms the thermal stability of the original limestone structure. $\mathrm{H}_{2} \mathrm{~S}$ has still not been prevented from reaching the core of the particle (the stone has been exposed to a $1 \% \mathrm{H}_{2} \mathrm{~S}$-gas-phase for one hour at $900^{\circ} \mathrm{C}$ ).

\subsubsection{2) Particles with higher conversion to CaS.}

Figure 8.12 (magnification $=49 \mathrm{X}$ ) shows a totally dissimilar sulfur distribution. The only difference in the experimental conditions under which Figure 8.11 was obtained is the presence of $2 \%$ of $\mathrm{H}_{2} \mathrm{~S}$ in gas feed instead of $1 \%$. As mentioned in Section 8.1, there was a five-fold increase in the conversion of $\mathrm{CaCO}_{3}$ to $\mathrm{CaS}(50 \%$ against $10 \%)$. The inside of the particle, near the center, is similar to what was observed in Figure 8.11, with the sulfur surrounding the pores. However, we can also see a crust of $\mathrm{CaS}$ enveloping the whole particle (clear gray on the picture). The presence of this crust indicates a change in the reaction mechanism between 10 and $50 \%$ conversion. There is a switch from a "Progressive-ConversionMechanism" to an "Unreacted-Core-Mechanism", in term of the commonly-used terminology in the gas-solid-reaction field (Levenspiel, 1972). It would appear that, after a few percent conversion (perhaps as low as 10 to $15 \%$ ), the CaS layer that coats the limestone pores becomes much more resistant to $\mathrm{H}_{2} \mathrm{~S}$ diffusion. Moreover, most of the small diameter pores would then be clogged because of CaS sintering, and it would become very difficult for $\mathrm{H}_{2} \mathrm{~S}$ in the gas phase 
to reach the center of the particles through the pore network. It also seems that the number of small-diameter pores is much lower in the CaS crust (Figures 8.12 and 8.10) than in the rest of the stone. This observation supports the proposed change of mechanism in the course of the reaction. If $\mathrm{H}_{2} \mathrm{~S}$ cannot easily reach the core of the pellet any more, the reaction would have to proceed mainly via diffusion through the CaS crust and the few pores that survived the CaS sintering. The characteristic diffusion time of this new limiting step in the reaction kinetics is larger than the preceding characteristic time of the former limiting mechanism. We are possibly in the presence of ionic diffusion of $\mathrm{S}^{2-}$ and $\mathrm{CO}_{3}{ }^{2}$ through the product layer, as advanced by Borgwardt for the mechanism of sulfidation of $\mathrm{CaO}$ (Borgwardt et al, 1984). This explanation is consistent with the observation made by Borgwardt on the drastic slowing of the rate of reaction between $\mathrm{H}_{2} \mathrm{~S}$ and limestone after about $11 \%$ conversion (Borgwardt et al, 1984). However, this hypothesis does not explain very well how the conversion of the.limestone can be increased to $50 \%$ by doubling the $\mathrm{H}_{2} \mathrm{~S}$ concentration. Additional experimental work will be required to answer this question. 


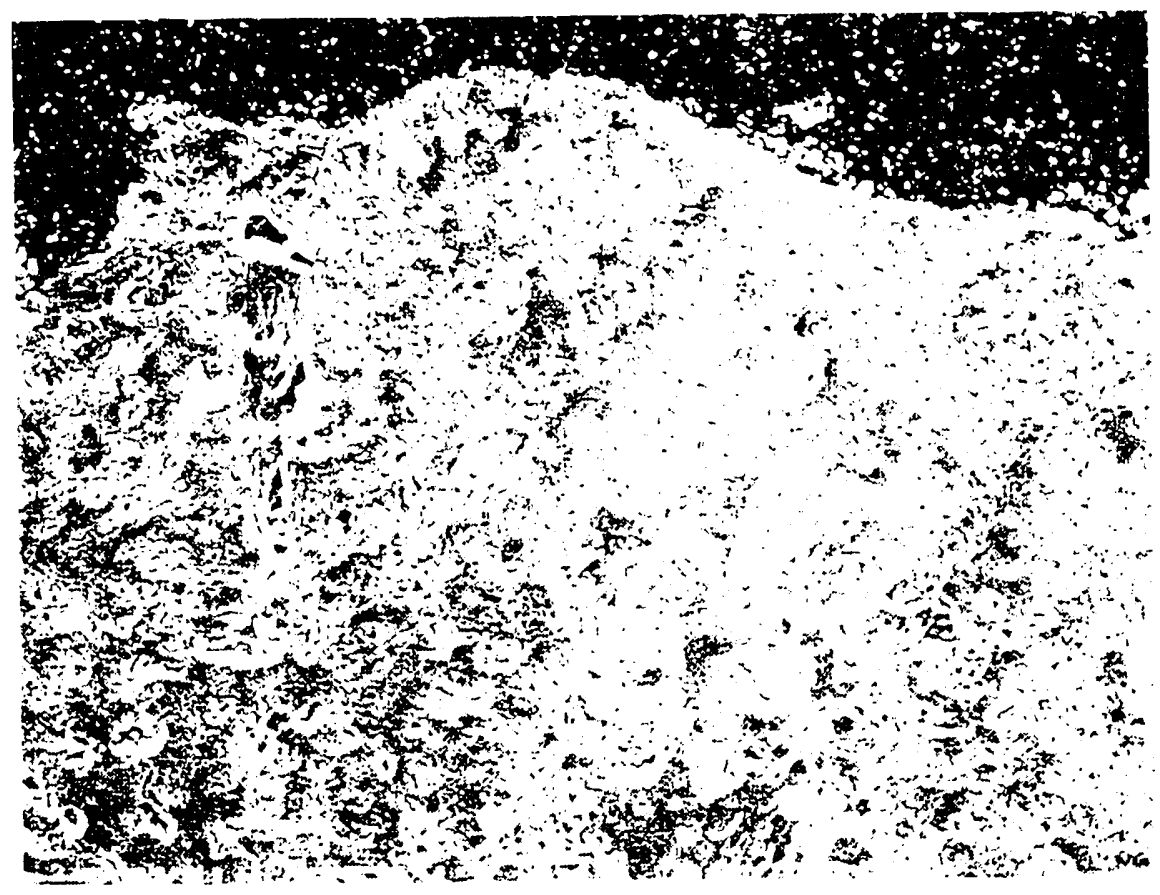

Figure 8.11: Cross-section of sulfided limestone (low conversion).

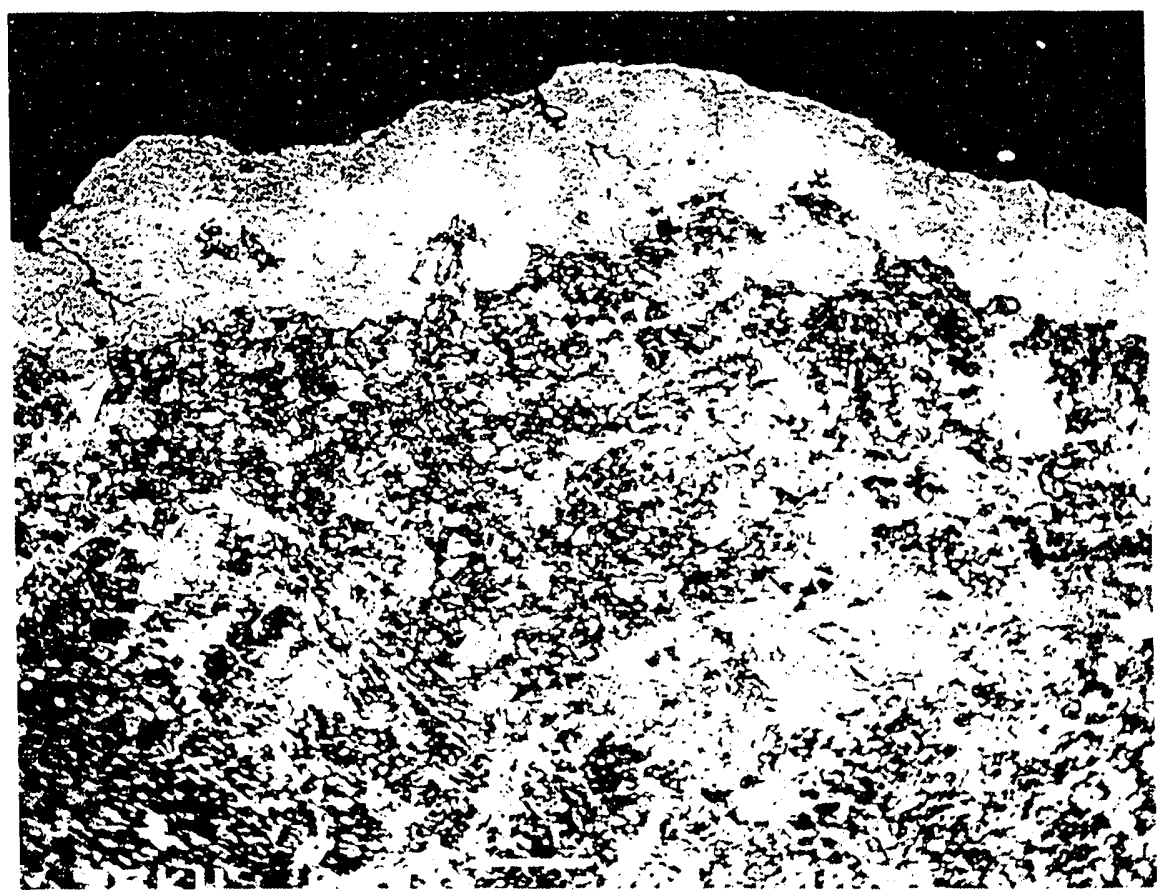

Figure 8.12: Cross-section of sulfided limestone (high conversion). 


\section{CHAPTER 9: MORPHOLOGICAL BEHAVIOR OF THE CaS PRODUCT-LAYER}

SEM pictures of partially sulfided limestone particles reveal that the CaS product layer formed around a limestone grains sinters and prevents more $\mathrm{H}_{2} \mathrm{~S}$ from reaching the grain's core (see Chapter 8). As mentioned in Section 2.3, the molecular volume of calcium sulfide is significantly lower than that of $\mathrm{CaCO}_{3}$. So, we expected some "cracks" to form on the grain surface as the reaction proceeds so that more calcium carbonate would be exposed to the gas phase and a complete conversion would be reached since the thermodynamics is very favorable. However, we showed in Section 7.2.1 that $\mathrm{CaS}$ undergoes strong sintering when $\mathrm{CO}_{2}$ is present in the gas phase. That could explain the absence of rough angles and small cracks on the SEM pictures of the sulfided limestone grain surface if the sintering time scale is smaller or comparable to our experimental time scale (an hour). Moreover, the SEM pictures also reveal that the larger pores (diameter larger than $1 \mu \mathrm{m}$ ) are not really affected by the CaS sintering: limestone samples that have been converted to $50 \%$ CaS still exhibit large pore patterns very similar to those present in the original limestone samples before the sulfidation took place.

\section{1) Mullins sintering model.}

W.W. Mullins (1957 and 1963) proposed a simple model to describe the evolution of a surface groove at the grain boundary of a polycrystal exposed to high temperature. He assumed that diffusion (either surface or volume) was the limiting step in nass transport. He used the Gibbs-Thompson equation to relate the chemical potential to the sur iace curvature (eq 9.1). He recognized curvature as the driving force for the sintering phenomenon; a similar hypothesis was postulated in the German-Munir model we used to describe the CaS sintering kinetics: 


$$
\mu=K \boldsymbol{\gamma} \Omega
$$

where $\mu$ is the increase in chemical potential per atom that is transferred from a point of zero curvature to a point of curvature $\mathrm{K}$ on the surface, $\mathrm{K}$ is the local curvature at a point of the surface, $\gamma$ is the surface tension (ie, the surface free energy per unit area), and $\mathbf{Q}$ is the molecular volume. He also used the two-dimensional Nernst-Einstein equation to account for the material flux (eq 9.2):

$$
V=-\frac{D}{k T} \frac{\partial \mu}{\partial s}
$$

where $\mathrm{V}$ is the average velocity of surface atoms, $\mathrm{D}$ is the coefficient of diffusion (either surface or volume), $\mathrm{k}$ is the Boltzmann constant, $\mathrm{T}$ is the absolute temperature, $\mathrm{s}$ is the arc length along the surface profile, and $C_{0}$ is the vacancy fraction in the CaS lattice. He then determined the temporal evolution of a two-dimensional gas-solid interface profile in a 2 -dimensional $(x, y)$ cartesian system:

$$
\frac{\partial y}{\partial t}=-B \frac{\partial^{4} y}{\partial x^{4}} \quad \text { with } B=\frac{D_{s} \gamma Q^{4 / 3}}{k T}
$$

for a surface-diffusion sintering mechanism ( $D_{\mathfrak{l}}$ being the surface-diffusion coefficient).

For the volume-diffusion kinetics, the derivation supposed that the surface profile is defined by a series of sine waves (Fourier series). It also assumed that each term of the sine wave behaves independently of the others. So, for $y=a \cos (\omega t)$ the kinetic equation becomes:

$$
\frac{\partial y}{\partial t}=C \omega \frac{\partial^{2} y}{\partial x^{2}} \quad \text { with } C=\frac{D_{v} \gamma \Omega^{2} C_{0}}{k T}
$$


where $D_{v}$ is the volume-diffusion coefficient.

These two last equations are rigorously correct only if the slope of the curve describing the groove profile is negligible compared to one. Equations 9.3 and 9.4 are derived in Appendix 3.

We can apply these two kinetic equations to describe the temporal evolution of squareshaped cracks of various widths on the surface of a solid. It is clear that the slope of the profile at the edges of the channels is not small (it is actually infinite!). However, the edge slope will decrease rapidly as the sintering goes on and smooths the surface profile. So, after a short time equations 9.3 and 9.4 will be completely valid. Moreover, the rectangular profile can be described by a Fourier series and the maximum value of the slope of each term of the Fourier expansion is roughly given by the height-to-width ratio for the groove. Since the derivative of a finite sum of terms is the sum of the derivatives of the terms (we use a finite number of terms in the Fourier expansion), equations 9.3 and 9.4 can be applied individually to each term of the Fourier expansion. Thus, the small-slope approximation will be legitimate if the height-to-width ratio of the square cracks is smaller than unity.

\section{2) Computer simulations.}

A program has been wr ten in BASIC by J.W. Bullard (1992) to solve equations 9.3 and 9.4 when the solid surface is described by a Fourier expansion. He assumed that the channel pattern was periodic and two dimensional. I modified and corrected his version to account for some particular surface geometries. The program has been run on a 486-IBM compatible desktop computer. The graphic outputs of the program are presented in Figures 9.1 and 9.2. Table 9.1 gives the value of all of the physical parameters used in the two simulations. 
Table 9.1: Values of the parameters used in Figures 9.1 and 9.2.

\begin{tabular}{||l|c|c||}
\hline & Surface diffusion & Volume diffusion \\
\hline Atomic volume $\left(\mathrm{m}^{3}\right)$ & $10^{-29}$ & $10^{-29}$ \\
\hline Surface tension $\left(\mathrm{J} / \mathrm{m}^{2}\right)$ & 1 & 1 \\
\hline Temperature $(\mathrm{K})$ & 1273 & 1273 \\
\hline $\begin{array}{l}\text { Activation energy of the } \\
\text { diffusion coeff. (cal/mol) }\end{array}$ & 20000 & 20000 \\
\hline $\begin{array}{l}\text { Pre-exponential factor of the } \\
\text { diffusion coeff. }\left(\mathrm{m}^{2} / \mathrm{s}\right)\end{array}$ & $2.7110^{-5}$ & $2.7110^{-10}$ \\
\hline Large channel width $(\mu \mathrm{m})$ & 0.05 & 0.05 \\
\hline Small channel width $(\mu \mathrm{m})$ & 0.5 & 0.5 \\
\hline Spacing between channel $(\mu \mathrm{m})$ & 1 & 1 \\
\hline Channel height $(\mu \mathrm{m})$ & 1 & 1 \\
\hline $\begin{array}{l}\text { Number of terms considered in the } \\
\text { Fourier expansion }\end{array}$ & 500 & 500 \\
\hline Characteristic time $(\mathrm{s})$ & $\tau=10^{-5}$ & $\Omega=30$ \\
\hline
\end{tabular}

9.3) Discussion of the vilues of the physical parameters.

i) Since most atom radii vary between 1 and $2 \AA$, the atomic volume is approximately $10^{-30}$ to $10^{-29} \mathrm{~m}^{3}$.

ii) A surface tension of $1 \mathrm{~J} / \mathrm{m}^{2}$ is recommended by Mullins as a reasonable order of magnitude for most materials. Since we do not have any data on the surface tension of $\mathrm{CaS}$ this value has been assumed for all the profile simulations.

iii) The diffusion coefficients are based on the value observed in copper at $1035^{\circ} \mathrm{C}$ (cited in Mullins). The volume diffusion coefficient is roughly equal to $10^{-13} \mathrm{~m}^{2} / \mathrm{s}$, whereas the surface 
diffusion coefficient is about $10^{-8} \mathrm{~m}^{2} / \mathrm{s}$ at this temperature. This $10^{5}$ ratio between the two diffusion coefficients is also generally accepted for several other materials. The values of the diffusion coefficients are unknown for CaS and these coefficients may vary over several orders of magnitude. They are the most imprecise and critical physical parameters in these simulations and may significantly change the characteristic sintering times ( $\tau$ and $\Omega)$.

iv) We assumed that the diffusion coefficients follow an Arrhenius law. The activation energy generally varies between 10 and $50 \mathrm{kcal} / \mathrm{mol}$. A value of $20 \mathrm{kcal} / \mathrm{mol}$ was used for both surface and volume diffusion coefficients.

v) Finally, the fraction of vacancy $C_{0}$ has been estimated to be about $4 \cdot 10^{-4}$. This relatively small value is often observed in metals. It is impossible to obtain a better estimation at this point for $\mathrm{C}_{0}$, whose variation may also greatly influence the volume-diffusion-controlled characteristic time of sintering.

\section{4) Analysis of the computer simulations.}

Figures 9.1 and 9.2 demonstrate that a narrow channel disappears much more quickly than a wide one. This explains why no small cracks nor sharp angles on the CaS product layer were observed in the limestone-sulfidation experiments. A 500- $\AA$ wide and $1-\mu \mathrm{m}$ deep channel will vanish in about a second to an hour, depending on the sintering mechanism, whereas a 5000$\AA$ wide channel will last about a thousand times longer. It is interesting to note that these characteristic times are comparable to our experimental time scale. SEM pictures of partially sulfided limestones exposed to $\mathrm{H}_{2} \mathrm{~S}$ for about an hour show a very smooth CaS product layer but large pores (diameter of $0.5 \mu \mathrm{m}$ or more) are still present and will require more time to decay.

As I stressed above, at the beginning of the sintering process (i.e., before 10 to 100 times the characteristic evolution time) the small-slope approximation is poor. This explains why we 
can see little "bumps" on the edge of the channel. These bumps are not "physical", they just come from a poor description of the physical phenomenon around the edges for the low times. If the channel height-to-width ratio is decreased, the bumps' amplitude diminishes. Unfortunately, in this case the profile becomes too flat and it is very difficult to follow any shape evolution scause of the limited graphic resolution of the computer. Another major reason for the presence of these bumps around the edges of the channels is the inherent "instability" problem encountered at any discontinuity describ»d by a Fourier series with a finite number of terms in the expansion. To actually get a "clean" square shape, a very large number of terms is required. However, as the sintering goes on, the higher-order terms of the Fourier series decay much more quickly than the first. When the characteristic time $\tau$ or $Q$ is reached only the first fifty ierms or so of the expansion still have a significant amplitude. The amplitude of the other terms is basically zero (the tem? ral decay of each amplitude term in the Fourier expansion is proportional to a positive power of $\exp \left(-n^{3} t\right)$ for volume diffusion and $\exp \left(-n^{4} t\right)$ for surface diffusion, where $\mathrm{n}$ is the term number in the series). More details are available in Appendix 3.

A complete resolution of the general kinetic equations, wherein the small-slope approximation has been relaxed, is much more involved and will not give better physical insight nor different orders of magnitude for the characteristic times of sintering. 

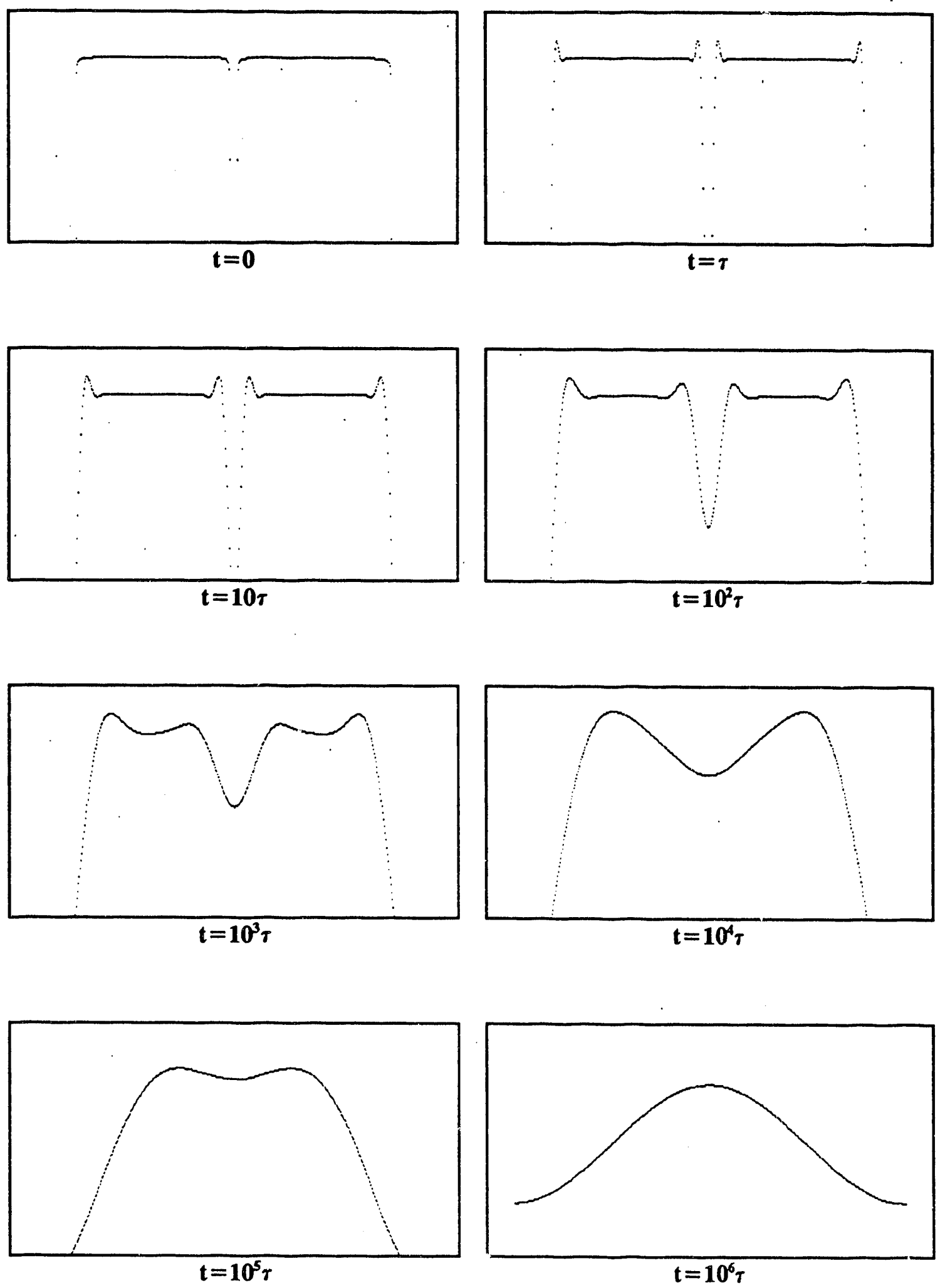

Tigure 9.1: Channels evolution for surface diffusion sintering $\left(\tau=10^{-5} \mathrm{~s}\right)$. 

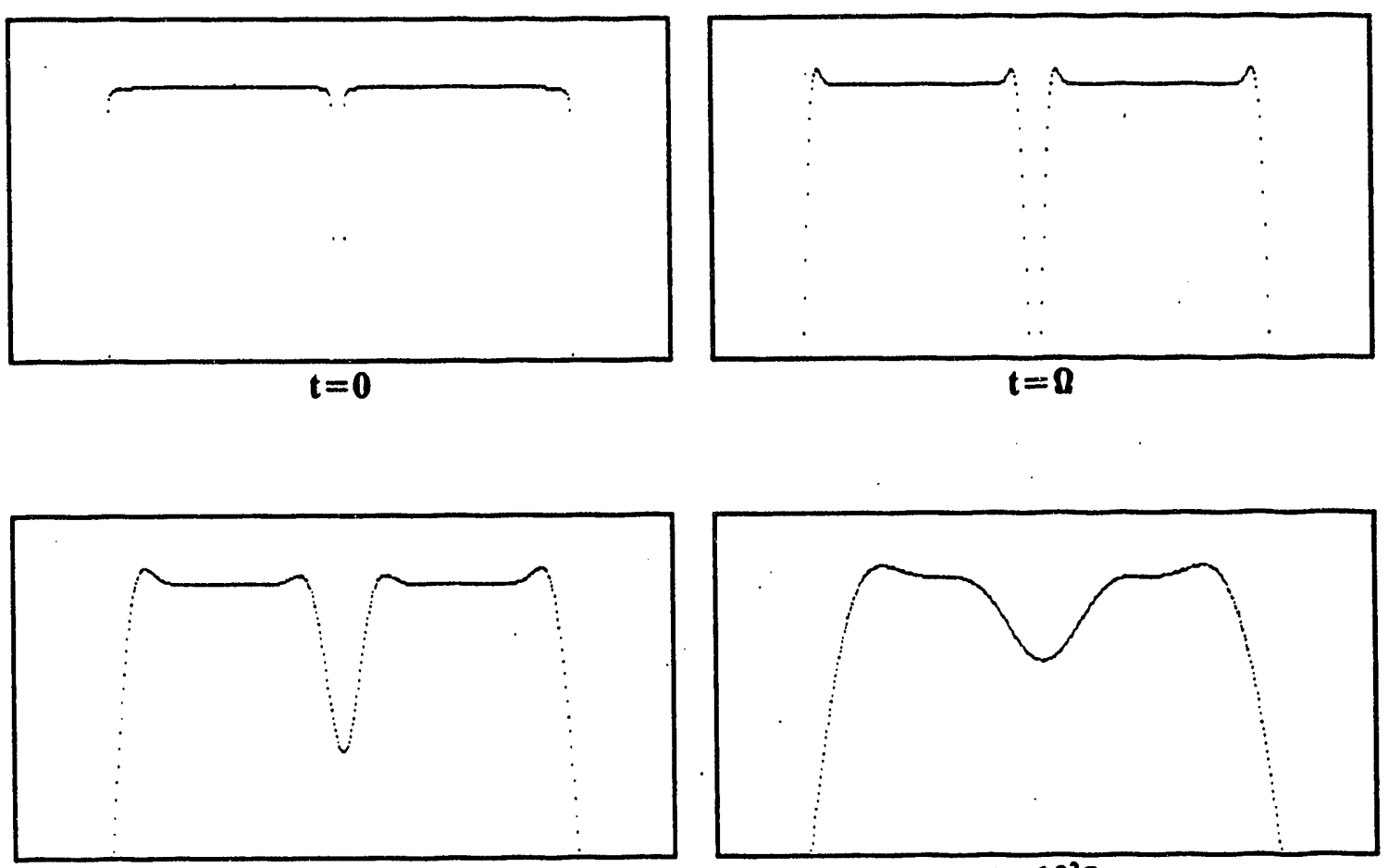

$t=10 \Omega$
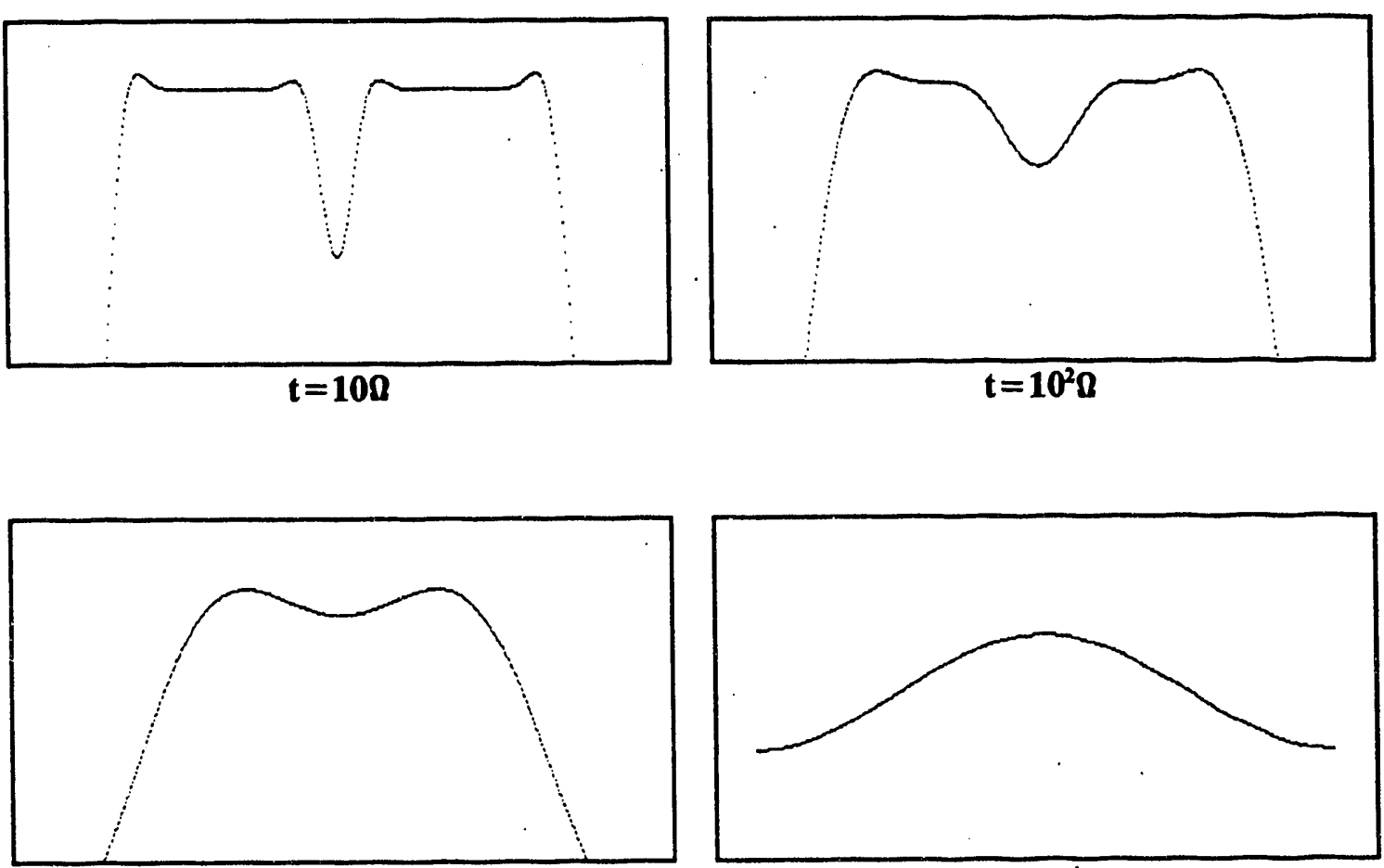

$t=10^{3} \Omega$

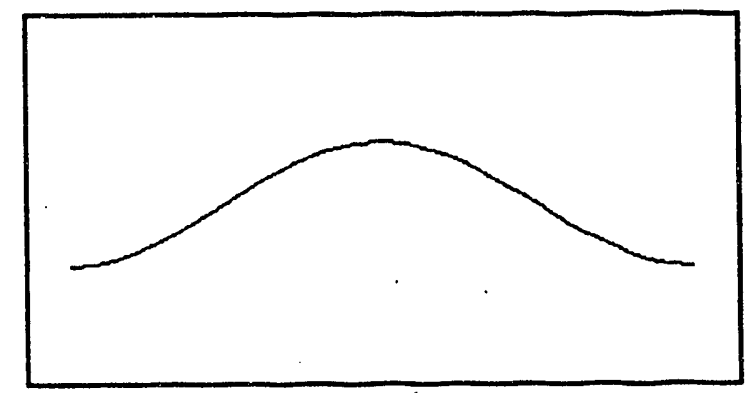

$t=10^{4} \Omega$

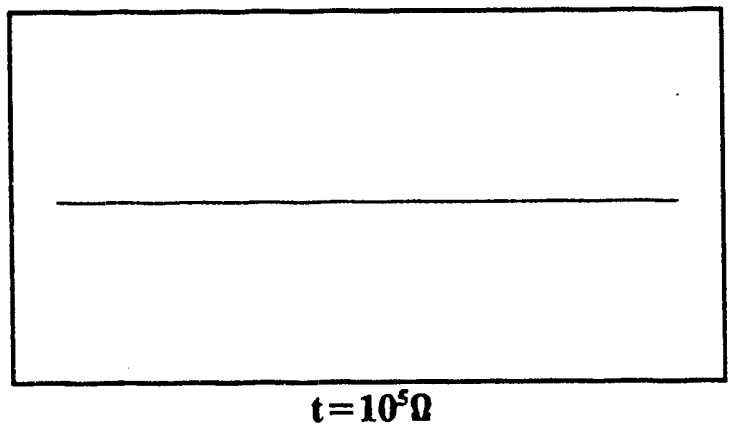

Figure 9.2: Channels evolution for volume diffusion sintering $(\boldsymbol{Q}=30 \mathrm{~s})$. 


\section{CHAPTER 10: CONCLUSIONS}

Limestone sulfidation exhibits a complex mechanism. In the first stages of the reaction, up to 10 to $15 \%$ conversion, the limiting step in the kinetics can be attributed either to the chemical reaction or to the diffusion of gaseous $\mathrm{H}_{2} \mathrm{~S}$ through the limestone pores. Hydrogen sulfide can diffuse through the pores to reach the core of the particle, provided a sufficient pore network exists, and react with the calcium carbonate. After the formation of a sufficiently thick CaS layer, the limiting step in the kinetics changes. Whereas the original limestone structure is not affected by long exposures to high temperatures, the CaS product-layer sinters rapidly when $\mathrm{CO}_{2}$ is present in the gas phase and forms a quasi-impermeable coating around the $\mathrm{CaCO}_{3}$ grains that prevents more $\mathrm{H}_{2} \mathrm{~S}$ from reaching the still unreacted parts of the stone. Moreover, most of the pores initially present within the limestone structure have been clogged or have significantly shrunk. From then on, subsequent conversion will be limited by diffusion of $\mathrm{H}_{2} \mathrm{~S}$ through the CaS layer, possibly by $\mathrm{S}^{2-}$ ionic diffusion. The kinetics is then adequately described by a shrinking-core mechanism, in which a sharp front of completely converted limestone is assumed to progress toward the center of the pellet.

This process is much slower than the initial one, which explains the sharp decrease in conversion rate observed after $11 \%$ conversion by Borgwardt in his experiments (Borgwardt, 1984). He was, however, incorrect in proposing limestone sintering as the cause for the decrease in the rate of sulfidation. The experimental evidence accumulated in the present work strongly suggests instead that $\mathrm{CaS}$, the product of the reaction, sinters rapidly compared to calcium carbonate on a time scale typical of these experiments.

The sintering mechanism has not been unequivocally identified, but the catalytic effect of $\mathrm{CO}_{2}$ on the $\mathrm{CaS}$ sintering rate suggests that a surface phenomenon is involved. Scanning 
electron microscope photographs do not rule out a kinetics controlled by surface diffusion. Some authors (Mullins, 1963) also point out that, when both surface and volume diffusion are possible, the impact of surface diffusion on the morphology of sintering solids is generally much larger than that of volume diffusion on surface features with sizes are smaller than about $10 \mu \mathrm{m}$. Considering that the grain diameter typical of the limestone we used throughout this work was 1 to $10 \mu \mathrm{m}$, it seems very likely that a surface-diffusion-controlled sintering mechanism of the CaS product layer is responsible for the sharp decrease in the sulfidation rate of the limestone after an initial conversion of 10 to $15 \%$. 


\section{REFERENCES}

Abbasian, J., Rehmat, A., Leppin, D., Banerjee, D.D., Desulfurization of Fisels with Calciumbased Sorbents, Fuel Processing Technology, 25, 1-15, (1990).

Alexander, S., Rabin, Y., Zeitag, R., Vacancy-controlled Interdiffusion : Non-linear Effects, Journal of Chem. Phys., 95(3), 2012-2019, (1991).

Anderson, P.J., Morgan, P.L., Effects of Water Vapour on Sintering of $\mathrm{MgO}$, Trans. Faraday Soc., 60, 930-937, (1964).

Attar, A., Reactions of Sulphur in Coal-Gas Reactions, Fuel, 5, 201-212, (1978).

Attar, A., Dupuis, F., The Rate and the Fundamental Mechanisms of the Reaction of Hydrogen Sulfide with the Basic Minerals in Coal, Ind. Eng. Chem. Process Des. Dev., 18(4), 607-618, (1979).

Barthelemy, Improved Heat Recovery and High-Temperature Clean-up for Coal-gas Fired Combustion Turbines, Master Thesis, Department of Chemical Engineering, UC Berkeley, CA, (1991).

Borgwardt, R.H., Sintering of Nascent Calcium Oxide, Chem. Eng. Science, 44(1), 53-60, (1989)A.

Borgwardt, R.H., Calcium Oxide Sintering in Atmospheres Containing Water and Carbon Dioxide, Ind. Eng. Chem. Res., 28, 493-500, (1989)B.

Borgwardt, R.H., Roache, N.F., Reaction of $\mathrm{H}_{2} \mathrm{~S}$ and Sulfur with Limestone Particles, Ind. Eng.

Chem. Process Des. Dev., 23, 742-748, (1984).

Borgwardt, R.H., Roache, N.F., Bruce, K.R., Surface Area of Calcium Oxide and Kinetics of Calcium Sulfide Formation, Environ. Progress, 3(2), 129-135, (1984).

Borgwardt, R.H., Bruce, K.R., Blake, J., An Investigation of Product-layer Diffusivity for CaO Sulfation, Ind. Eng. Chem. Res., 26, 1993-1998, (1987).

Brown, D.J., Froth Flotation (D.W. Fuerstenau Editor), AIME and Petroleum Engineering,Inc, New York, (1962).

Bullard, J.W., Department of Materials Science and Mineral Enginnering, University of California at Berkeley, Personal communication (1992).

Chan, R.K., Murthi, K.S., Harrison, D., Thermogravimetric Analysis of Ontario Limestones and Dolomites. I. Calcination, Surface Area, Porosity, Canadian Journal of Chenistry, 48, 29722978, (1970). 
Chang, E.Y., Thodos, G., Complex Nature of the Sulfation Reaction of Limestones and Dolomites, AIChE Journal, 30(3), 450-457, (1984).

Coble, R.L., Sintering Crystalline Solids. I. Intelmediate and Final State Diffusion Models, Journal of Applied Physics, 32(5), 787-792, (1961).

Freund, H., Kinetics of Limestone/Dolomite with $\mathrm{H}_{2} \mathrm{~S}$ under Rich Combustion Conditions, Combustion Science and Technology, 26, 83-88, (1981).

Fulkerson, W., Judkins, R.R., Sanghvi, M.K., "Energy from Fossil Fuels", Scientific American, (September 1990).

Fuller, E.L. Jr., Yoos, T.R., Surface properties of Limestones and their Activation Products, Langmuir, 3, 753-760, (1987).

German, R.M., Munir, Z.A., Surface Area Reduction During Isothermal Sintering, Journal of the American Ceramic Society, 59, 379-383, (1976).

Harte, J., Consider a Spherical Cow. A Course in Environmental Problem Solving, p 241, University Science Books, Mill Valley, CA, (1988).

Hartman, M., Pata, J., Coughilin, R.W., Influence of Porosity of Calcium Carbonates on their Reactivity with Sulfur Dioxide, Ind. Eng. Chem. Process Des. Dev., 17(4), 411-419, (1978).

Irabien, A., Viguri, J.R., Ortiz, I., Thermal dehydration of the Calcium Hydroxide. 2. Surface Area Evolution, Ird. Eng. Chem. Res. 29, 1601-1611, (1990).

Jones, T.J., Berard, M.F., Ceramics: Industrial Processing and Testing, First Edition, pp 104113, Iowa State University Press, Ames, Iowa, (1972).

Levenspiel, O., Chemical Reaction Engineering, Chapter 12, John Wiley \& Sons, New York, Second Edition, (1972).

Lowell, S., Karp S., Determination of low Jurface Areas by the Continuous Flow Method, Analytical Chemistry, 44, 1706-1707, (1972).

Lowell, S., Shields, J.E., Powder Surface Area and Porosity, Second Edition, Chapman and Hall Ltd., London, (1984).

Lynch, A.J., Johnson, N.W., Manlapig, E.V., Thorne, C.G., Mineral and Coal Flotation Circuits (Developments in Mineral processing; 3), Elsevier Sci. Publishing Comp., AmsterdamOxford-New York, (1981).

Mullins, W.W., Theory of Thermal Grooving, Journal of Applied Physics, 28(3), 333-339, (1957).

Mullins, W.W., Solid Surface Morphologies Governed by Capillarity, Metal Surfaces: Structure, Energetics, and Kinetics. ASM Seminar. Metal Park, Ohio, pp 17-65, (1963). 
Nicholson, D., Variation of Surface Area during Thermal Decomposition of Solids, Trans. Faraday Soc., 61, 990-998, (1965).

Nowacki, P., Coal Gasification Processes, Noyes Data Corporation, Park Ridge, New Jersey, U.S.A., (1981).

Perry, R.H., Green, D.W., Perry's Chemical Engineers' Handbook, Sixth Edition, p. 21.15 (table 21.6), McGraw-Hill Book Company, New York, (1984).

Ruth, L.A., Squires, A.M., Graff, R.A., Desulfurization of Fuels with Half-calcined Dolomite: First Kinetic Data, Env. Sci. Technol., 11(5), 488-491, (1972).

Squires, A.M., Graff, R.A, Pell, M., Desulfurization of Fuel with Calcined Dolomite. I. Introduction and First Kinetic Results , Chem. Eng. Prog. Symp. series, 67(115), 23-34, (1971).

Towler, G.P., Development of an High-Temperature Gas-Cleaning Process using Limestone, PhD Dissertation Part I, Department of Chemical Lingineering, UC Berkeley, CA, (1992).

Yen, J.H., Kinetic and Structural Studies in the Sulfidation of Dolomite, PhD Dissertation, Department of Chemical Engineering, Carnegie-Mellon University, (1979). 


\section{APPENDICES}

The two appendicies to this thesis, totalling 39 pages, give the details of the BET surface area measurements used to determine limestone and $\mathrm{CaS}$ sintering. They are available from $\mathrm{S}$. Lynn through LBL. 

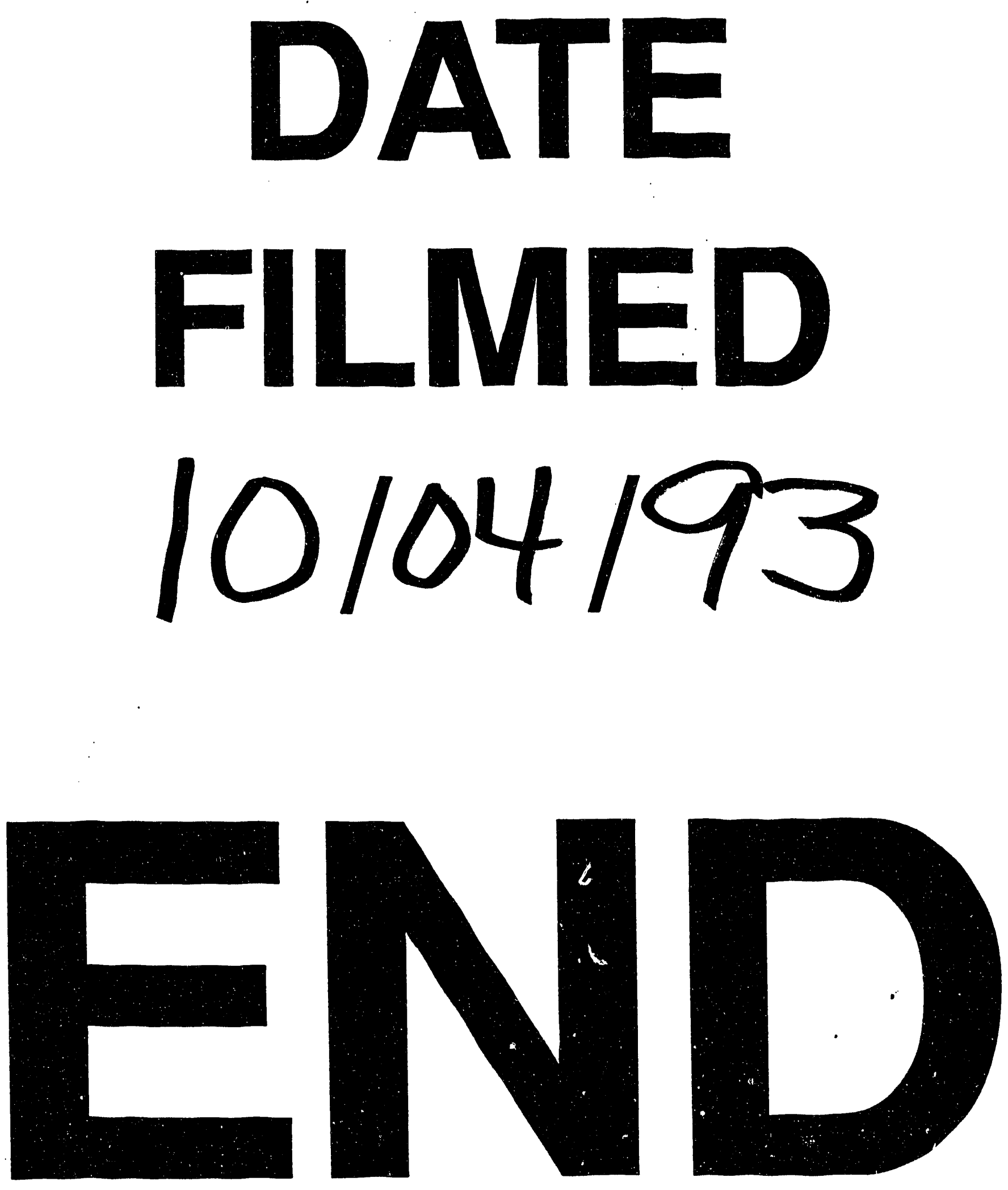
